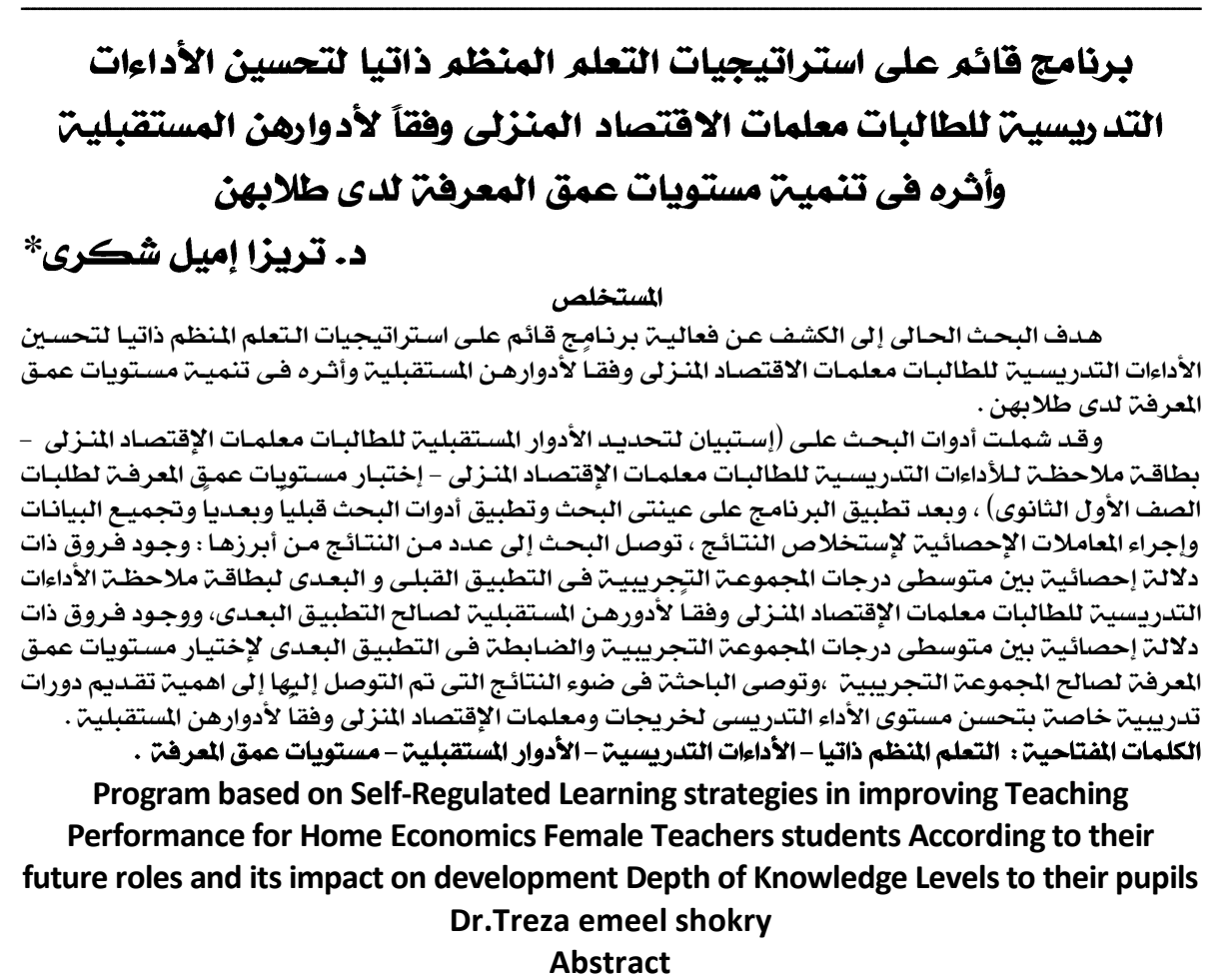

The research aimed to identify the effectiveness of Program based on SelfRegulated Learning strategies in improving Teaching Performance for Home Economics Female Teachers students According to their future roles and its impact on development Depth of Knowledge Levels to their pupils.

The Research tools included ( a questionnaire to identify the future roles for Home Economics Female Teachers students - a monitoring Card of teaching Performance for Home Economics Female Teachers students According to their future roles - Depth of Knowledge Levels Test for First secondary pupils) After the application of the program to the two research sample, and pre and post application of research tools and compilation of data And conduct statistical analysis to extract the results of research, that were reached most prominent or which were ,The presence of statistically significant difference between the mean scores of experimental group in the pre and post application of the monitoring card of teaching Performance for Home Economics Female Teachers students According to their future roles in favor of the post application, and The presence of statistically significant difference between the mean scores of experimental group 
and control group in the post application of Depth of Knowledge Levels Test in favor of the experimental group .

It is recommended by the researcher in the light of the results reached to the importance of providing training for Graduates and home economics teacher to improving Teaching Performance According to their future roles .

key words : Self-Regulated Learning - Teaching Performance - future roles - Depth of Knowledge Levels .

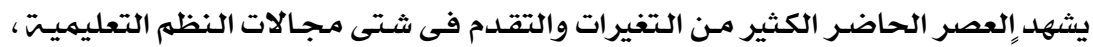

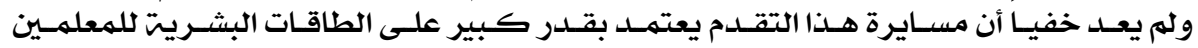

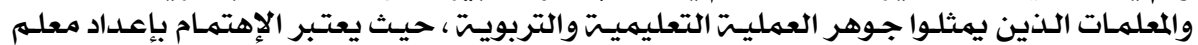

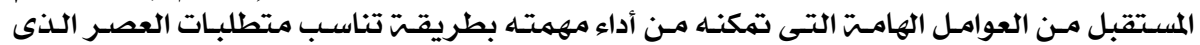

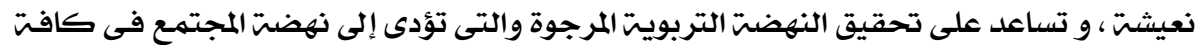

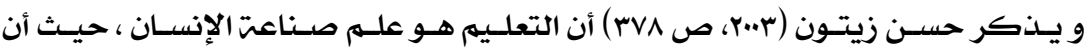

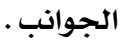

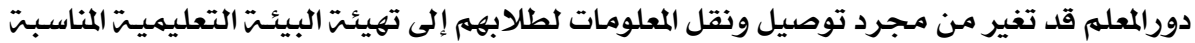

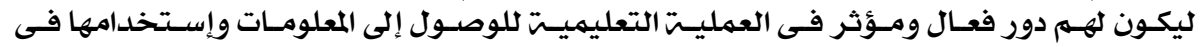

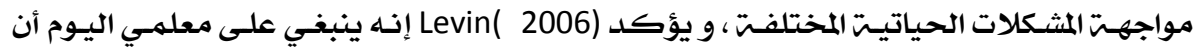

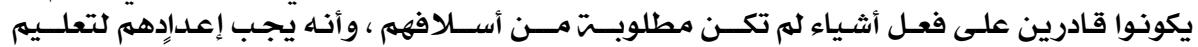

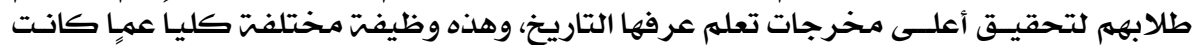

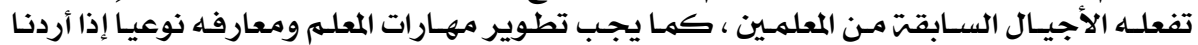
تطوير تحصيل طلابهم . توجيابن.

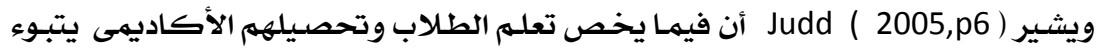

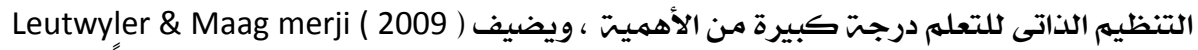

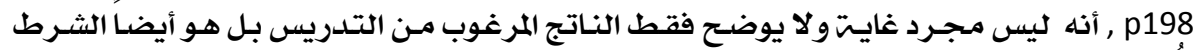

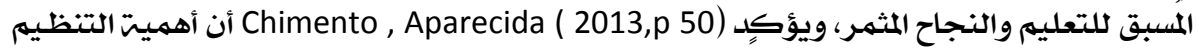

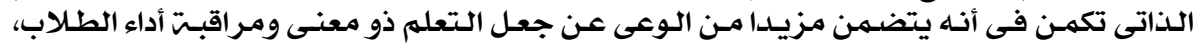

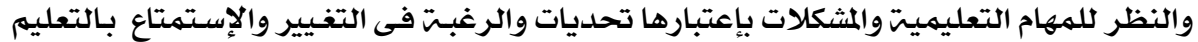

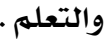

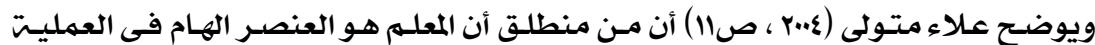

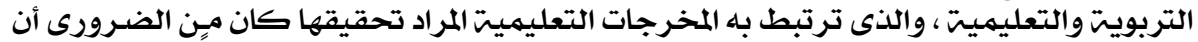

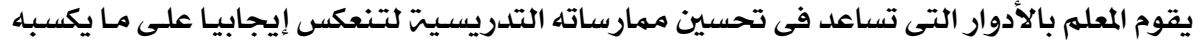

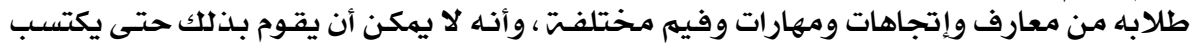

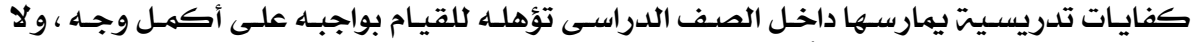

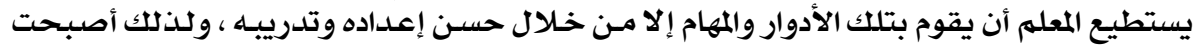

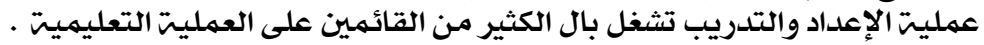

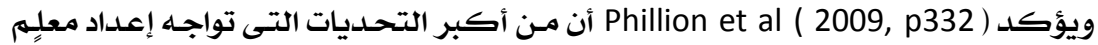

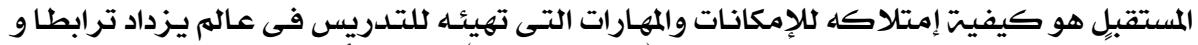

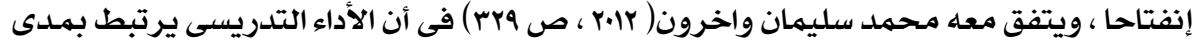

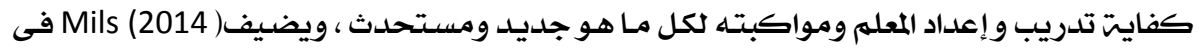




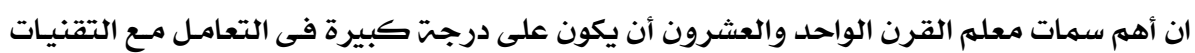

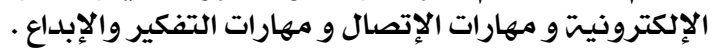

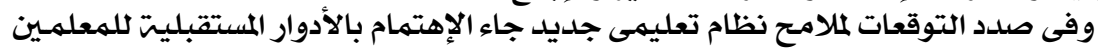

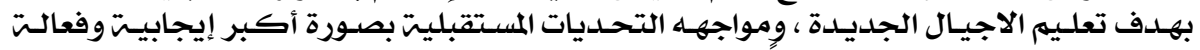

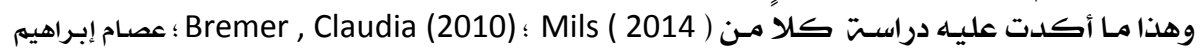

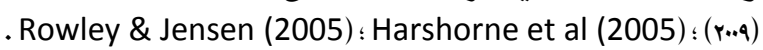

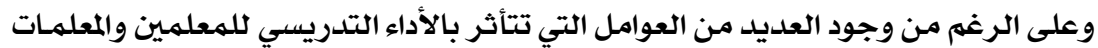

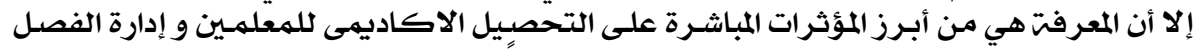

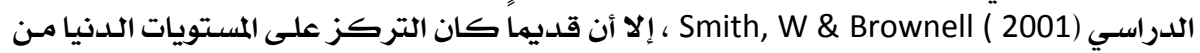

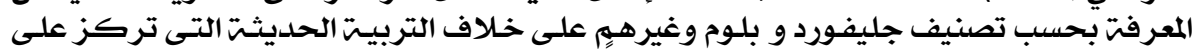

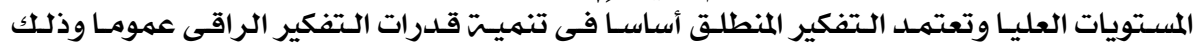

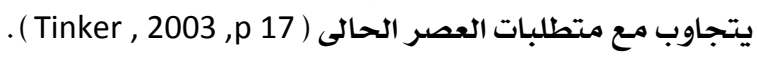

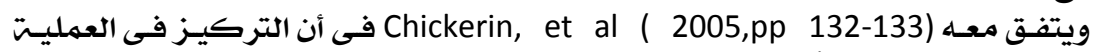

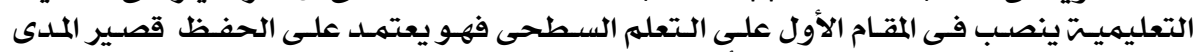

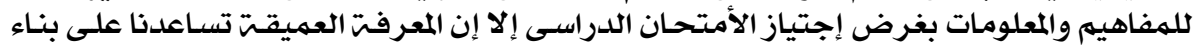

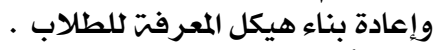

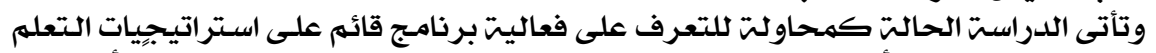

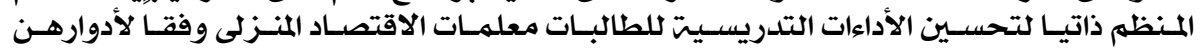

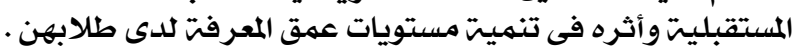

\section{مشكلثة البحث}

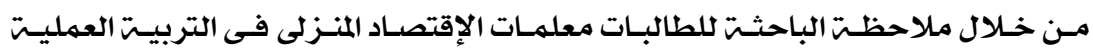

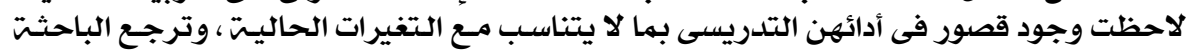

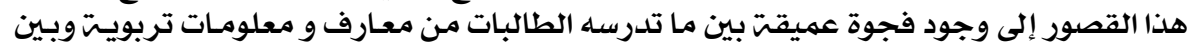

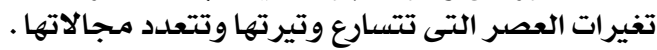

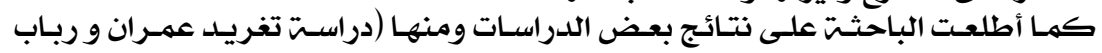

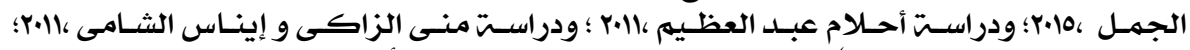

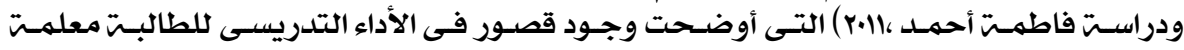

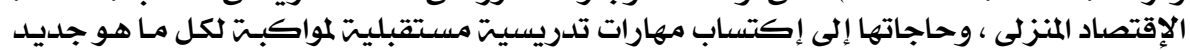

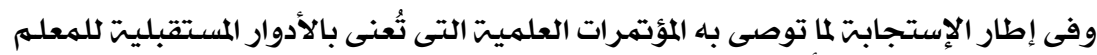

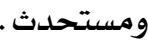

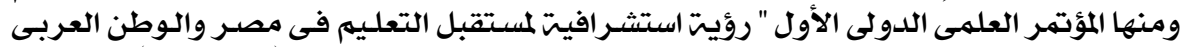

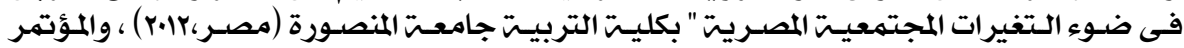

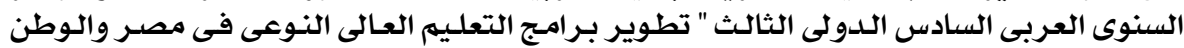

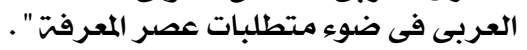

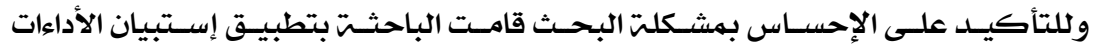

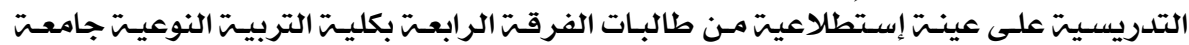

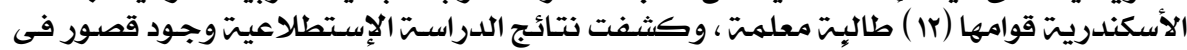

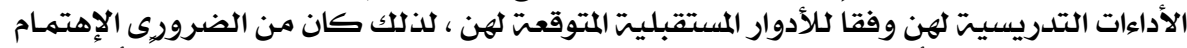

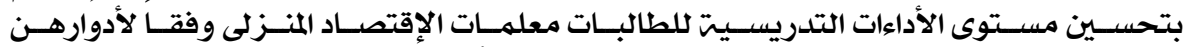

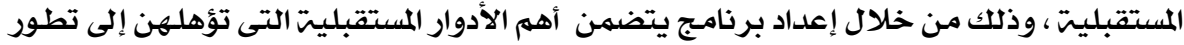

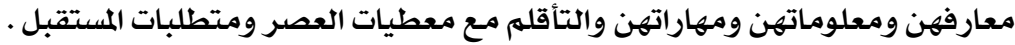




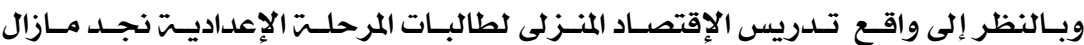

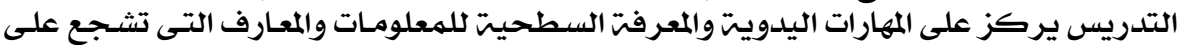

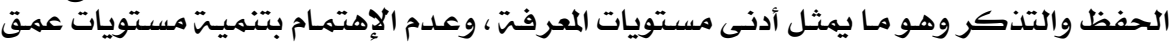

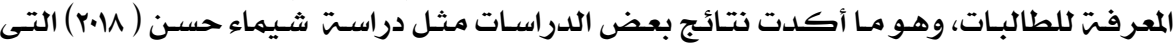

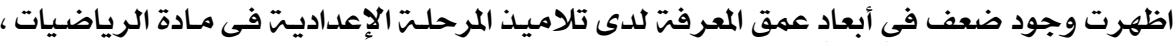

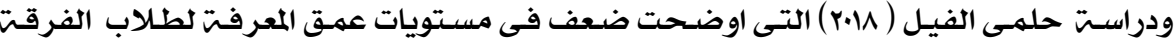

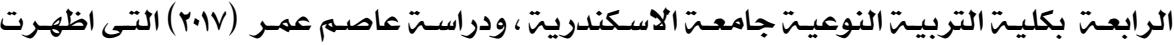

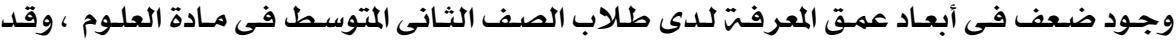

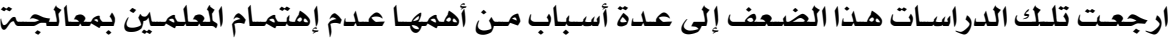

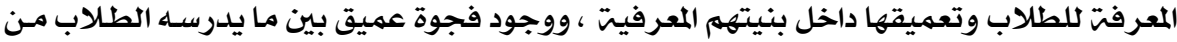

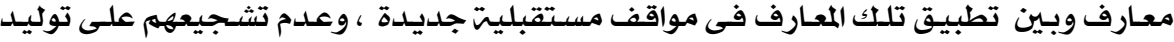

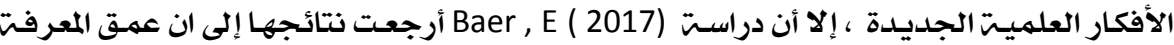

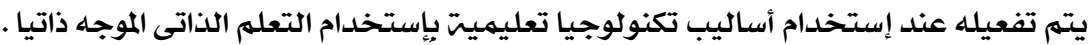

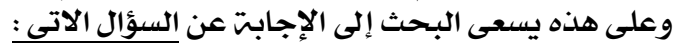

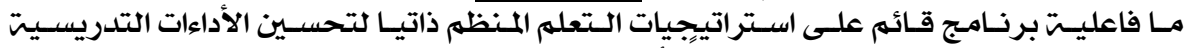

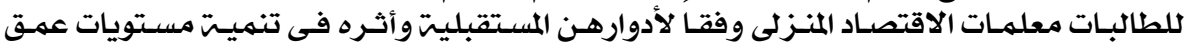

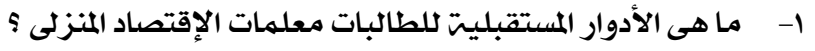

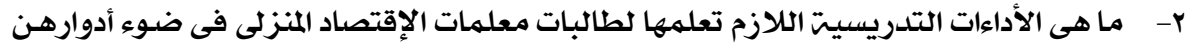

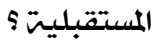

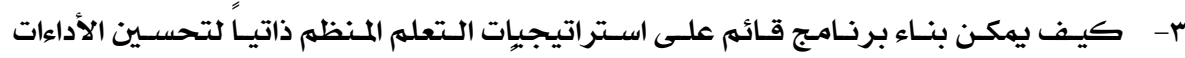

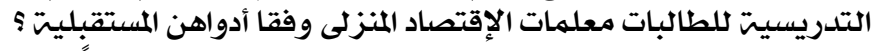

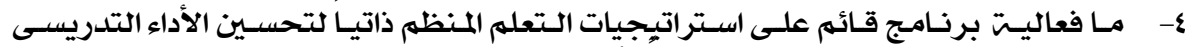

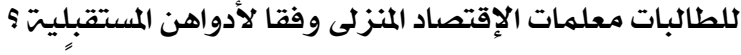

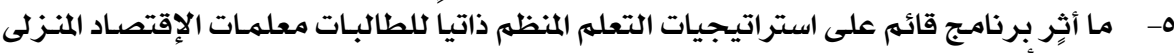

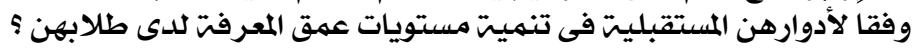

$$
\text { هدف البحث الحالى إلى : }
$$

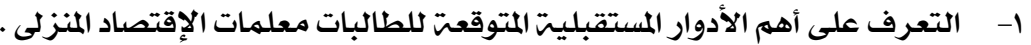

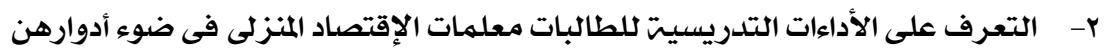

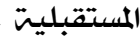

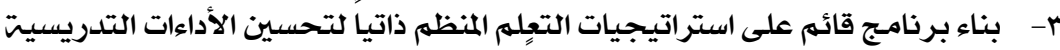

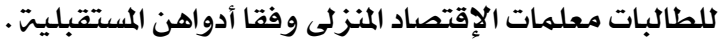

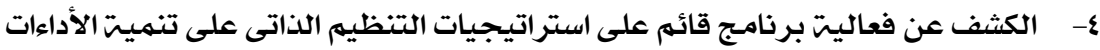

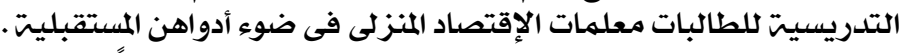

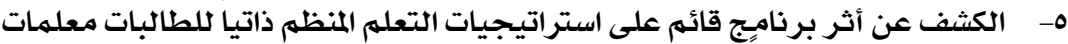

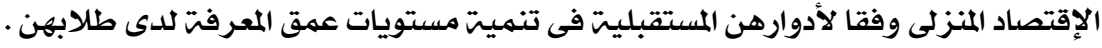




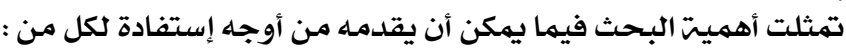

\section{أهمينت البحث أهثبت}

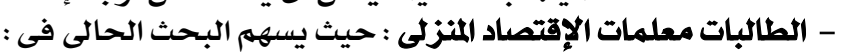

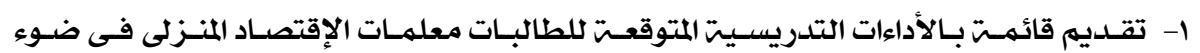
أدوارهن المستقبليتة.

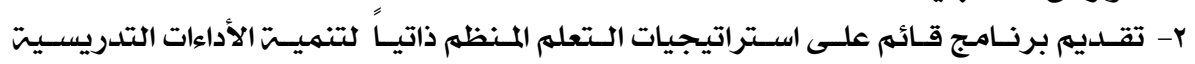

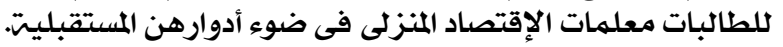

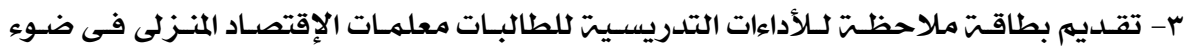
أدوارهن المستقبليتئ.

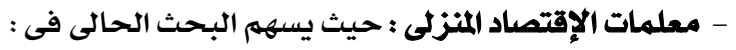

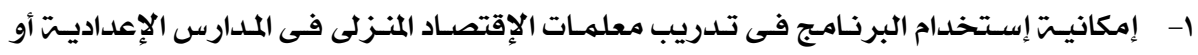
الثانويتة.

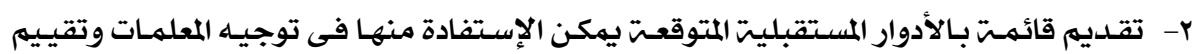

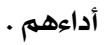

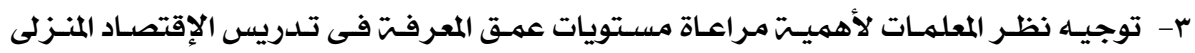

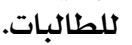

- الباحثين ومطورى المناهج : حيث يسهم البحث الحالى فى :

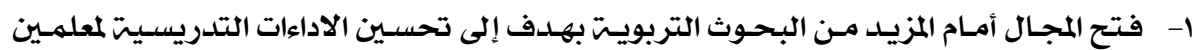

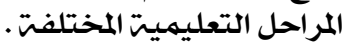

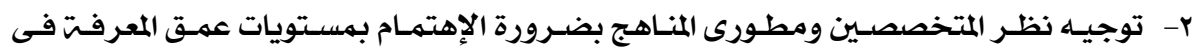

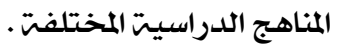

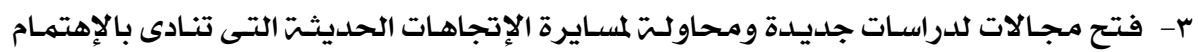

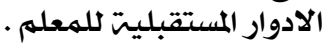

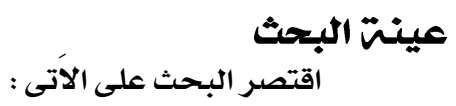

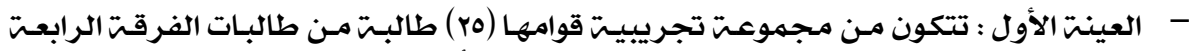

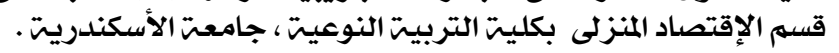

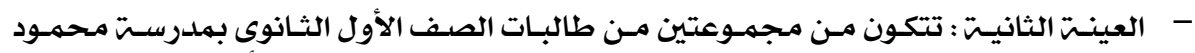

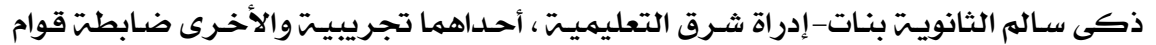
كل مجموعت (rr) طالبت.

أدوات البحث

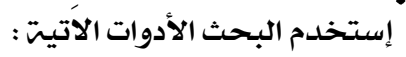

1- إستبيان لتحديد الأدوار المستقبليت للطالبات الاتيت معلمات الإقتصاد المنزلى ( إعداد الباحثت) .

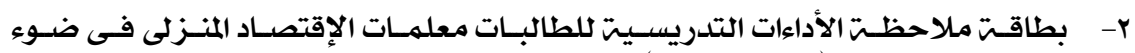
أدوارهن المستقبليت (إعداد الباحتشثية).

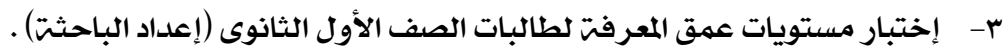




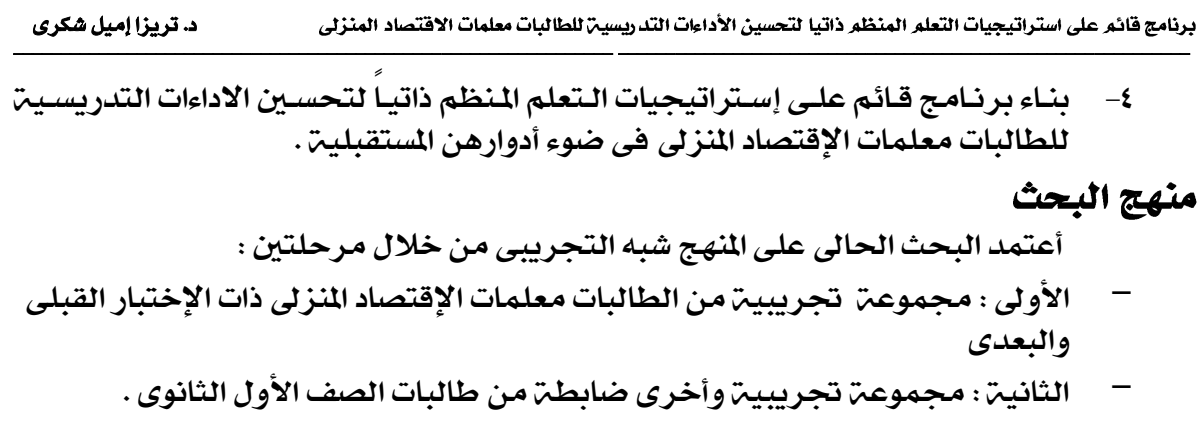

\section{مصدالحماث البحث}

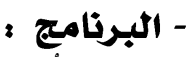

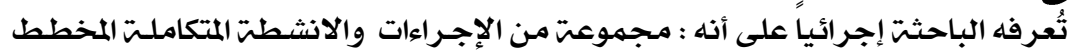

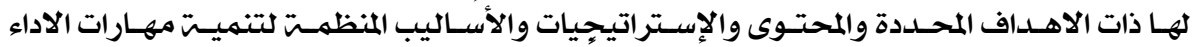

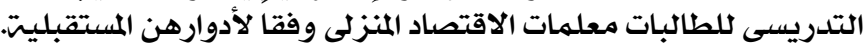

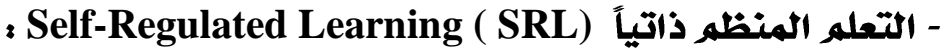

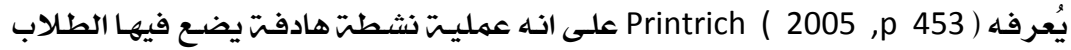

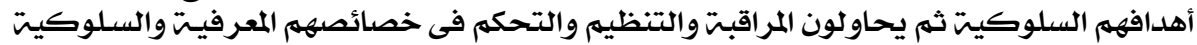

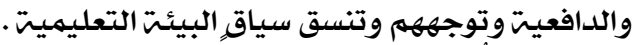

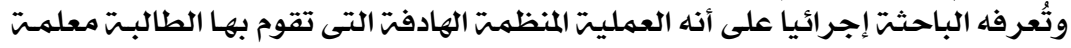

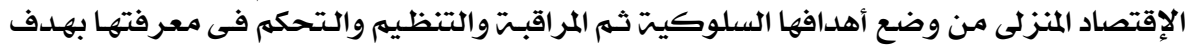

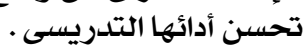

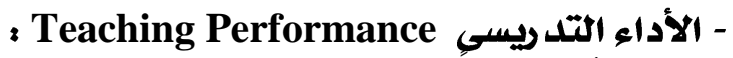

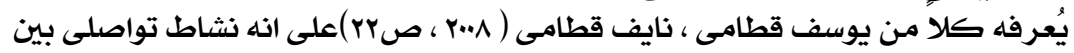

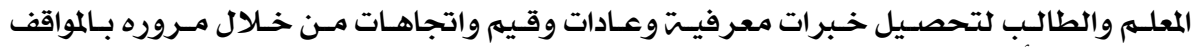

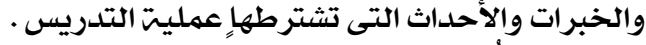

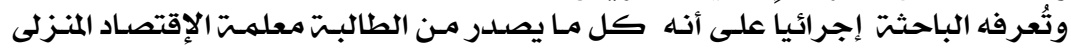
من أنشطت وإجراءات وسلوكيات التهيات داخل الغرفياته أنه الصفيت.

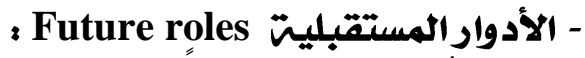

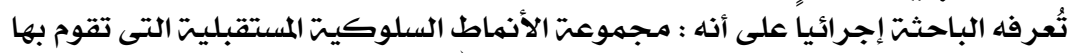

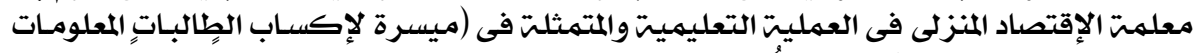

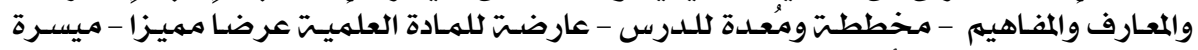

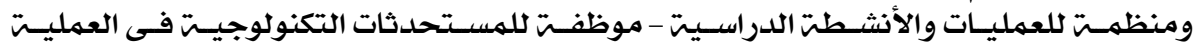

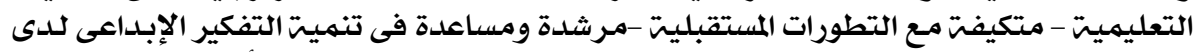

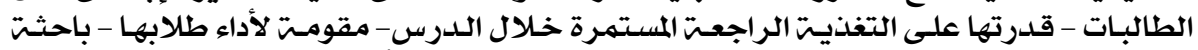

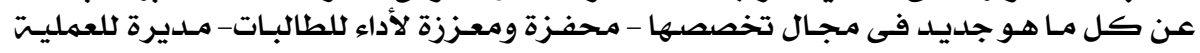

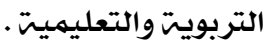

\section{- Depth of Knowledge Levels مستويات عمق المعرفتر}

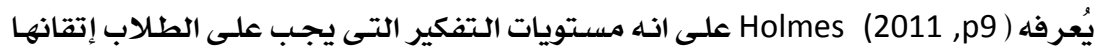

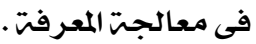




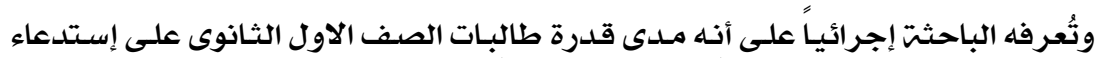

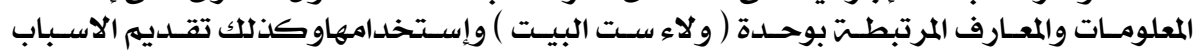

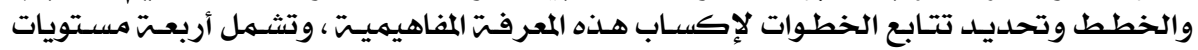

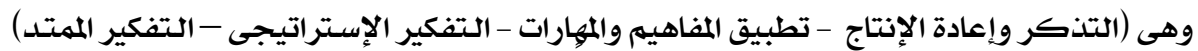

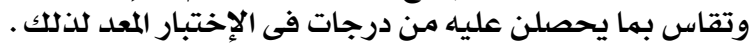

$$
\text { فروض البحثث فروض البحثل }
$$

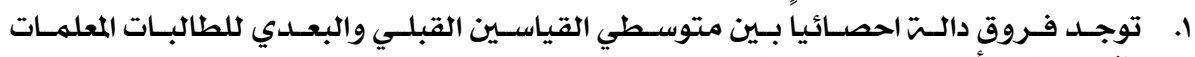

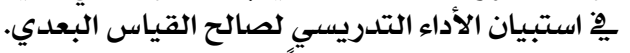

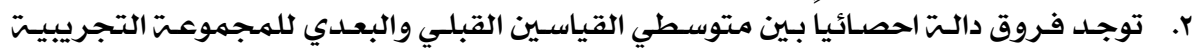

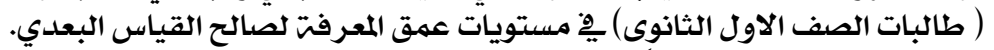

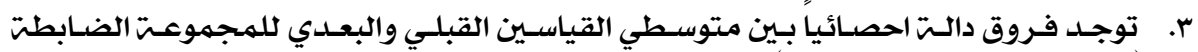

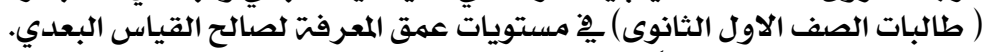

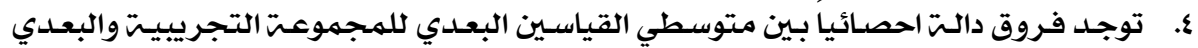

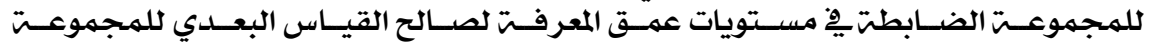

التجريبيت.

$$
\begin{aligned}
& \text { خطوات البحث وإجراءواته } \\
& \text { جاءت إجراءات البحث الحاءله الحالى للإجابت عن أسئلته على النحو التالى : }
\end{aligned}
$$

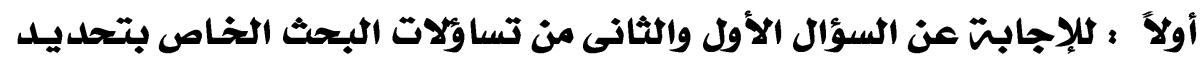

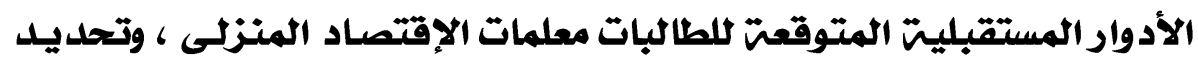

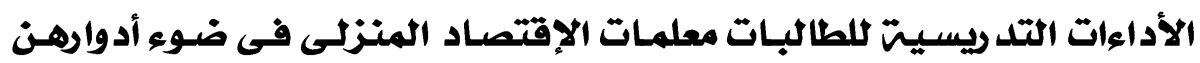

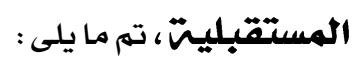

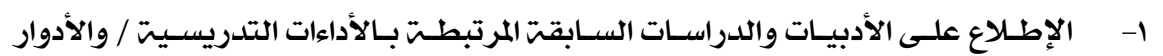
المستقبليت للمعلمين.

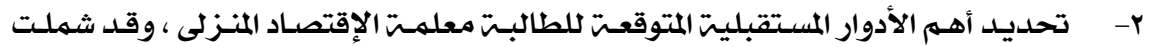

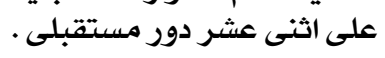

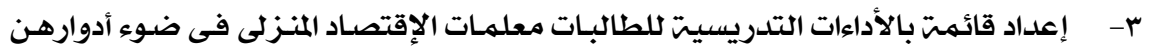

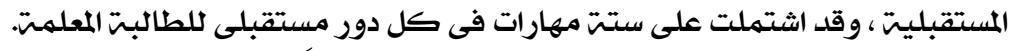

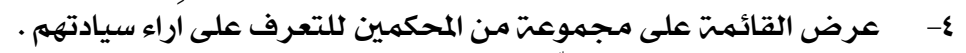

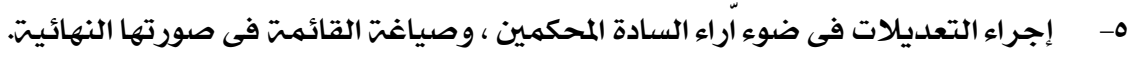

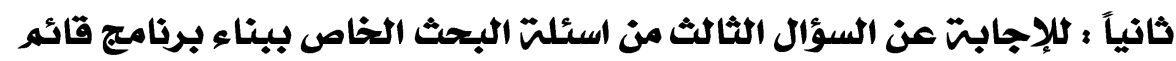

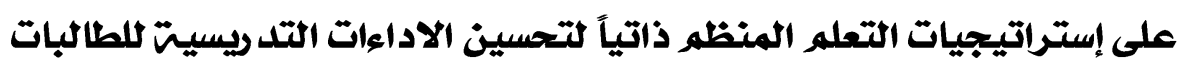

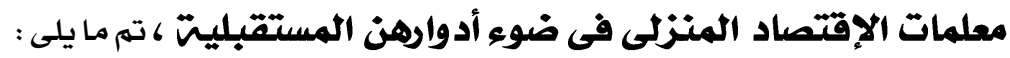

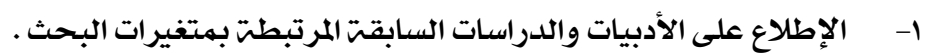




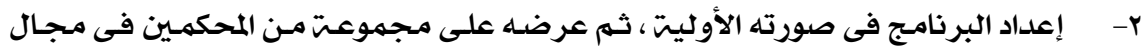

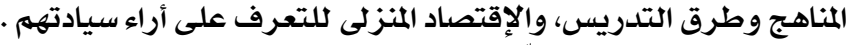

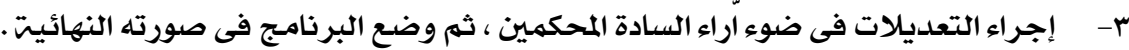

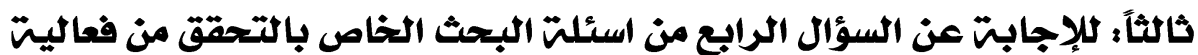

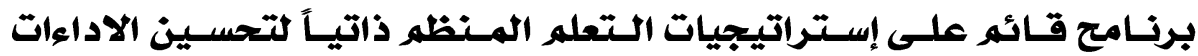

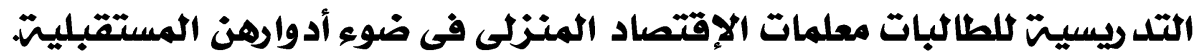
تمر ما يلى :

تصميهم بطاقت الملاحظت بهدف قياس الأداءات التدريسيت للطالبات للطالبات معلمات $-1$

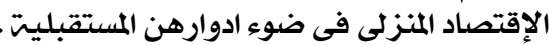

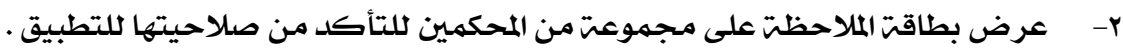

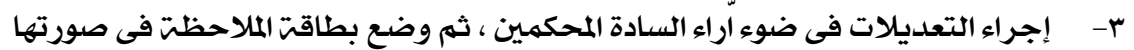
النهائيت.

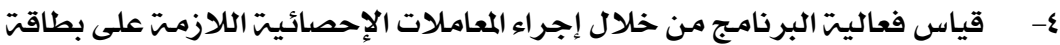

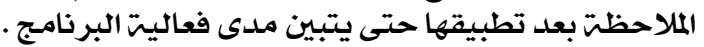

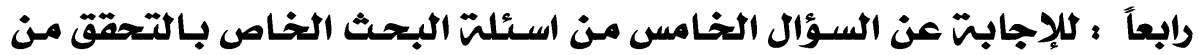

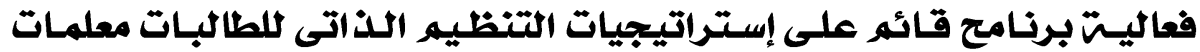
الإقتصاد المنزلى وأثره على تنميـت مستويات عمق المعرفت لـى لدى طلابهن .

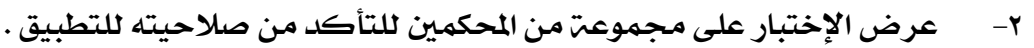

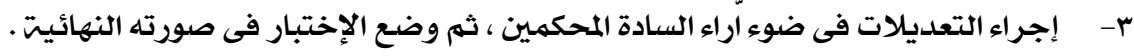

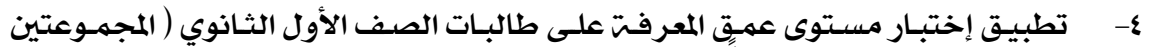

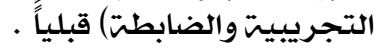

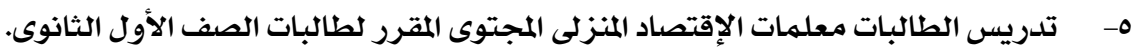

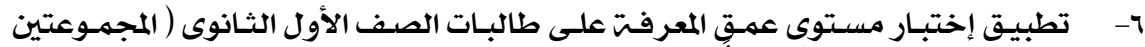

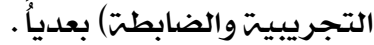

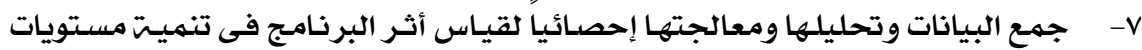

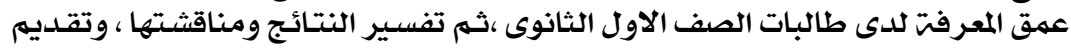
التوصيات والمقترحات . المعن لديات

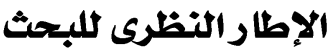

\section{المبحث الأول : التعلم المنظم ذاتياً :}

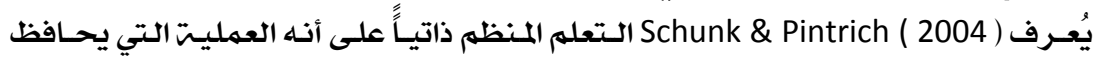

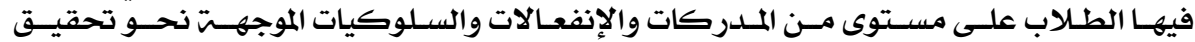

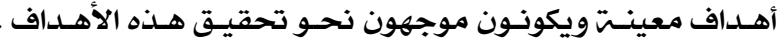


ويتفق كلاً من ( Bembenutty(2006,p223 ؛ Pintrich(2000) فى تعريف التعلم المنظم

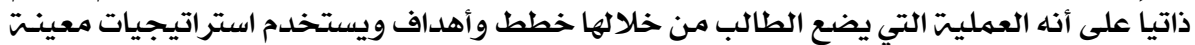

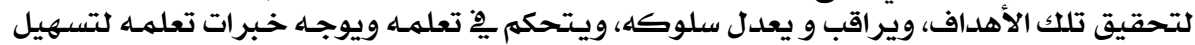

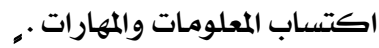
صفات الطلاب المنظمون ذاتيا :

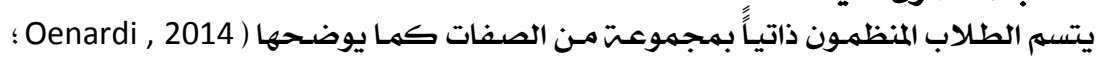

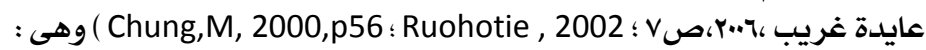

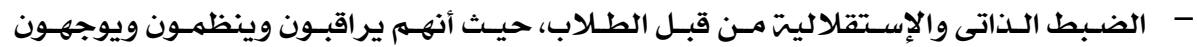

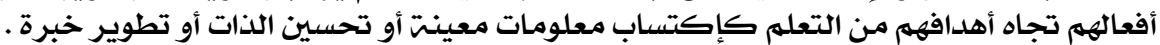

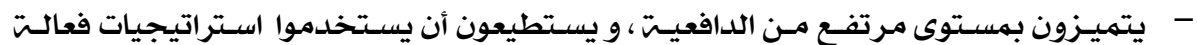
لتحقيق الأهداف ، ويؤدون المهام المطلوبت بطريقت جيدة الميدة .

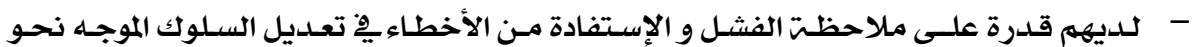
أهدافهم التعليميت.

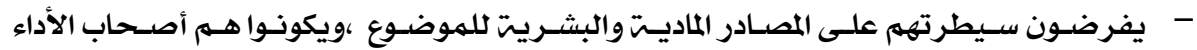

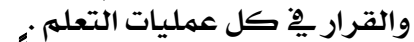
استراتيجيات التعلم المنظم ذاتياً:

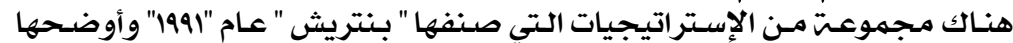
: Nata ( 2003 ,p 107)

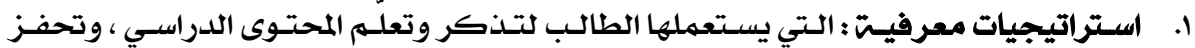

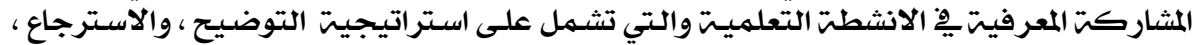
والتنظيم ،والتفكير الناقد.

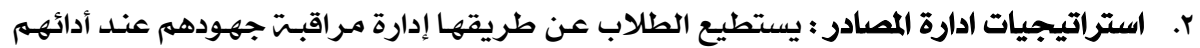

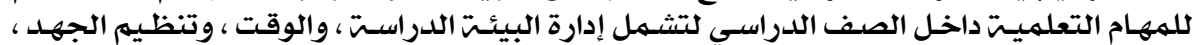

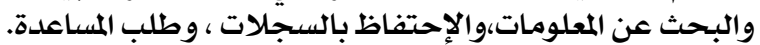

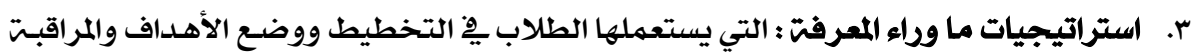

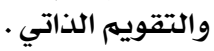

ع. إستراتيجيات الدافعيتة : وهى التي تقوم على اسـتراتيجيت الدافعيت الذاتيتة ، وفعاليت الدات

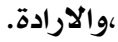

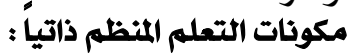

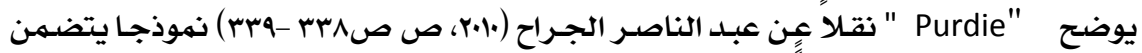
أربعتّ مكونات للتعلهم المنظم ذاتياً :

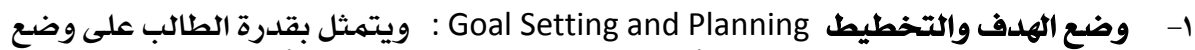

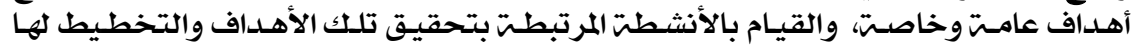

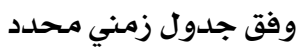

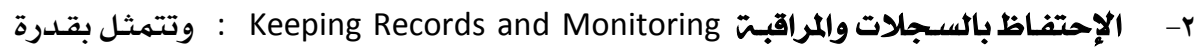

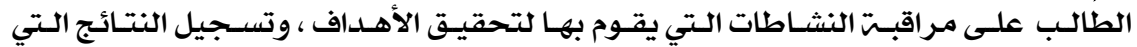

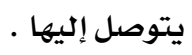


r- التسـميع والحفظ Rehearsing and Memorizing : ويتمثل بقدرة الطالب على حفظ

المادة عن طريق تسميعها بصورة صامتتش أو جهريت.

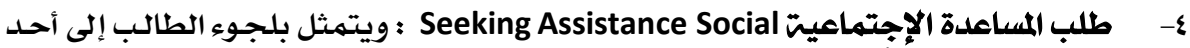

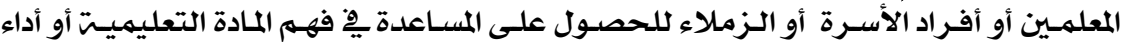

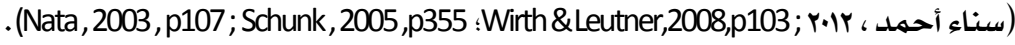

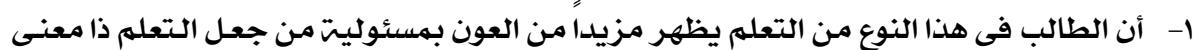

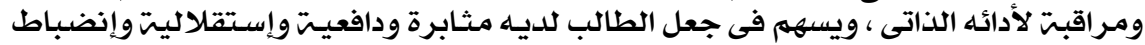

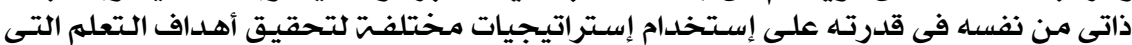

وضعها لنفسله .

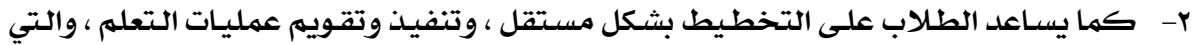

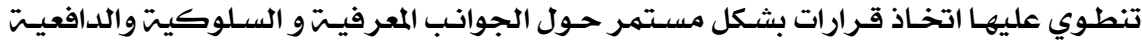

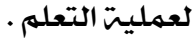

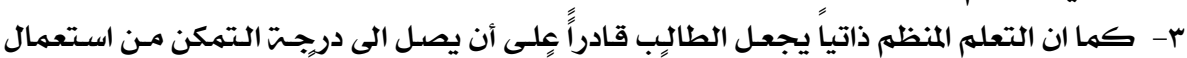

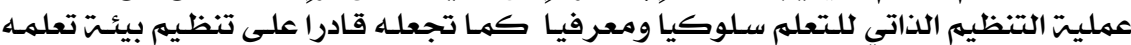

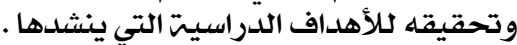

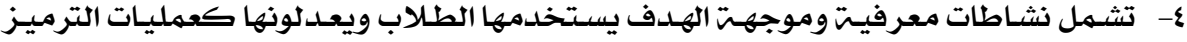

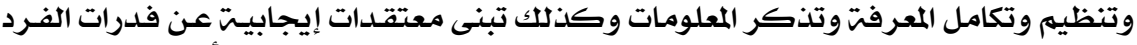

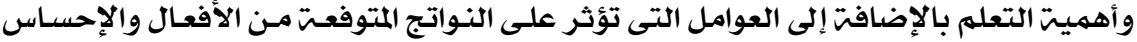
بالرضا عن مجهود الطالب.

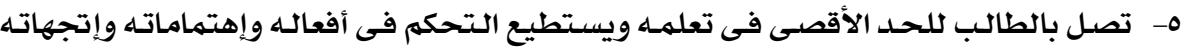

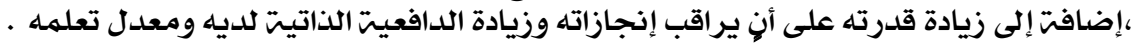

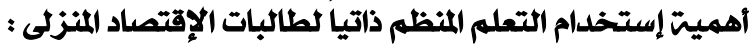

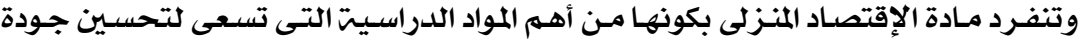

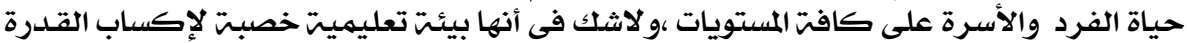

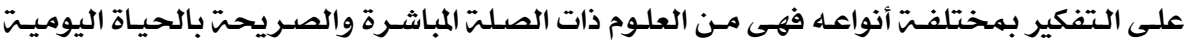

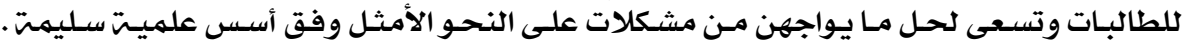

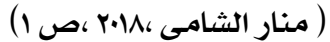

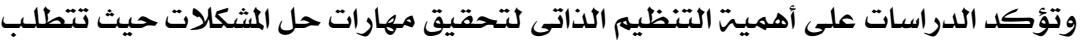

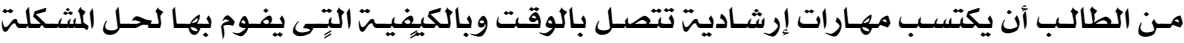

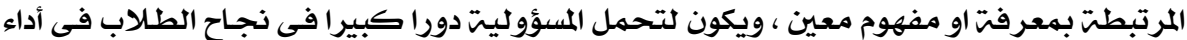

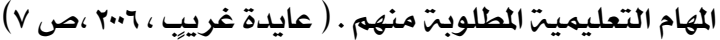

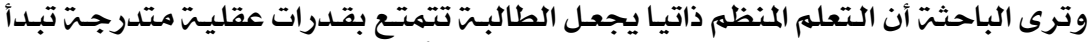

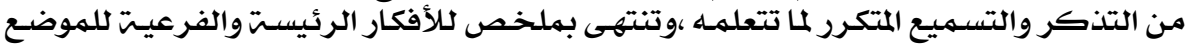

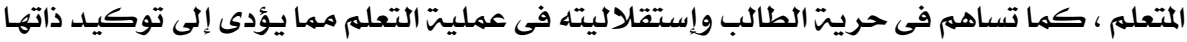




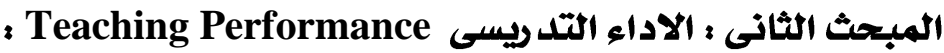

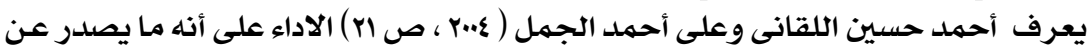

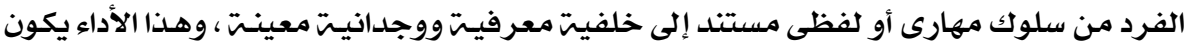

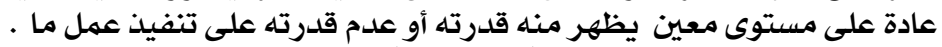

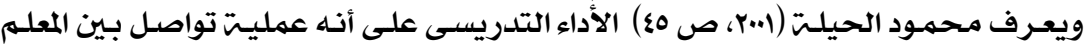

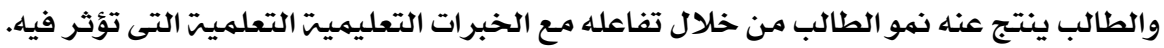

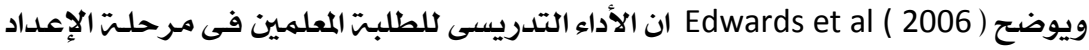

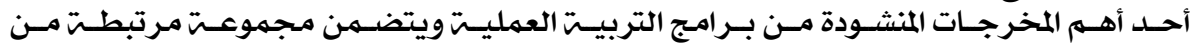

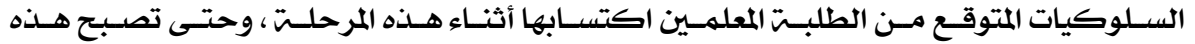

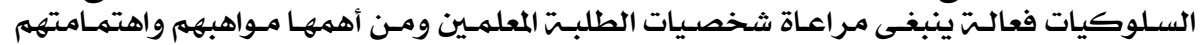

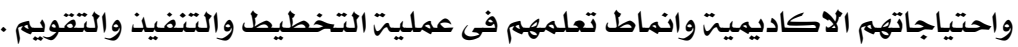

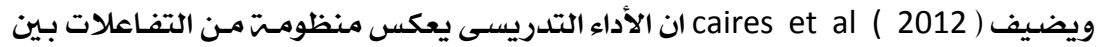

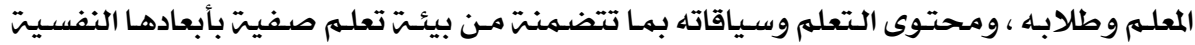
والماديت.

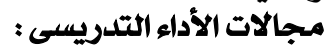
المجال الأول : تخطيط الألتوريس التدريس:

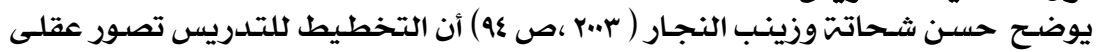

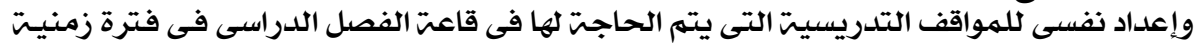

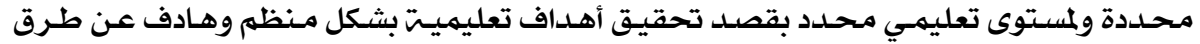

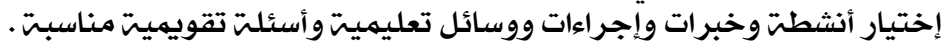
المجال الثانى : تنفيذ التدريس:

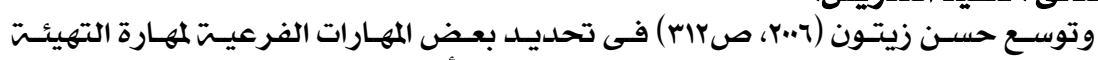

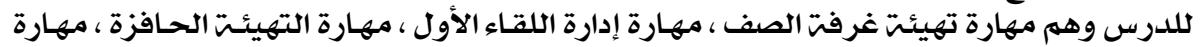

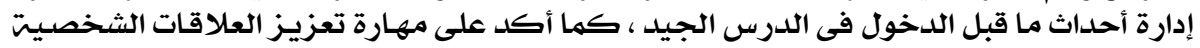

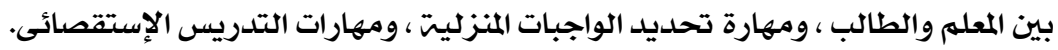
المجال الثالث : تقويم التدريس:

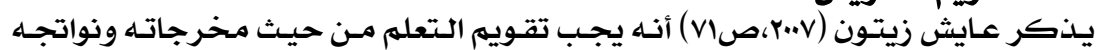

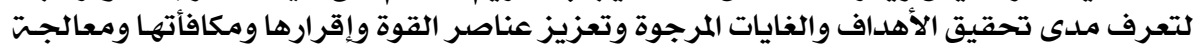

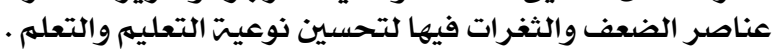

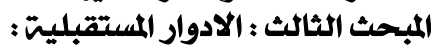

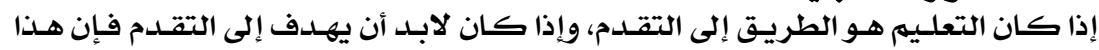

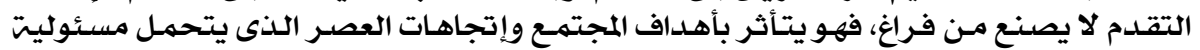

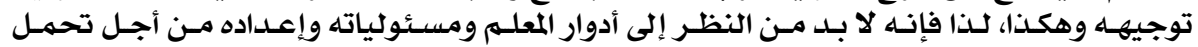

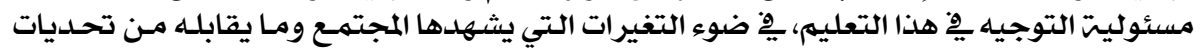

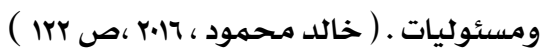

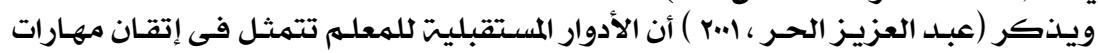

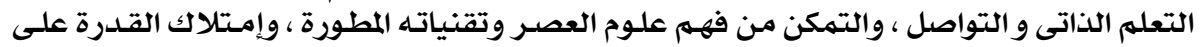

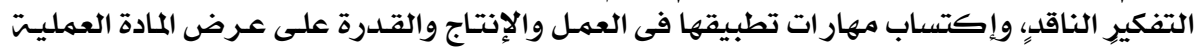

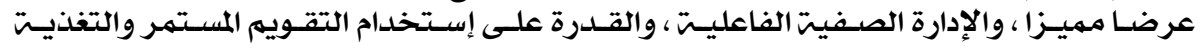
الراجعت فى أثناء التدريس . الارة المفيل 


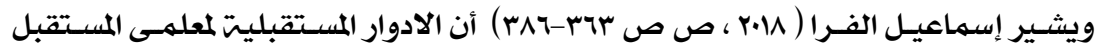

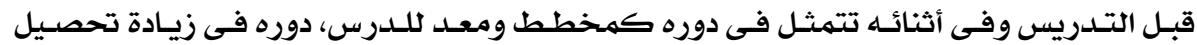

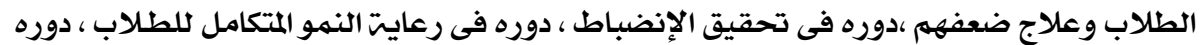

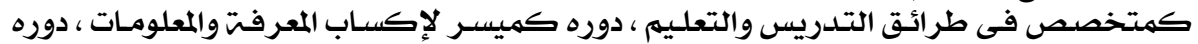

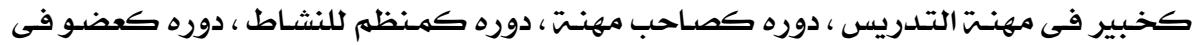

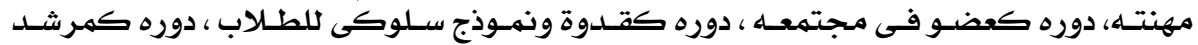

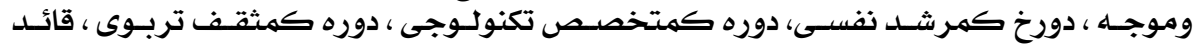

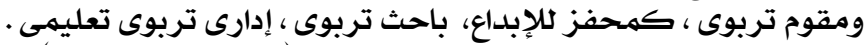

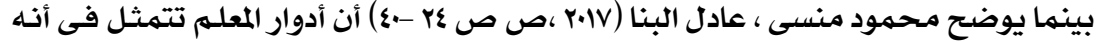

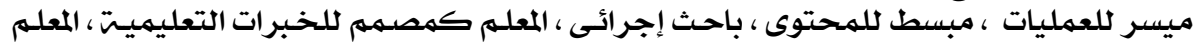

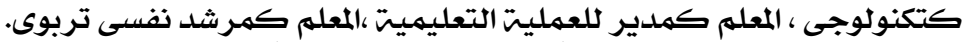

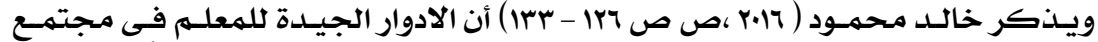

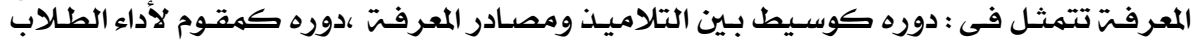

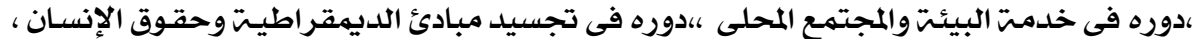

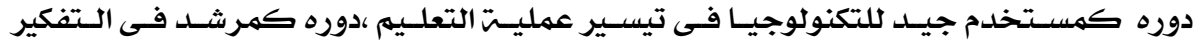

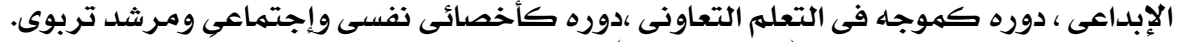

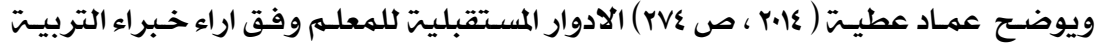

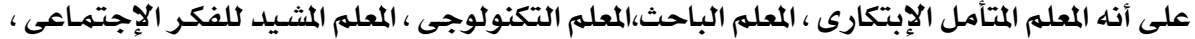

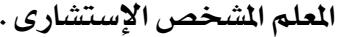

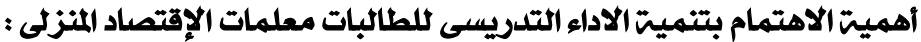

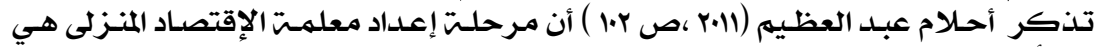

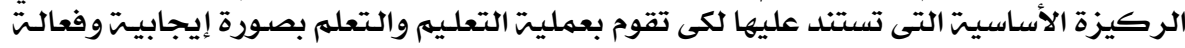

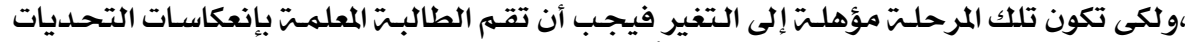

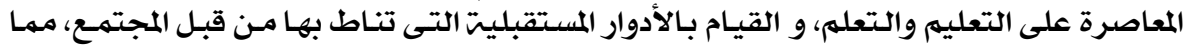

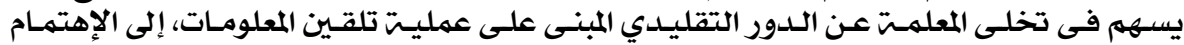

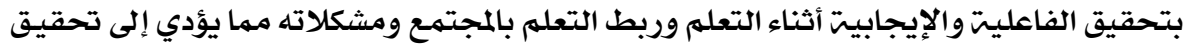

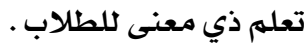

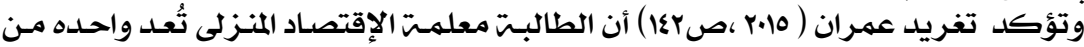

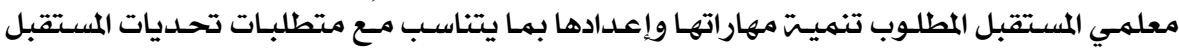

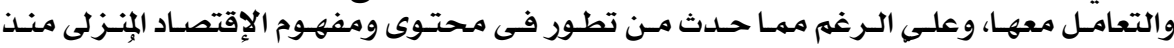

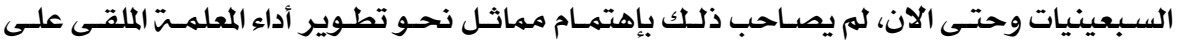

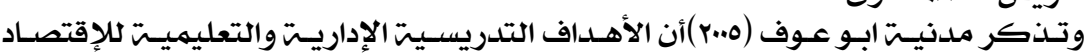

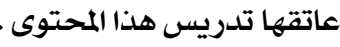

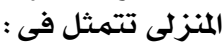

- تحقيق أهداف العمليت التعليميت من قبل المعلمته والطالبات .

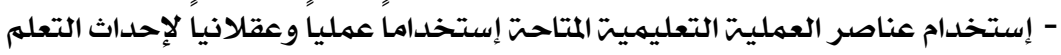

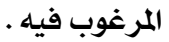

- تنظيه وتنسيق الجهود المبذولت من قبل المعلمته وطلابها بما يتفق مـع الاهداف المنشودة. - تصميه الخبرات التعليميت اللازمت لإنتمام عمليتيت التعله. - تهيئت الاسلوب المناسب لعمر الطالبت وخبرتها لإتهام عمليت التعلهم . 


$$
\begin{aligned}
& \text { - إيجاد روح التفاهم والتعاون بين المعلمت والطالبات لممارست العمل الفردى والدماعى } \\
& \text { لإتمام التعلم. } \\
& \text { - إيجاد الطرق المناسبت لمساعدة الطالبات على التعله والنمو الشامل على جميع الجوانب } \\
& \text { السلوكيت. }
\end{aligned}
$$

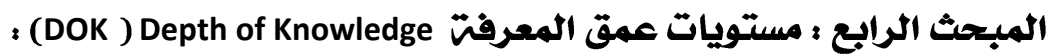

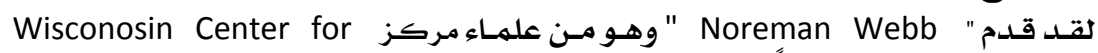
" Educathon Research "

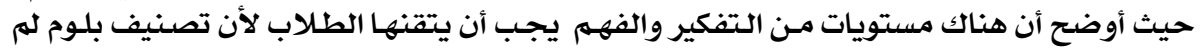

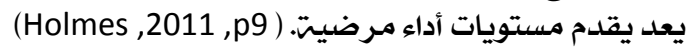

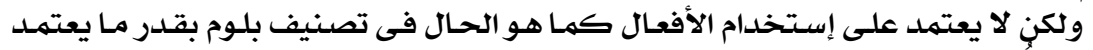

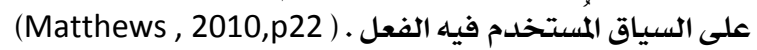

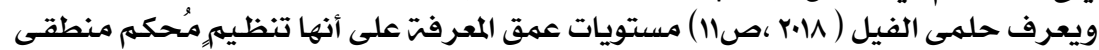

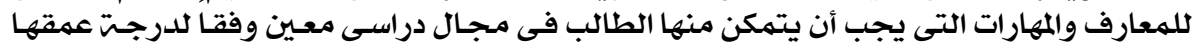

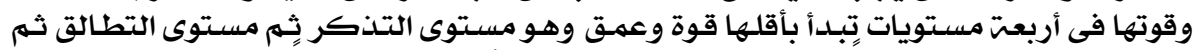

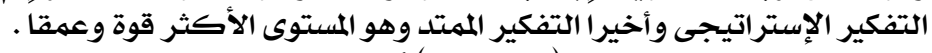

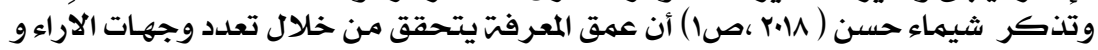

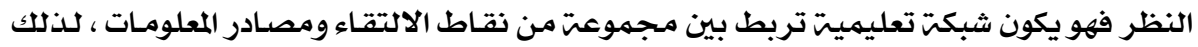

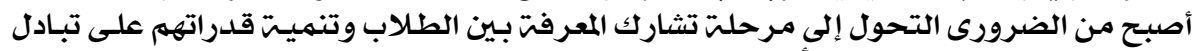

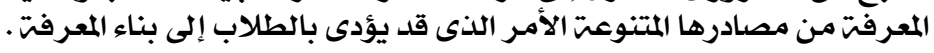

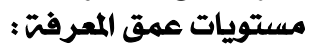

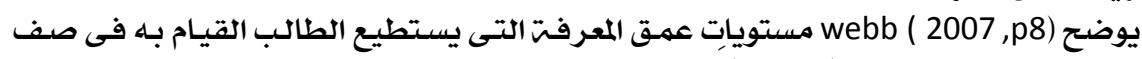

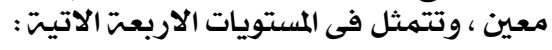

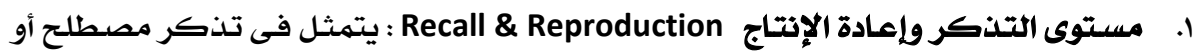

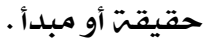

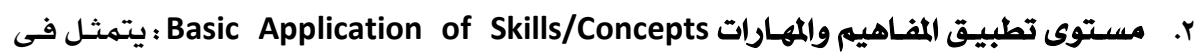

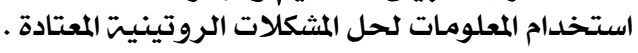

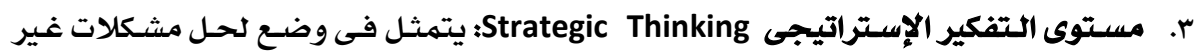

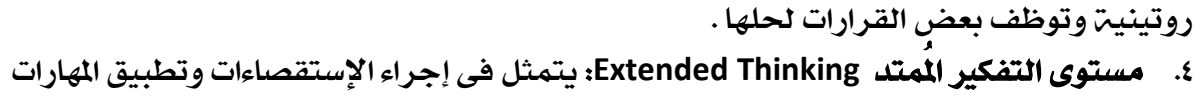

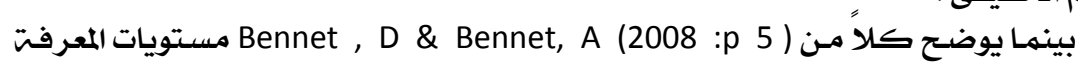

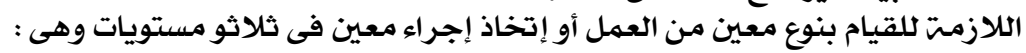

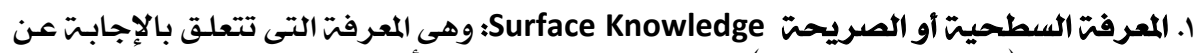

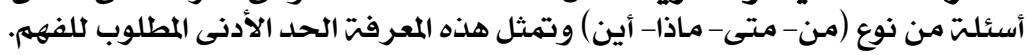

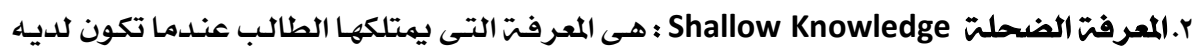

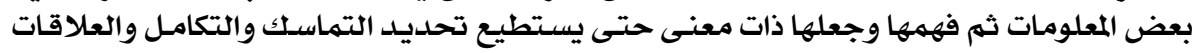

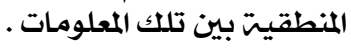

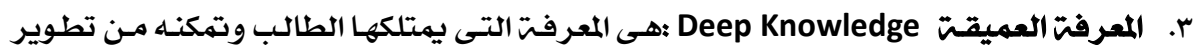

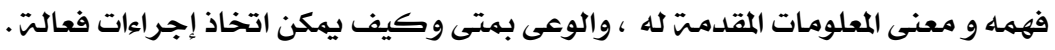




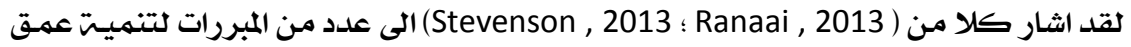

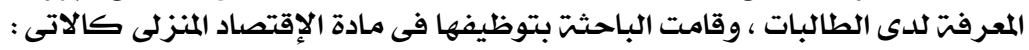

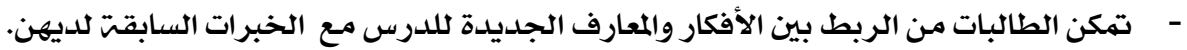

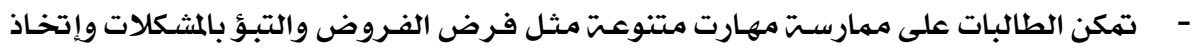

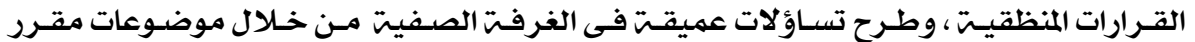

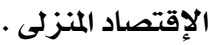
- تمكن الطالبات مـع التفاعل مـع بعضهن لتحقيق الفهـم الاعمق للمعلومـات فى مـادة الإقتصـاد

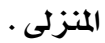
- تمكن الطالبات من ترتيب افكار الدرس ترتيباً منطقياً.

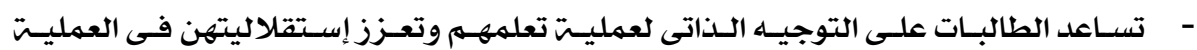
- تساعد على بقاء أثر التعلم مدة أطول لدى الطالبات .

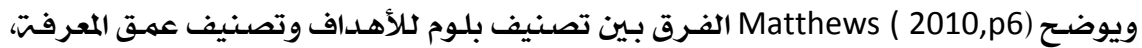

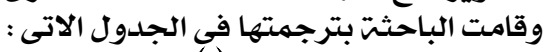

جدول (r) : الفرق بين تصنيف بلوم للأهداف وتصنيف عمق المعرفت

\begin{tabular}{|c|c|}
\hline تصنيف عمق المعرفت & تصنيف بلوم \\
\hline إلإستدعاء الحاء: & 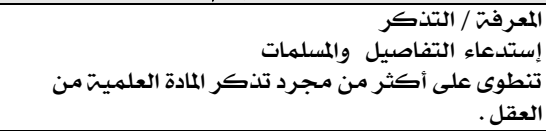 \\
\hline & 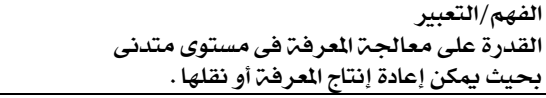 \\
\hline إستخدام المعلومات ، المفاهيم المعارف المفاهيميت ( غالباً تته على مرحلتين) & استخدام المعلومات والمعارف في مواقف مشابهه . \\
\hline 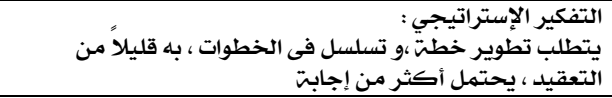 & تجزأة المعلومات للكثف عن العلاقات بين أجزاءها وفهمها . \\
\hline 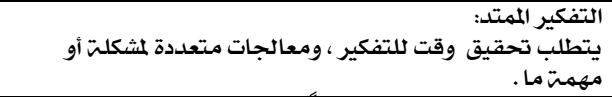 & 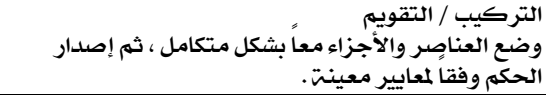 \\
\hline
\end{tabular}

ويذكر ( Matthews , b, (2010,p8 توقعات اداء الطلاب وفقأ لمستويات عمـق المعرفتة، وقامت الباحثت بترجمته كالاتى : 


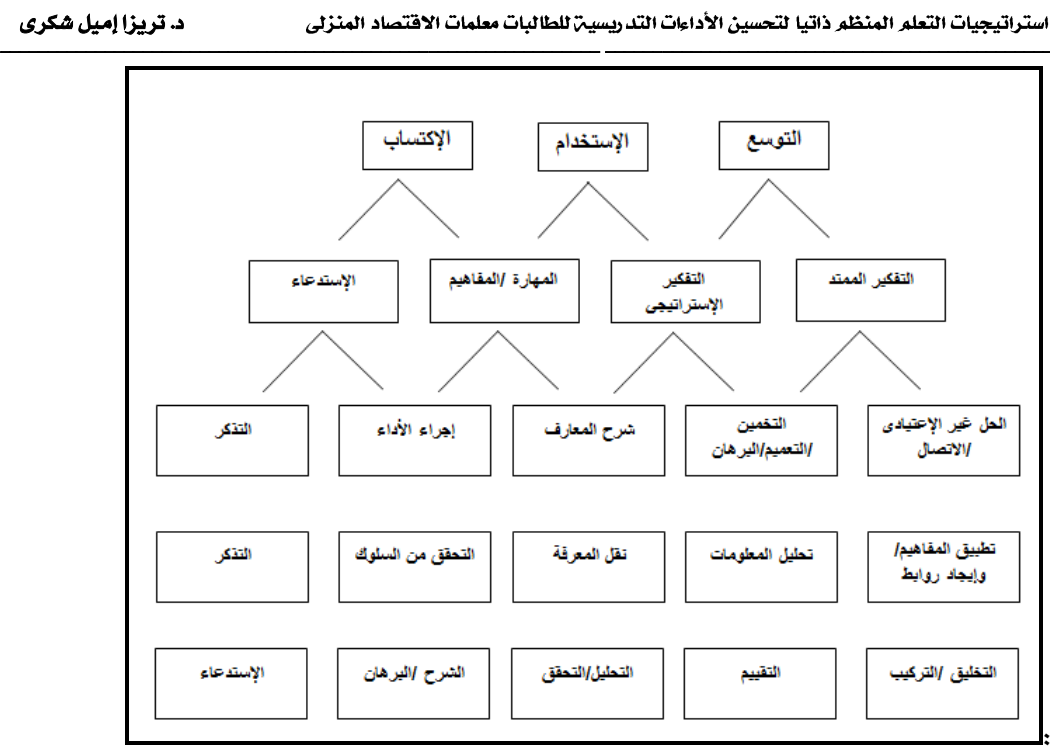

ثكل (r ) توقعات اداء الطلاب وفقاً لمستويات عمق المعرفت

أهميت مستويات عمق المعرفت :

يذكر ( Matthews ( 2010, p13 أن أهميت مستويات عمق المعرفت تكمهن فى أنها تمثل

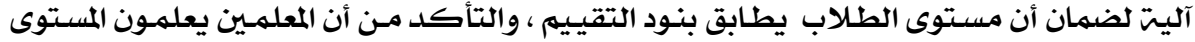

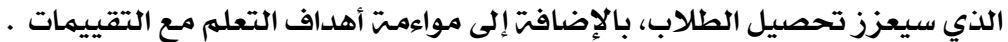

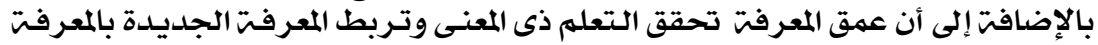

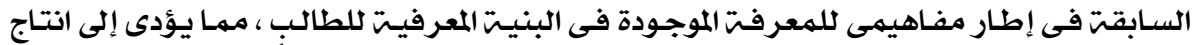

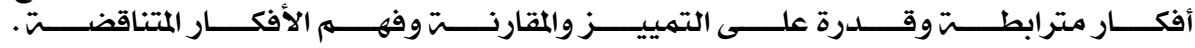
( Thomas \& Jonathan, 2017)

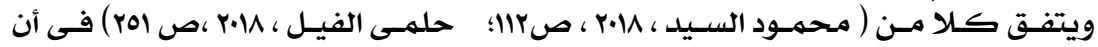

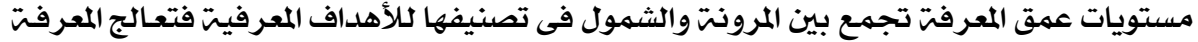

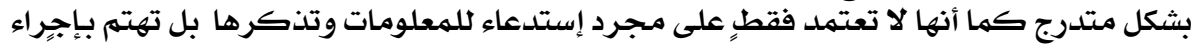

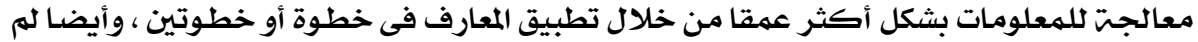

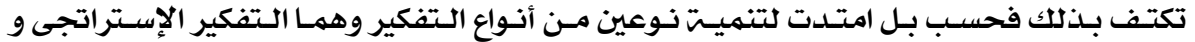

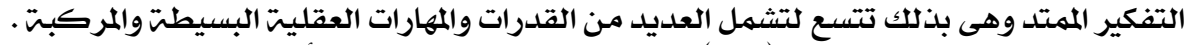

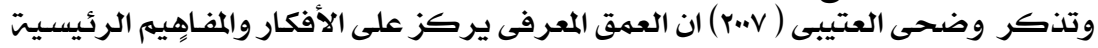

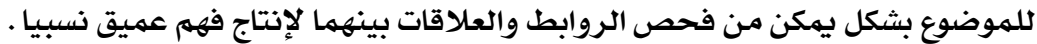

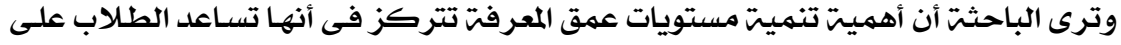

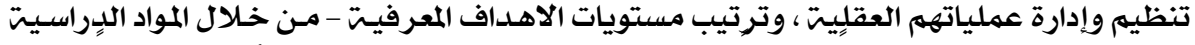

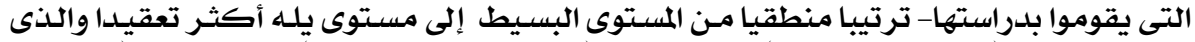

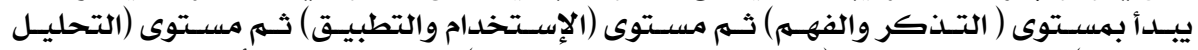

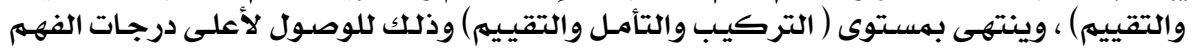
والتعمق فى المعرفتئ.

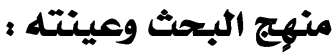

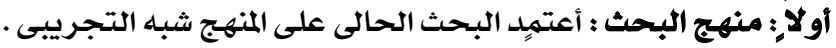

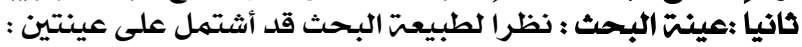




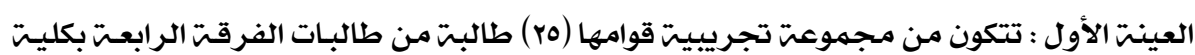

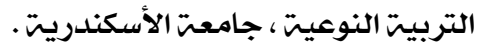

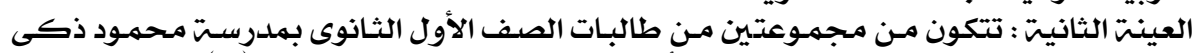

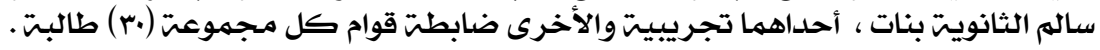

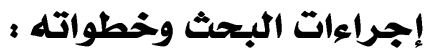

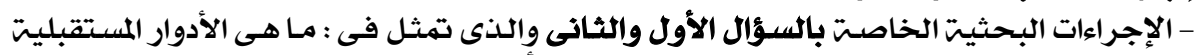

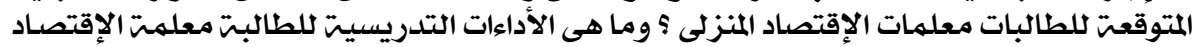

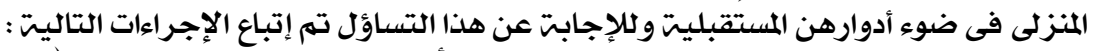

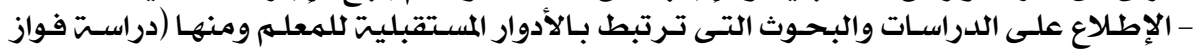

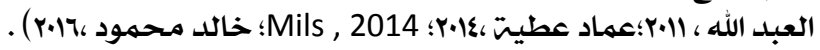

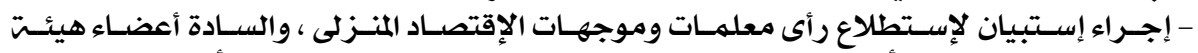

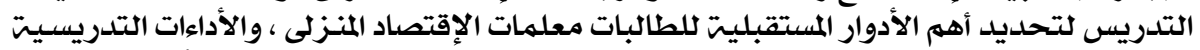

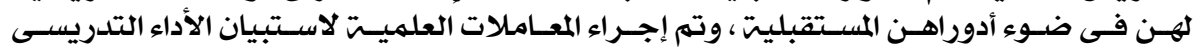

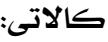

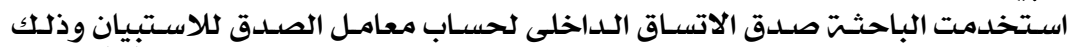

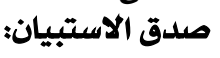

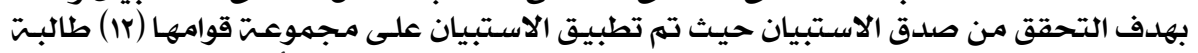

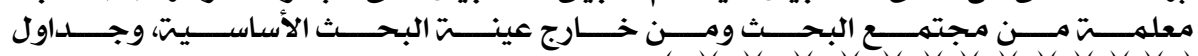

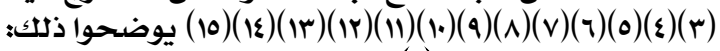

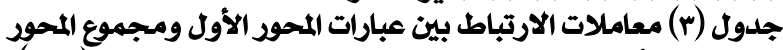

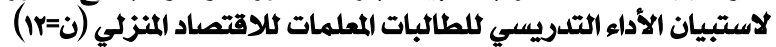

\begin{tabular}{|c|c|c|c|c|}
\hline المحسيمتّر & الانحياري المعري & المتوسطب & العبارات & $\hat{\imath}$ \\
\hline$\because 9 r$ & $1.2 \mathrm{~V}$ & Y.^r & القدرة على حث طالبتها على جمـع المعلومات من مصادر متعلددة. & 1 \\
\hline $.9 \mathrm{~V}$ & 1.0. & r.r. & التعليميتة. القلى توفير مصادر تعلم كافيت تناسب احتياجات الطالبات & r \\
\hline .94 & $1 . \mathrm{rA}$ & r.^ & القدرة على استخدام اسـاليب البحث عن المعلومـت. & r \\
\hline .91 & 1.7. & r... & القدرة على تحفيز طالبتها لمزيد من الاطلاع والبحث . & $\varepsilon$ \\
\hline $.9 V$ & 1.10 & r... & المتتوعتة. على الربط بين استخدام الكتاب المدرسى ومصادر التعلم & 0 \\
\hline $.9 V$ & $1 . \mathrm{MI}$ & r.\&Y & القدرة على تبسيط المحتوى العلهى وتزويدة بالآمثلت المناسبت. & 7 \\
\hline
\end{tabular}

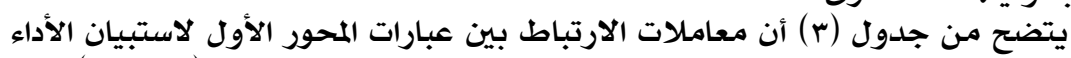

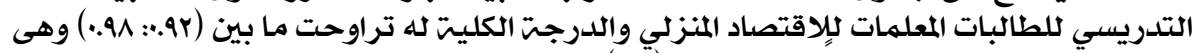

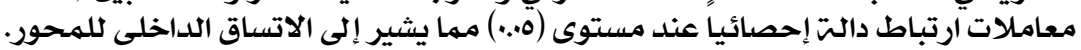




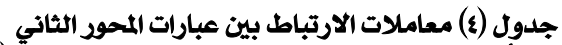

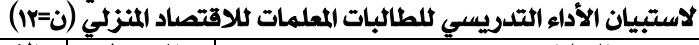

\begin{tabular}{|c|c|c|c|c|}
\hline تلميمتشرد & الإنحراف المعياري & المتوسط المصسابي & العبارات & ค \\
\hline $.9 \varepsilon$ & 1.7. & Y.Vo & القدرة على تحلل المحتوى الدراسى إلى عناصرة الرئيسيت. & 1 \\
\hline .911 & $1 . £ \mathrm{~V}$ & Y.^r & القدرة على تحديد المفاهيم والمصطلحات الرئيسيت للدرس. & r \\
\hline $.9 \mathrm{~V}$ & $1 . \leqslant \varepsilon$ & r.TV & القدرة على صياغت الاهداف بصورة سلوكيتت. & $r$ \\
\hline .94 & $1.7 \mathrm{~V}$ & Y.TV & طلابها . على إستخدم استراتيجيات تعليميت تناسب ميول وخصائص & $\varepsilon$ \\
\hline .97 & 1.07 & r.rr & القدرة على التخطيط للدروس العمليت والنظريتة & 0 \\
\hline $.9 \varepsilon$ & I.YV & r.IV & القدرة على إسخدام وسائل تعليميت مناسبت للدرس . & 7 \\
\hline
\end{tabular}

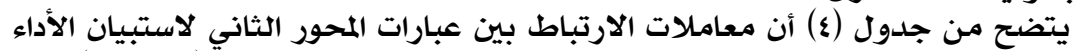

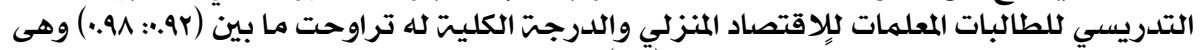

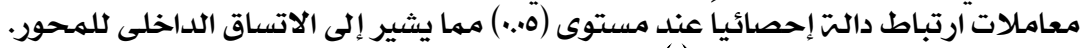

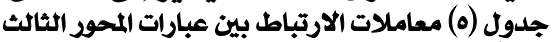

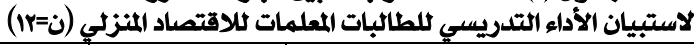

\begin{tabular}{|c|c|c|c|c|}
\hline المحسمتشي & الإنحراف & المحسابي & العبارات & P \\
\hline $.9 \mathrm{~V}$ & $1.2 \varepsilon$ & Y.TV & القدرة على تمهد الدرس بطريقت مشوقت وجذابت. & 1 \\
\hline .91 & 1.01 & $r . \wedge$ & القدرة على التسلسل فى عرض المادة العلميتّ بإتساق منطقى . & $r$ \\
\hline .91 & $1 . \mathrm{r \Lambda}$ & Y.AY & القدرة على توظيف الاسئلت التى تساعد على تحقيق الاهداف. & $r$ \\
\hline .97 & $1.2 \mathrm{~V}$ & r.IV & القدرة على مناقشت طالبتها عن أسئلتهن فى الدرس. & $\varepsilon$ \\
\hline .91 & $1.2 Y$ & r.ro & الطالدرة على إثراء المنهج بهعلومات اضافيت بما يناسب مستوى & 0 \\
\hline .90 & 1.07 & r.qY & القدرة على تطبيق المادة العلميت النظريت إلى مهارات عمليت. & 7 \\
\hline
\end{tabular}

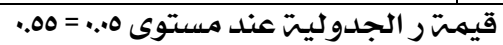

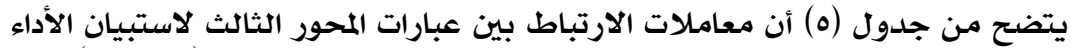

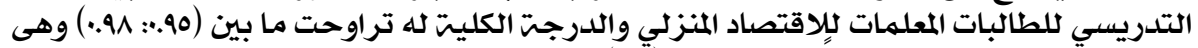

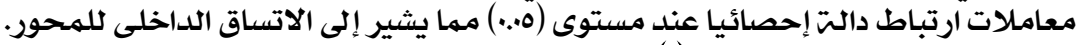

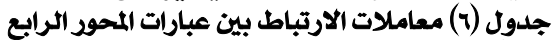

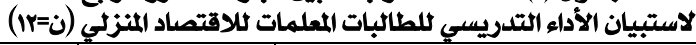

\begin{tabular}{|c|c|c|c|c|}
\hline المحسيمتيت & الانعياري المعري & المتوسابي & العبارات & 个 \\
\hline .97 & I.ry & r.Yo & الطالبرة على استخدام انشطت متتوعت لتعديل وضبط سلوك & 1 \\
\hline $.9 \mathrm{~V}$ & $1 . \Sigma 1$ & $r . . \cdot$ & القدرة على توظف الانشطت الصفيت بشكل مناسب. & $r$ \\
\hline .97 & $1 . \varepsilon \cdot$ & r.IV & القدرة على تنظم الانشطت التدريسيت الهادفت. & $r$ \\
\hline .90 & 1.ro & r... & القدرة على التنويع بين الانشطت الصفيتو واللا صفيت. & $\varepsilon$ \\
\hline .911 & $1 . \mathrm{r \Lambda}$ & r.৭Y & القدرة على توفر أنشطت اثرائيت لطالبتها وفق قدراتهن. & 0 \\
\hline .91 & $1 . \varepsilon \cdot$ & r.Ar & القدرة على ربط أنشطت المنهج بالبيئتت المحيطت بالطالبات . & 7 \\
\hline
\end{tabular}

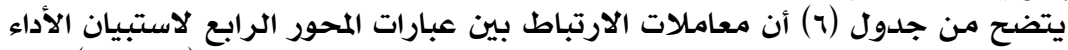

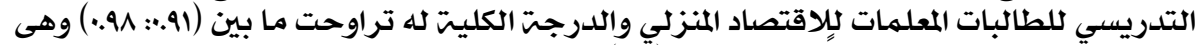

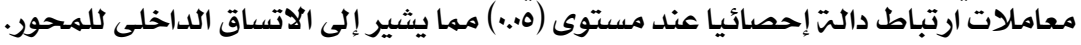




\begin{tabular}{|c|c|c|c|c|}
\hline \multicolumn{5}{|c|}{ 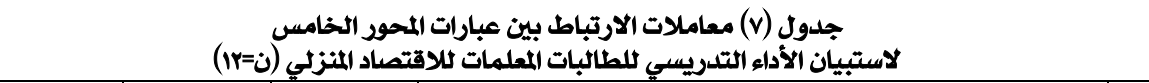 } \\
\hline المحسوبتر & الانمياري & الحسوسطي & (العبارات & P \\
\hline .97 & $1 . \mathrm{rq}$ & r.vo & القدرة على الإلمام بالاساليب التقنيت والتكنولوجيا الحديثت. & 1 \\
\hline .99 & 1.51 & r.\&Y & الدراسى . على توظف التقنيات والوسائط التكنولوجيت التى تخدم المنهج & $r$ \\
\hline .911 & $1 . \mathrm{r \Lambda}$ & $r \cdot \Lambda$ & 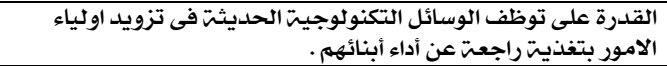 & $r$ \\
\hline $.9 \mathrm{~V}$ & $1 . \mathrm{rq}$ & r.ro & تحصيل الطالبات القدم وسائط تكنولوجيت متعددة متنوعت بهدف رفع & $\varepsilon$ \\
\hline $.9 \mathrm{~V}$ & 1.81 & r... & تقنيتة معاصرة مساعده طلابها على إكتساب المعرفت بأنفسهن من مصادر & 0 \\
\hline .91 & 1.ro & r... & القدرة على طلب واجبات تتطلب إستخدام شبكت الانترنت. & 7 \\
\hline
\end{tabular}

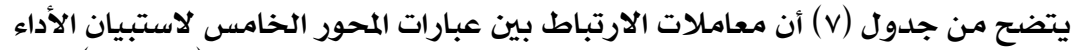

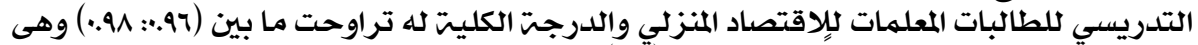

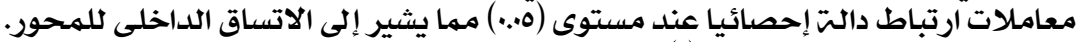

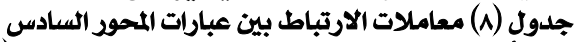

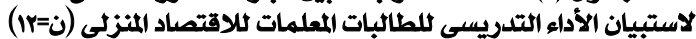

\begin{tabular}{|c|c|c|c|c|}
\hline المحسشوبت & الالانحياري & الحسابي & العبارات & م \\
\hline $.9 \varepsilon$ & $1 . \mathrm{rN}$ & $r \cdot \Lambda$ & القدرة على تفهـم علوم العصر وتقنياته. & 1 \\
\hline $.9 \mathrm{~V}$ & $1 . \mathrm{r} \Lambda$ & r.o. & كاستخدام الانتر نوت أو الفيسبوك المعرفت بإستخدام التقنيات الحديثتة & $\bar{r}$ \\
\hline $.9 r$ & 1.01 & r.\$Y & القدرة على التواصل مع طالبتها من خلال وسائل الاتصال الحديثت. & $r$ \\
\hline $.9 \mathrm{~V}$ & $1 . \mathrm{rv}$ & r.rr & الدراسيتر على تنفذ انشطت تواكب العصر وتحدياته ضمن خطتها & $\varepsilon$ \\
\hline $.9 \mathrm{~V}$ & 1.r & r.IV & القدرة على التنبؤ بأحداث مستقبليت معتمدة على معطيات راهنت. & ० \\
\hline $.9 \mathrm{~V}$ & 1.ro & r... & القدرة على إستخدام وسائل تعليميتت مطورة أثناء الدرس . & 1 \\
\hline
\end{tabular}

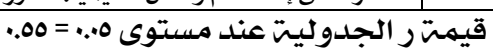

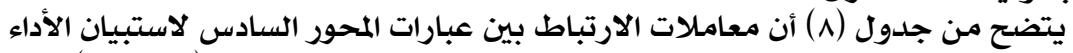

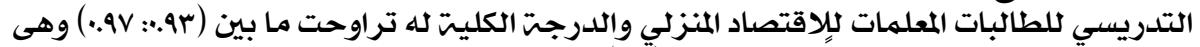

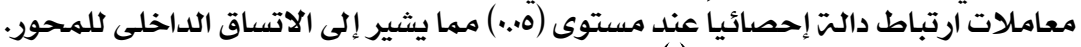

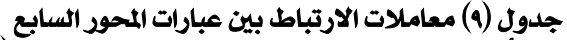

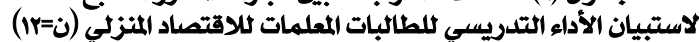

\begin{tabular}{|c|c|c|c|c|}
\hline المحسوبمتي & الانحياري & المتوسطابي & العبارات & $p$ \\
\hline .90 & I.YY & r.Yo & القدرة على توفير بيئت جاذبت وداعمت ومحفزة للتفكير والابداع. & 1 \\
\hline .90 & $1 . r \Lambda$ & r.৭Y & القدرة على تحفيز الطلاب على المبادرة. & $r$ \\
\hline 9 & $1 . \varepsilon \cdot$ & r.IV & 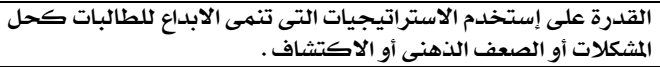 & $r$ \\
\hline $.9 \mathrm{r}$ & $1 . M 1$ & Y.9Y & القدرة على إبتكار اساليب ووسائل تخلدم العمليت التربويت والتعليميتت. & $\varepsilon$ \\
\hline .90 & 1.rr & r.rr & القدرة على تنميت مهارة التفكير الابتكارى لدى الطالبات. & 0 \\
\hline .99 & $1 . \mathrm{r} \Lambda$ & $r . \wedge$ & القدرة على تحفز الطلاب على الابداع & 7 \\
\hline
\end{tabular}

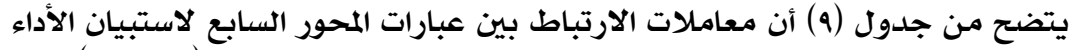

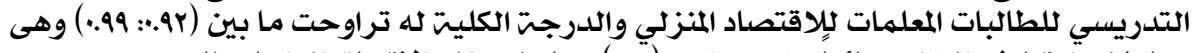

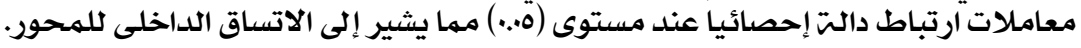




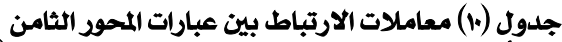

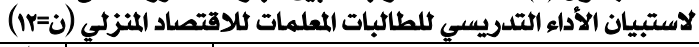

\begin{tabular}{|c|c|c|c|c|}
\hline المحسيمتوبت & الالانحياري & المتوسابي & 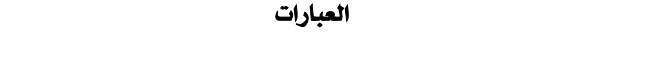 & 个 \\
\hline .90 & $1 . r 0$ & r... & القدرة على تقديم تغذيت راجعت فوريت أثناء الدرس . & 1 \\
\hline .91 & 1.81 & r... & بأنفسهن على تشجيع الطالبات على تصويب اخطائهن فى الدرس & r \\
\hline .97 & $1 . \varepsilon \cdot$ & r.IV & القدرة على وضـع خطط علاجيت فى ضوء نتائج التغذيت الراجعت. & $r$ \\
\hline .90 & I.YY & r.ro & القدرة على توفر تغذيت راجعت بأسلوب تربوى مناسب. & $\varepsilon$ \\
\hline .911 & 1.ru & r.৭r & القدرة على مراعاه الاستمراريت فى توفير تغذيت راجعت أثناء الدرس. & 0 \\
\hline $.9 \mathrm{~V}$ & $1 . r \varepsilon$ & r.^r & القدرة على معالجتَ إجابات الطالبات وتصحتح المفاهيم الخاطئتة. & 7 \\
\hline
\end{tabular}

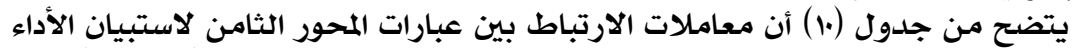

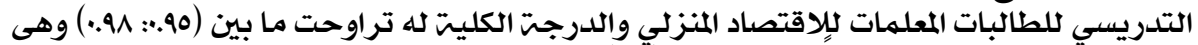

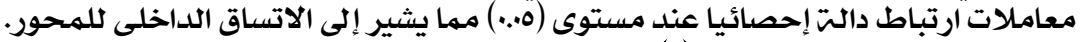

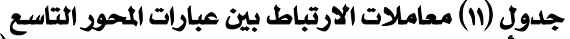

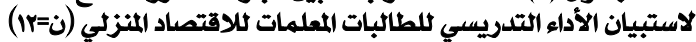

\begin{tabular}{|c|c|c|c|c|}
\hline المحسموبمتر & الانمحراف & المتوسطابي & العبارات & ค \\
\hline .99 & $1 . \mathrm{r} \wedge$ & r.^ & طالقدرة على تنويع أدوات التقويهم بما يراعى الفروق الفرديت بين & 1 \\
\hline .99 & 1.10 & $r . .$. & القدرة على على تحقيق الشموليت فى عمليت التقوييم. & $r$ \\
\hline .91 & 1.r६ & Y.^r & طلابها . على تعديل استراتيجيت التدريس المستخدمت فى ضوء نتائج & $r$ \\
\hline .94 & $1 . \mathrm{YV}$ & r.IV & الطالبات. القدرة على تطوير الاختبارات الدراسيت بما يناسب خصائص & $\varepsilon$ \\
\hline .97 & $1 . r \mu$ & r.rr & القدرة على مر اعاه تسلسل الاسئلةت من البسيط إلى المعقد. & 0 \\
\hline .99 & $1 . r 0$ & $r . *$ & القدرة على ربط الأسئلت الصفيت بأهداف الدرس . & 7 \\
\hline
\end{tabular}

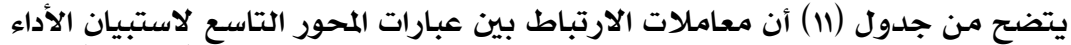

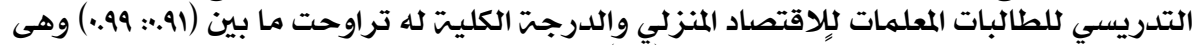

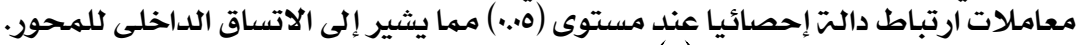

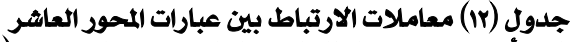

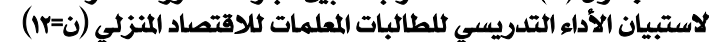

\begin{tabular}{|c|c|c|c|c|}
\hline المحسوبت & الالنحراف & الإتوسطابي & العبارات & p \\
\hline .91 & $1 . \mathrm{ro}$ & r... & القدرة على القيام بأبحاث إجرائيتة. & 1 \\
\hline .91 & $1 . \mathrm{r \Lambda}$ & $r . \wedge$ & 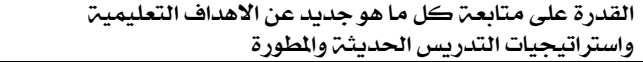 & r \\
\hline .97 & $1 . r r$ & r.rr & القدرة على متابعت كل ما هو جديد عن أساليب التقويم البديل . & $r$ \\
\hline .91 & $1 . \mathrm{r \Lambda}$ & $r . \wedge$ & القدرة على المثاركت ببحوث تحسن العمليت التعليميتت. & $\varepsilon$ \\
\hline $.9 \varepsilon$ & $1 . \mathrm{rA}$ & r.৭Y & العميق لها. القلى البحث عن المعلومات والمعارف حتى تصل الى الفهم & 0 \\
\hline .94 & $1.2 Y$ & Y.VO & القدرة على القر أة والبحث بإستمـرار عن ما يخص مـجال تخصصها. & 7 \\
\hline
\end{tabular}

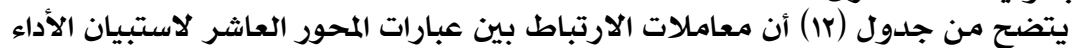

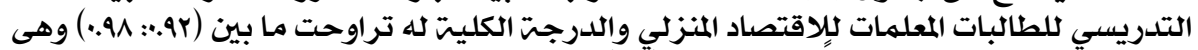

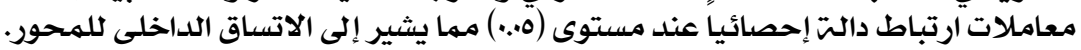




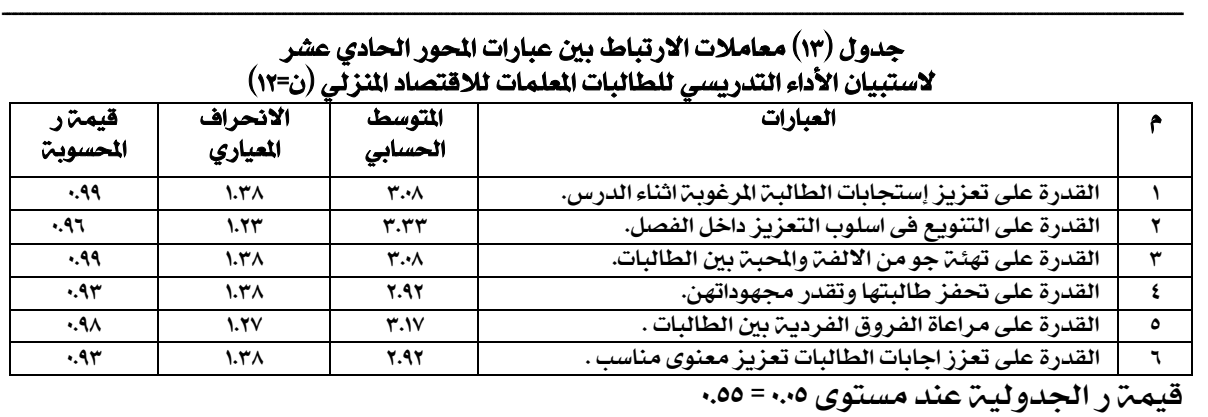

يتضح من جدول

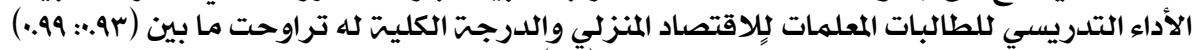

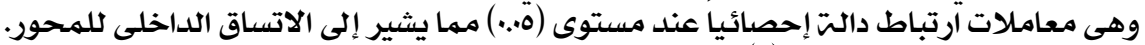

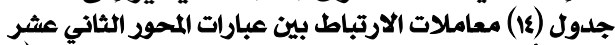

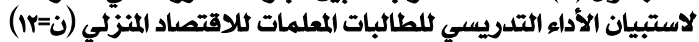

\begin{tabular}{|c|c|c|c|c|}
\hline المحسيوتيت & الانحياري & الحسابي & العبارات & p \\
\hline. .97 & 1.rr & r.rr & القدرة على تطبيق نظريات التعلم والتعليم فى المواقف التدريسيت المتنوعت. & 1 \\
\hline $.9 \mathrm{~V}$ & 1.51 & r... & القدرة على الادارة الصفيت الفعالت. & $r$ \\
\hline .91 & $1 . \mathrm{re}$ & r.৭r & القدرة على إمتثال دور القدوة والنموذج لطالبتها. & r \\
\hline $.9 \mathrm{~V}$ & 1.re & r.Ar & القدرة على اتخاذ قرارات حاسمتروفعالة. & $\varepsilon$ \\
\hline .94 & $1 . r 0$ & r... & القدرة على معالجت المواقف الصفيت الطارئت بطريقت تربويت. & ० \\
\hline $.9 \mathrm{~V}$ & 1.YV & r.IV & القدرة على توفر مناخا تعليميا ممتعا لطالبتها. & 7 \\
\hline
\end{tabular}

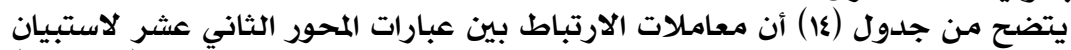

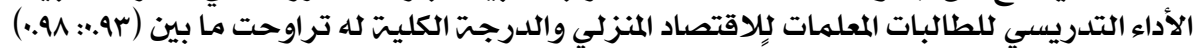

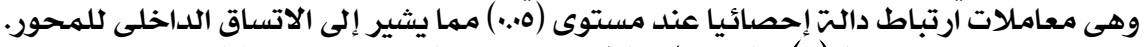

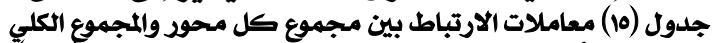

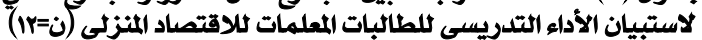

\begin{tabular}{|c|c|c|c|c|}
\hline قلمحسمتربت & الالمعياري & التحسوسبي & المحود & p \\
\hline .97 & $\wedge .81$ & M.TV & ميسره لإكساب الطالبات المعلومات والمعارف والمفاهيه. & 1 \\
\hline$\because 9$. & A.VV & IV.\&Y & مخططتة ومعدة للدرس. & r \\
\hline $.9 Y$ & $\Lambda .71$ & 11 & عارضت للمادة العلميت عرضا مميزا. & $r$ \\
\hline .94 & $\Lambda .1 \varepsilon$ & $1 \mathrm{N.IV}$ & ميسرة ومنظمت للعمليات والأنشطت الدراسيتة. & $\varepsilon$ \\
\hline .97 & V.^r & 19.0. & موظفت للمستجدات التكنولوجيت يِّ العمليت التعليميتة. & 0 \\
\hline $.9 \varepsilon$ & A.1६ & 19.0. & متكيفت مـع التطورات المستقبليت. & 7 \\
\hline $.9 \mathrm{~V}$ & V.Vo & M.TV & مرشدة ومساعدة يِّ تنهيت التفكير الإبداعي لدى الطالبات . & $\mathrm{v}$ \\
\hline .94 & V.9६ & $1 \mathrm{M.IV}$ & قدرتها على التغذيت الراجعت المستهرة خلال الدرس. & $\Lambda$ \\
\hline $.9 \mathrm{~V}$ & V.VI & M.EY & مقومـت لأداء تلاميذها. & 9 \\
\hline .99 & V.99 & $1 \mathrm{~A} . \mathrm{IV}$ & باحثت عن كل جديد ٌِِ مجال تخصصها. & 1. \\
\hline .911 & 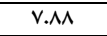 & 14.0. & محفزه ومفرزه لآداء الطالبات. & II \\
\hline .91 & V.AY & M.YO & مديرة للعمليت التربويت والتعليميتة. & ir \\
\hline
\end{tabular}

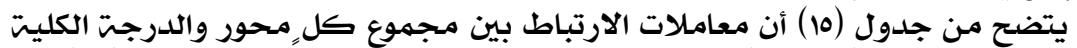

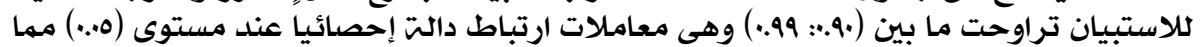

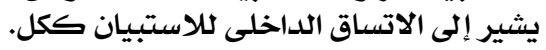


- مبات استبيان الأداء التدريسي:

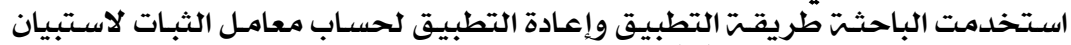

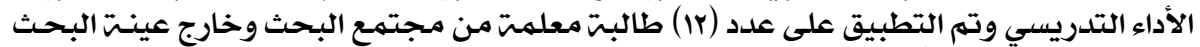

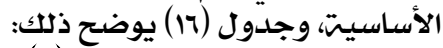

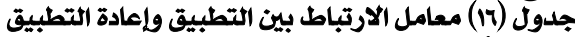

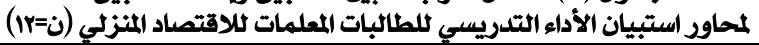

\begin{tabular}{|c|c|c|c|c|c|c|}
\hline \multirow{2}{*}{ ريمت } & \multicolumn{2}{|c|}{ التطبيق الثاني } & \multicolumn{2}{|c|}{ التطبيق الأول } & \multirow[t]{2}{*}{ المحاور } & \multirow[t]{2}{*}{ 个 } \\
\hline & $\varepsilon$ & P & $\varepsilon$ & م & & \\
\hline .97 & 0.0 . & $1 \xi .0$. & A.\$1 & $1 \wedge .7 V$ & ميسره لإكساب الطالبات المعلومات والمعارف والمفاهيه. & 1 \\
\hline .91 & $0 .\{\mathrm{V}$ & $1 \xi . \wedge 1$ & A.VV & IV.SY & مخططت ومعدة للدرس. & $r$ \\
\hline $.9 \mathrm{~V}$ & 0.81 & $1 \varepsilon .1 \mathrm{~V}$ & $\Lambda .71$ & 11 & عارضت للمادة العلميت عرضا مميزا. & $r$ \\
\hline .90 & $0 . \mathrm{Mr}$ & $1 \xi .1 \mathrm{~V}$ & A.1乏 & $1 \mathrm{N.IV}$ & ميسرة ومنظمت للعمليات والأنشطت الدراسيت. & $\varepsilon$ \\
\hline $.9 \xi$ & 0 & 10.rr & V.^r & 19.0. & موظفت للمستجدات التكنولوجيتت يْ العمليت التعليميتة. & 0 \\
\hline .97 & $\varepsilon .19$ & 10.rr & $0.1 \varepsilon$ & 19.0. & متكيفت مـع التطورات المستقبليت. & 7 \\
\hline .90 & 0.1 & IE.Vo & V.Vo & $1 \wedge .7 V$ & مـرشدة ومساعدة ِِْ تنميت التفكير الإبداعي لدى الطالبات . & $\checkmark$ \\
\hline .97 & $\$ .97$ & 1E.rT & V..$q$ & M.IV & قدرتها على التغذيت الراجعت المستمرة خلال الدرس. & $\wedge$ \\
\hline .911 & $\varepsilon . V^{4}$ & $\mid \varepsilon . \wedge r$ & V.VT & M.¿Y & مقومت لأداء تلاميذها. & 9 \\
\hline .97 & 0 & IE.rr & V.99 & $1 \mathrm{N.IV}$ & باحثت عن كل جلديد ٌِِ مجال تخصصها. & $1 \cdot$ \\
\hline $.9 \mathrm{~V}$ & $\varepsilon .19$ & 1E.Vo & 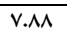 & 1A.0. & محفزه ومفرزه لاذداء الطالبات. & 11 \\
\hline $.9 \varepsilon$ & $0 . \mathrm{rV}$ & $1 \xi .1 \mathrm{~V}$ & V.AY & M.YO & مديرة للعمليت التربويت والتعليميتة. & ir \\
\hline .99 & $7 \cdot . \wedge 1$ & IV\&.Vo & 97. $7 \mathrm{~V}$ & YYI.\&Y & الاستبيان ككل & in \\
\hline
\end{tabular}

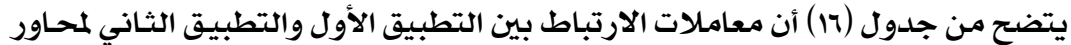

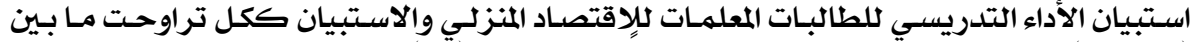

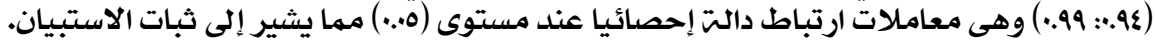

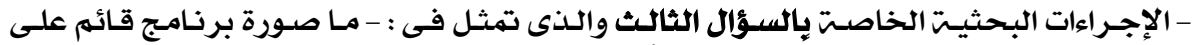

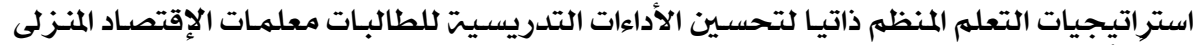

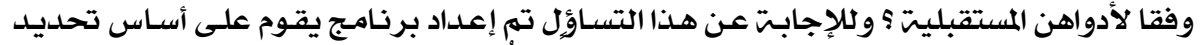

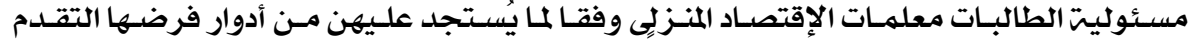

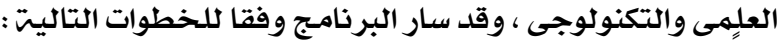

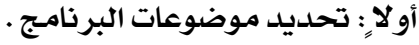

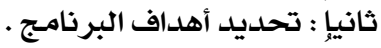

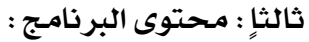
رابعا: إستراتيجيات البرت البرنامج .

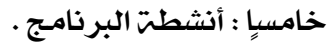

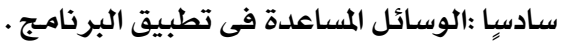

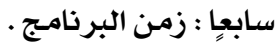

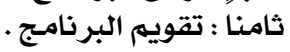

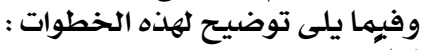

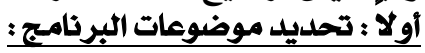

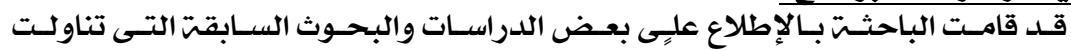

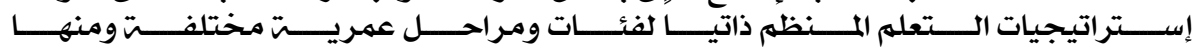

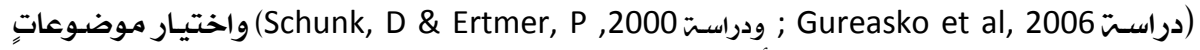

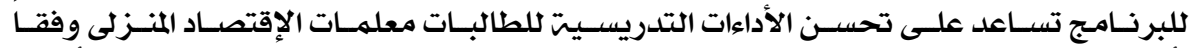

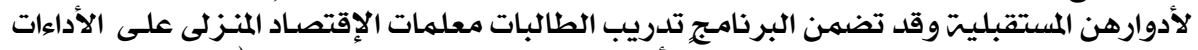

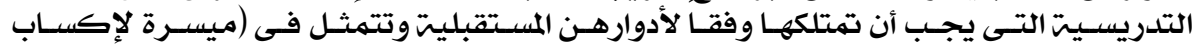




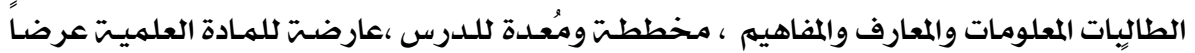

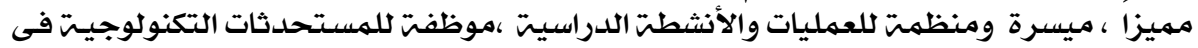

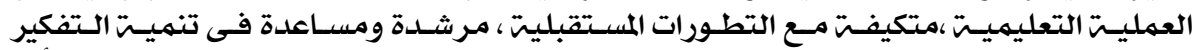

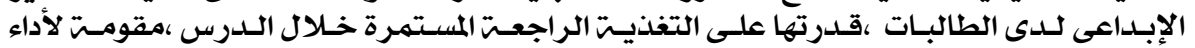

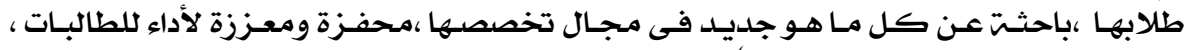

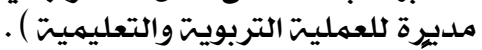
ثانيا: تحديد أهداف البرنامج :

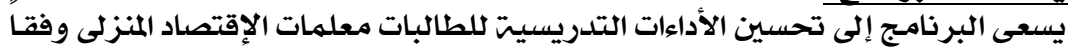

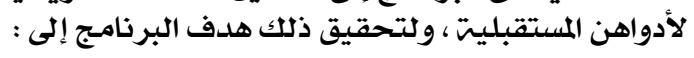

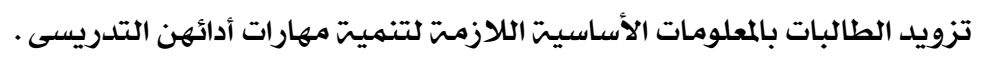

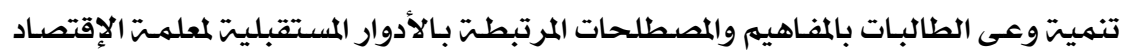

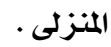

- إكساب الطالبات المعلمات بمهارات تدريسيت تثرى المواقف التعليميت.

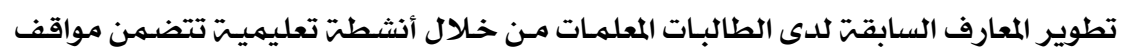

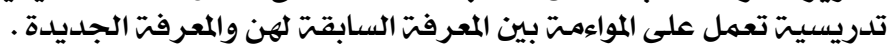

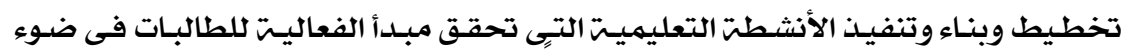

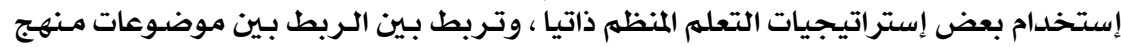

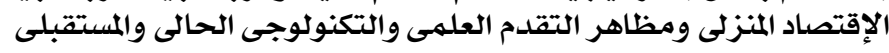

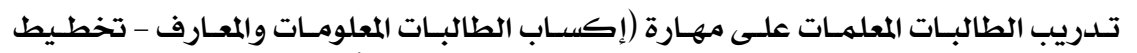

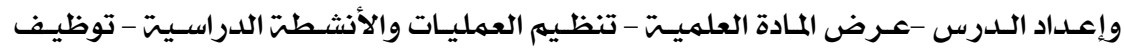

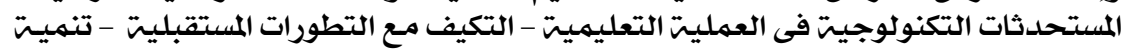

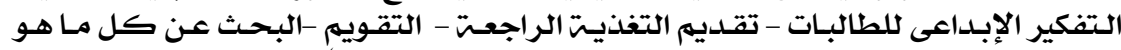

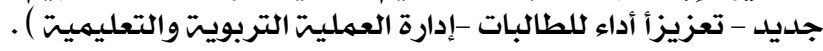

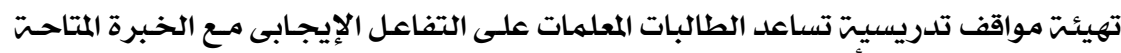

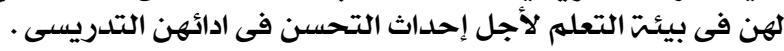

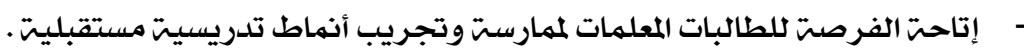

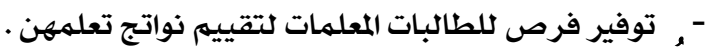

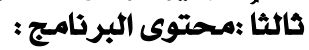

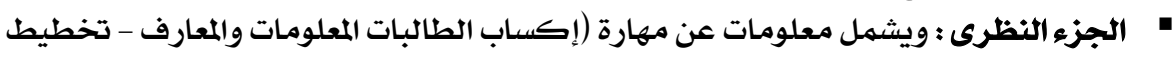

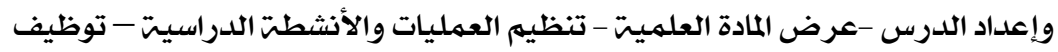

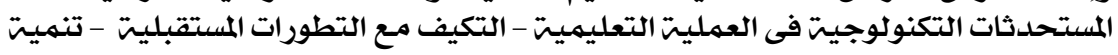

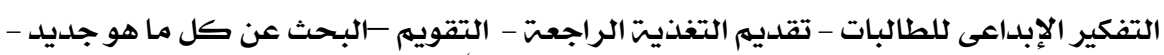

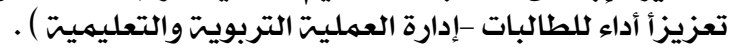

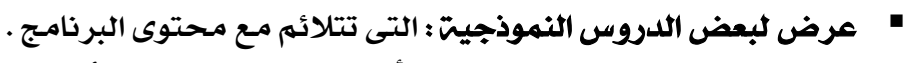

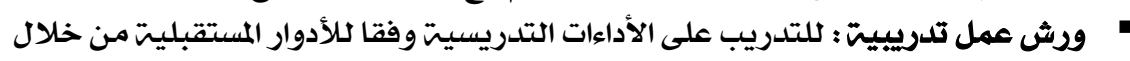
مجموعات العمل التعاونيتة. 
رابعاً :أستراتيجيات البرثامج : استخدم البحث إستراتيجيات التعله المنظم ذاتياً التاليت :

ا. تحديد الهدف: يشير تحديد الهدف إلي قدرة الطالب على وضع أهداف رئيسيتة وأهداف

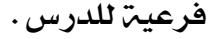

r.التخطيط :هو قدرة الطالبت المعلمت على تحلديد النقاط الرئيسيت والفرعيت للوصول لأهداف

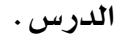

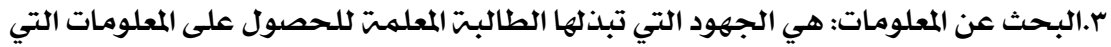

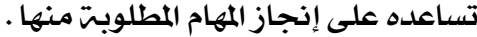

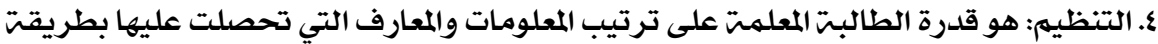
منطقيت متسلسلت .

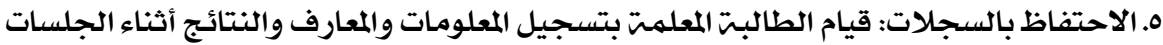

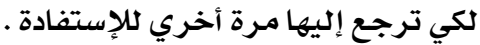

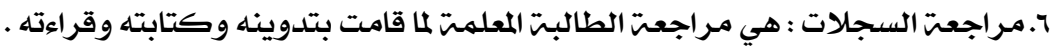

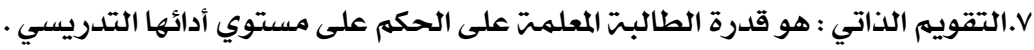

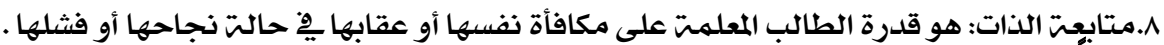

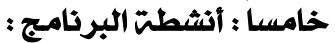
الانشطت الفرديت : المهام الفرديت - اوراق العمل - التقويهم الذاتى .

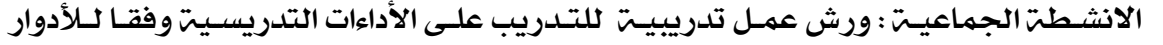

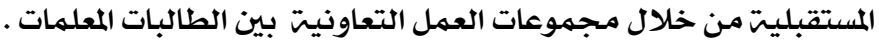

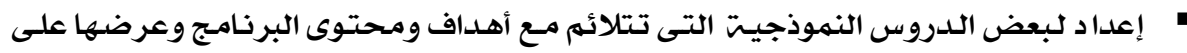

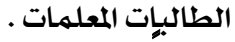

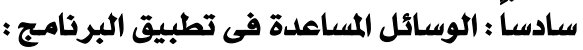

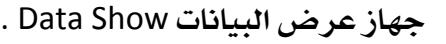

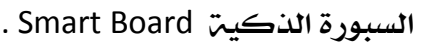

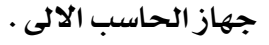

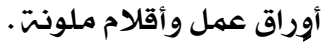

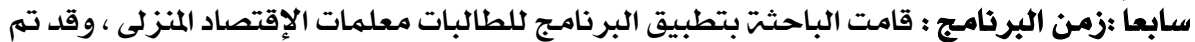

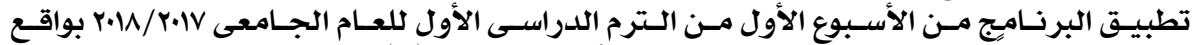

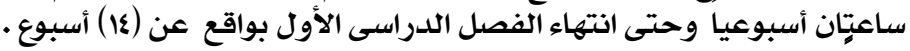

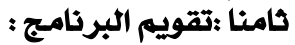

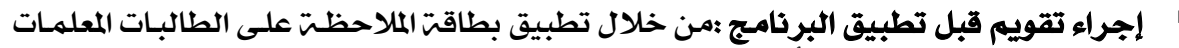

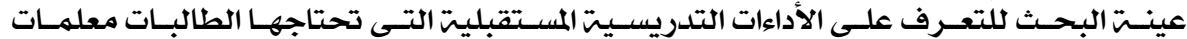

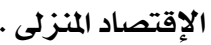

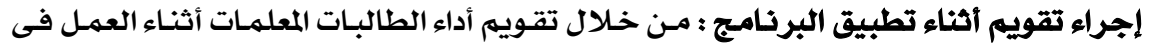

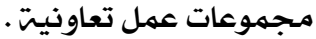
إجراء تقويه بعد تطبيق البرثامج : من خلالال تطبيق بطاقت الملاحظت على على الطالبـات المعلهـات

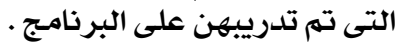

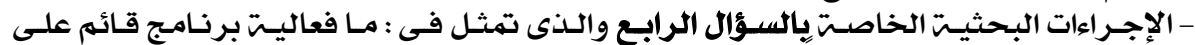

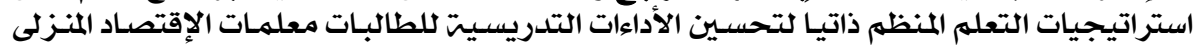


وفقاً أدواهن المستقبليت ؟ وللإجابت عن هذا السؤال تم إعداد بطاقت ملاحطت الأداعات التدريسيت

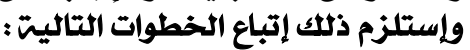

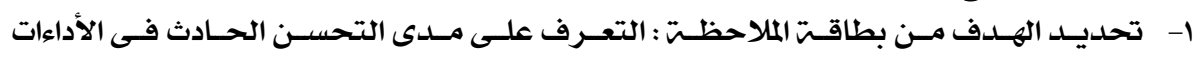

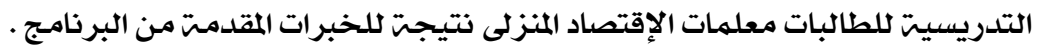

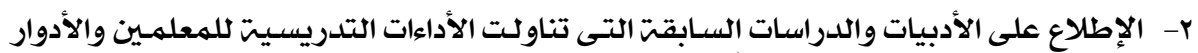

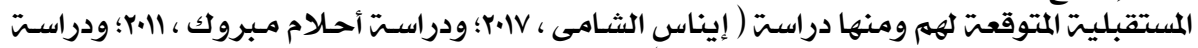

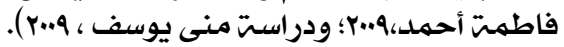

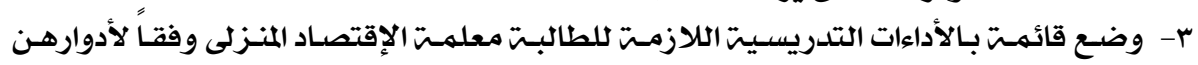

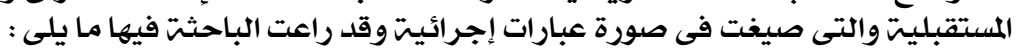

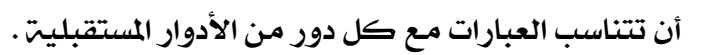

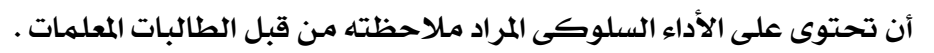

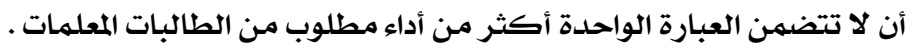

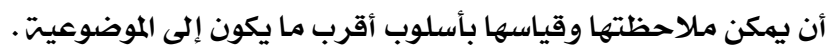

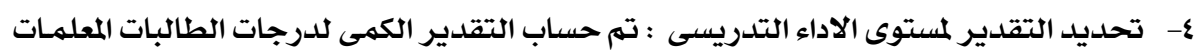

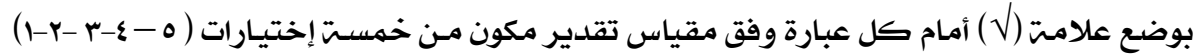

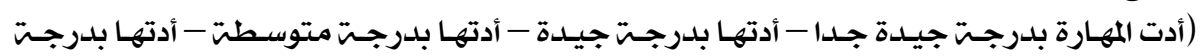

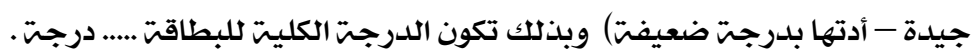

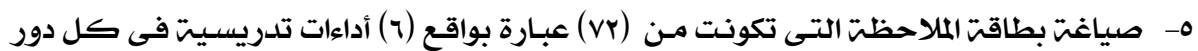

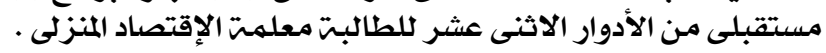

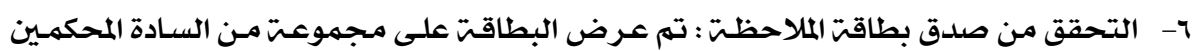

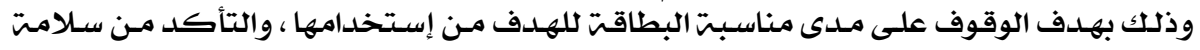

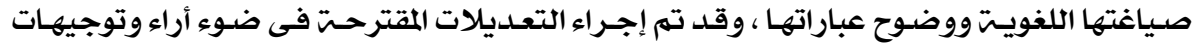

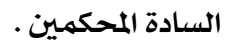
V- التحقق من ثبات بطاقت الملاحظتة : تم التحقق مـن ثبات بطاقت الملاحظت عن طريق اتفاق الملاحظين

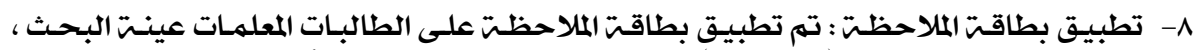

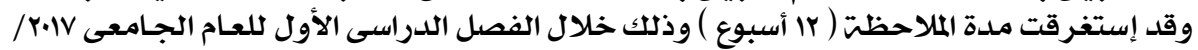
. r.11

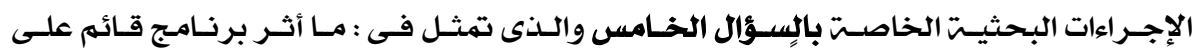

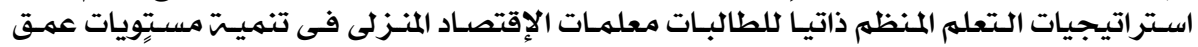

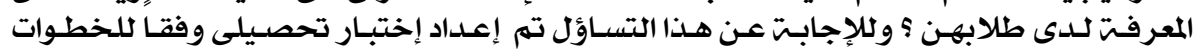

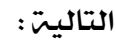

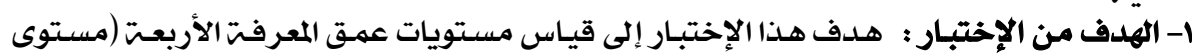

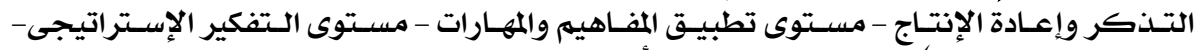

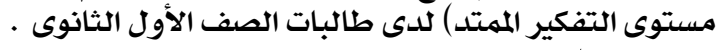

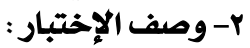

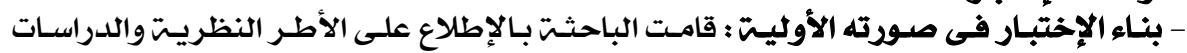

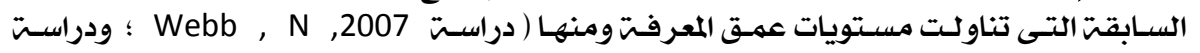




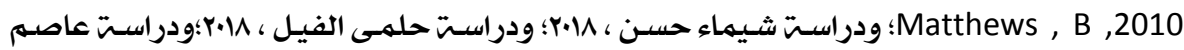

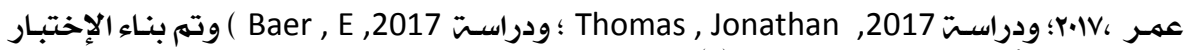

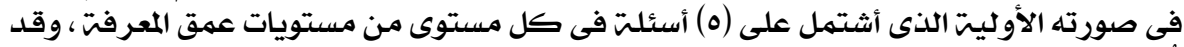

\% مناسبت الأسئلت لمستوى الطالبات .

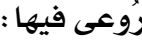

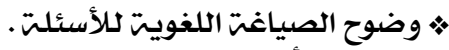

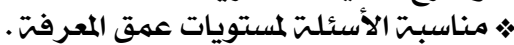

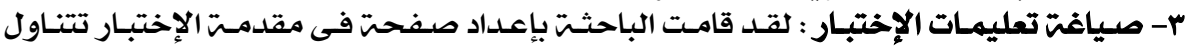

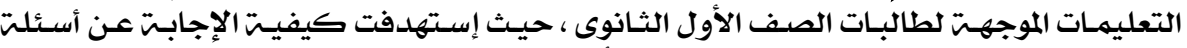

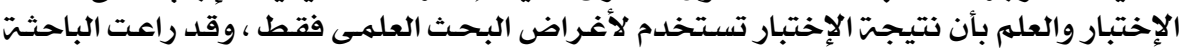

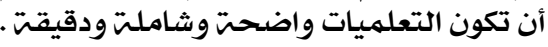

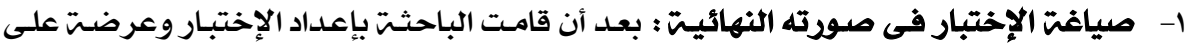

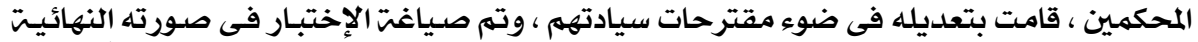

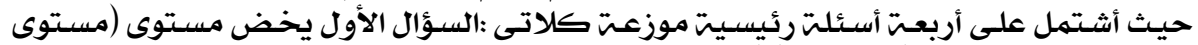

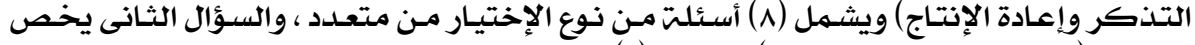

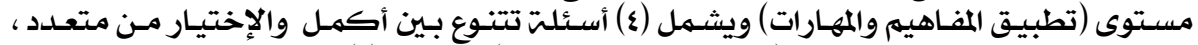

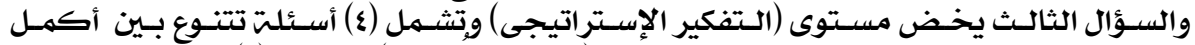

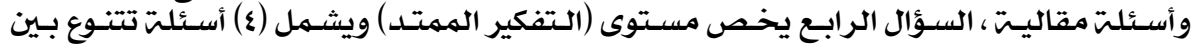

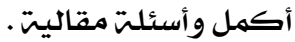

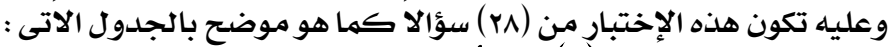

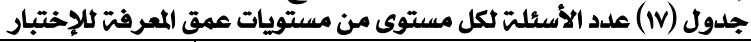

\begin{tabular}{|c|c|}
\hline علد المفردات & 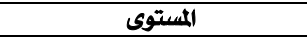 \\
\hline$\wedge$ & مستوى التذكر وإعادة الإنتاج \\
\hline$\varepsilon$ & مستوى تطبيق المفاهيم والمهارات \\
\hline$\varepsilon$ & مستوى التفكير الإستراتيجى \\
\hline$\varepsilon$ & مستوى التفكير الممتد \\
\hline
\end{tabular}

0- المعاملات العلميت لاختبار عمق المعرفت:

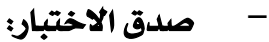

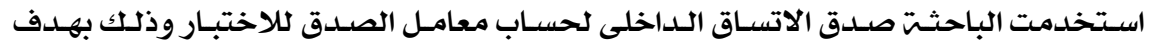

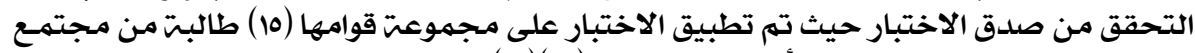

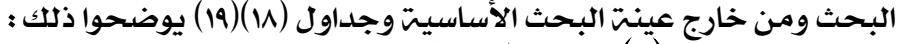

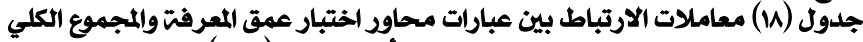

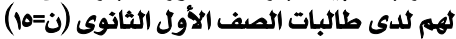

\begin{tabular}{|c|c|c|c|c|c|c|c|}
\hline \multicolumn{4}{|c|}{ المحور الثاني } & \multicolumn{4}{|c|}{ المحور الأول } \\
\hline المحسمستي ر & الأنعياري & المتوسطابي & $p$ & قلميمسورت & الأنحراف & المتوسابط & $p$ \\
\hline $.9 \varepsilon$ & .09 & .94 & 1 & $\cdot .19$ & $.7 \varepsilon$ & $\cdot . \wedge \mathrm{V}$ & 1 \\
\hline .90 & $.7 \varepsilon$ & $\because \wedge \mathrm{V}$ & $r$ & $.9 \mathrm{~V}$ & $\because V \varepsilon$ & $\cdot \wedge \mathrm{V}$ & $r$ \\
\hline .90 & .70 & $1 . \cdots$ & $r$ & .90 &.$\wedge r$ & $\cdot \wedge \mathrm{V}$ & $r$ \\
\hline .91 & $\because \wedge$. & .94 & $\varepsilon$ & r. & $\cdot \wedge \wedge$ & .94 & $\varepsilon$ \\
\hline & & & & $.9 \xi$ & $\because \mathrm{V} \cdot$ & .94 & 0 \\
\hline & & & &. .19 & .70 & 1... & 7 \\
\hline & & & & $.9 \mathrm{~V}$ & $\because \wedge^{*}$ & .94 & $\mathrm{v}$ \\
\hline & & & & .97 & .10 & $1 . \cdots$ & $\Lambda$ \\
\hline
\end{tabular}




\begin{tabular}{|c|c|c|c|c|c|c|c|}
\hline \multicolumn{4}{|c|}{ المحود الرابع } & \multicolumn{4}{|c|}{ المححور الثالث } \\
\hline المحسويت & الانحياري & الحسابي & $p$ & المحسونت & الالمعياري & المحسابي & م \\
\hline .99 & 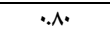 & $1 . . v$ & 1 & .94 & $\bullet \wedge \cdot$ &. $\mathrm{Vr}$ & $T$ \\
\hline .97 & $\cdot \wedge \bullet$ & .94 & $r$ & .97 & $\cdot \wedge r$ & $\because \wedge \mathrm{V}$ & $\begin{array}{rr} \\
\end{array}$ \\
\hline .94 &. $\mathrm{VV}$ & $\cdot \wedge$. & $r$ & $.9 \mathrm{~V}$ & .10 & $1 . . *$ & $r$ \\
\hline $.9 Y$ & $\cdot{ }^{\circ} \Lambda^{\circ}$ & I.YV & $\varepsilon$ & $.9 \xi$ & $\cdot . \wedge r$ & 1.15 & $\varepsilon$ \\
\hline
\end{tabular}

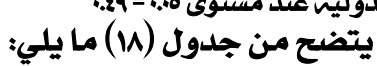

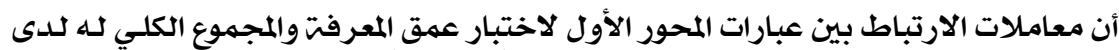

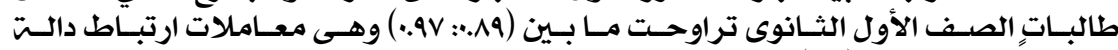

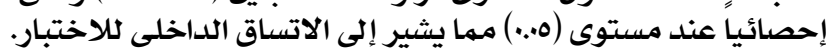

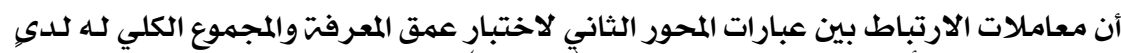

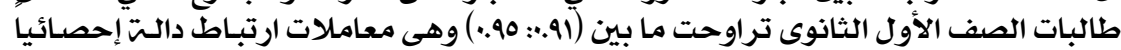

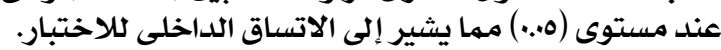

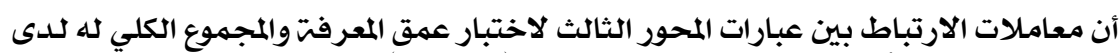

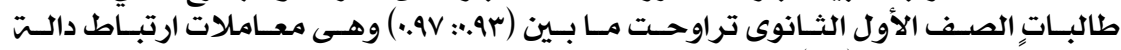

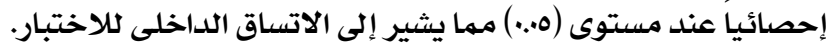

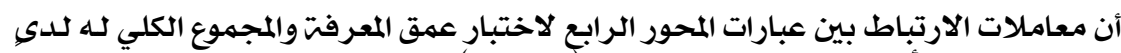

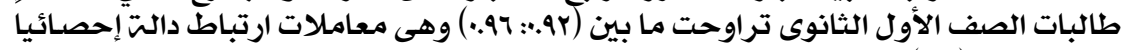

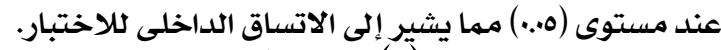

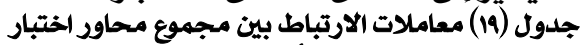

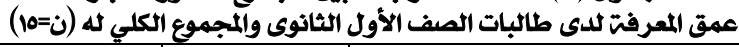

\begin{tabular}{|c|c|c|c|c|}
\hline قيمت ر المحسوبت & الالنحراف & المتوسطابي & المحاور & ค \\
\hline .91 & $0 . V \varepsilon$ & V.६. & مستوى التذكر و إعادة الإنتاج. & 1 \\
\hline .99 & Y.or & r.vr & مستوى تطبيق المفاهيم والمهارات. & $r$ \\
\hline .99 & $r .10$ & $r . v r$ & مستوى التفكير الاستراتيجي. & $r$ \\
\hline .99 & Y.१9 & $\varepsilon . \vee$ & مستوى التفكير الممتد. & $\varepsilon$ \\
\hline
\end{tabular}

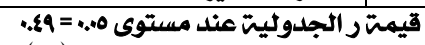

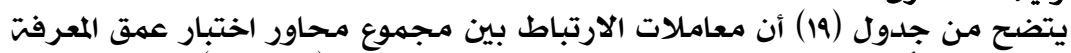

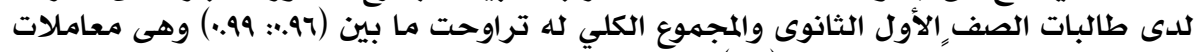

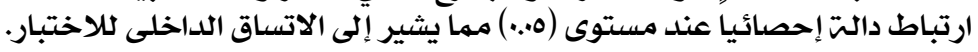

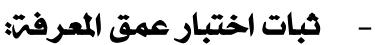

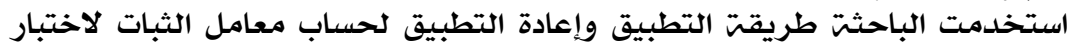

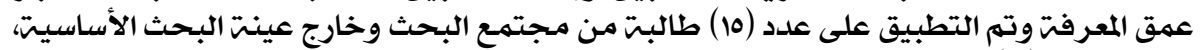

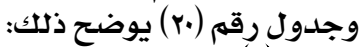

جدول (r.r) معامل الارتباط بين التطبيق وإعادة التطبيق لاختبار عمق المعرفت لدى طالبات الصف الأول الثانوى (ن= 10)

\begin{tabular}{|c|c|c|c|c|c|c|}
\hline \multirow[t]{2}{*}{ قيمترد } & \multicolumn{2}{|c|}{ التطبيق الثاني } & \multicolumn{2}{|c|}{ التطبيق الأول } & \multirow[t]{2}{*}{ المتغير } & \multirow[t]{2}{*}{ P } \\
\hline & $\varepsilon$ & $P$ & $\varepsilon$ & $p$ & & \\
\hline .97 & 8.79 & $7.7 \mathrm{~V}$ & $0 . v \varepsilon$ & V.乏. & مستوى التذكر وإعادة الإنتاج. & 1 \\
\hline .94 & 1.52 & $r . \cdot v$ & Y.OY & $r . v r$ & مستوى تطبيق المفاهيم والمهارات. & $r$ \\
\hline .97 & $1.9 Y$ & r.Ir & $r .10$ & $r . v r$ & مستوى التفكير الاستراتيجي. & $r$ \\
\hline $.9 \mathrm{~V}$ & $1 . \mathrm{VV}$ & r.or & r.99 & $\xi . \vee V$ & مستوى التفكير الممتد. . & $\varepsilon$ \\
\hline .911 & 9.01 & $17.2 \cdot$ & IE.Y乏 & 14.94 & الاختبار ككل & 0 \\
\hline
\end{tabular}




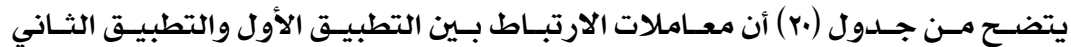

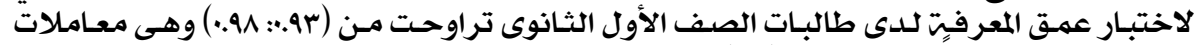

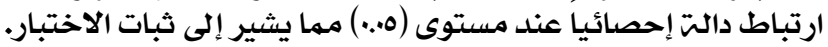

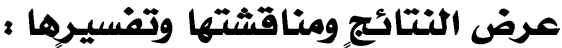

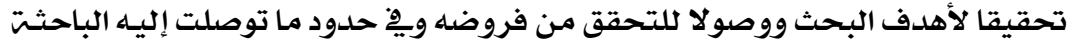

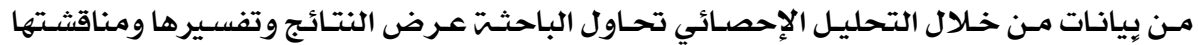
طبقا لفروض البحث التاليت:

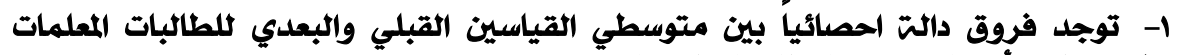

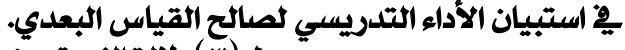

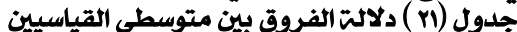

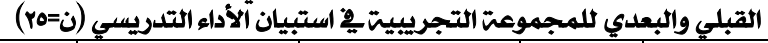

\begin{tabular}{|c|c|c|c|c|c|c|c|c|}
\hline \multirow{2}{*}{ "المحسويت "تيمت" } & \multirow{2}{*}{ معلتغل } & \multicolumn{2}{|c|}{ بعدي } & \multicolumn{2}{|c|}{ قبلي } & \multirow{2}{*}{ القياس } & \multirow[t]{2}{*}{ المتغير } & \multirow[t]{2}{*}{ r } \\
\hline & & $\varepsilon$ & م & $\varepsilon$ & م & & & \\
\hline IV.AN & 1Ar.07 & $r . v r$ & ro.0r & T.ro & $9 .$. & درجت & 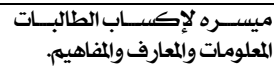 & $T$ \\
\hline r.VO & ITr.II & Y.TI & 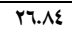 & $r . .$. & $1 . Y \varepsilon$ & درجت & مخططت ومعدة للدرس. & $r$ \\
\hline rт.99 & 170.11 & Y.VA & M.T. & r.IV & 9.11 & درجت & 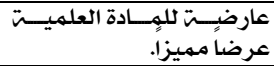 & $r$ \\
\hline YO.YT & IEY.YT & 1.99 & Yo.Th & r.9. & $1 . \%$ & درجت & 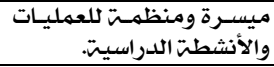 & $\varepsilon$ \\
\hline Yr.\$O & 107.YY & T.T & ro.0Y & r.90 & 9.97 & درجت | درجت & 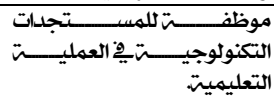 & 0 \\
\hline $1\{.10$ & $|\xi 1 . \xi|$ & $r .1 \%$ & Y\&.VY & r.or & $1 . Y \varepsilon$ & درجت & 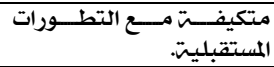 & 7 \\
\hline "قلحيمت"ت" & التغير & $\varepsilon$ & بص & $\varepsilon$ & م & القياس & | المتغير & r \\
\hline $17 . Y 1$ & Irr.v7 & $r .99$ & YO.YE & E.YY & $\frac{1}{11 . Y \Lambda}$ & درجت & 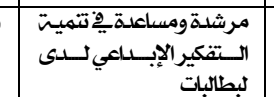 & $\mathrm{v}$ \\
\hline $17 . r \varepsilon$ & 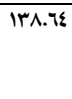 & $r .70$ & ro.r. & r.YA & 1.07 & درجت & 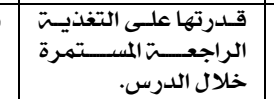 & $\Lambda$ \\
\hline 18.59 & 10..Y. & 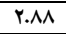 & ro.1r & $r . \$ 9$ & $1 . . \%$ & درجت & مقومت لأداء تلاميذها. & 9 \\
\hline $\mid \varepsilon . \Gamma \varepsilon$ & IEY.Y. & 7.11 & TV.rY & $\xi .1$ & II.YN & درجت & بِّف مجال عن تخصل جدها. & 1. \\
\hline 10.rr & IYV.YV & r.VI & rצ... & r.\&v & $11 . £ \varepsilon$ & درجت | درجن & الطـالبـاته ومفـرزه لأداء & 11 \\
\hline $19.9 \mathrm{~V}$ & 101.17 & $r \cdot \wedge$ & ro.9r & T.AV & T.r.r & درجت & التربويتير والتعليميتيتة. & $\pi$ \\
\hline Vr.IV & 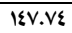 & $1 . Y \Lambda$ & 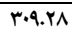 & 1.94 & $\mid r \xi . \wedge \varepsilon$ & درجت & الاستبيان ككل & $\overline{15}$ \\
\hline
\end{tabular}

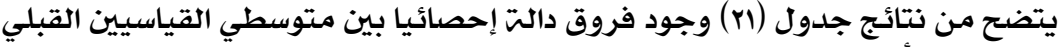

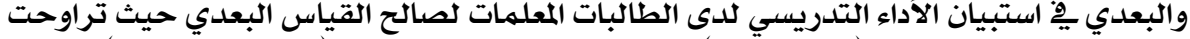

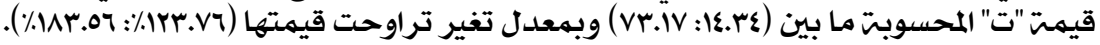




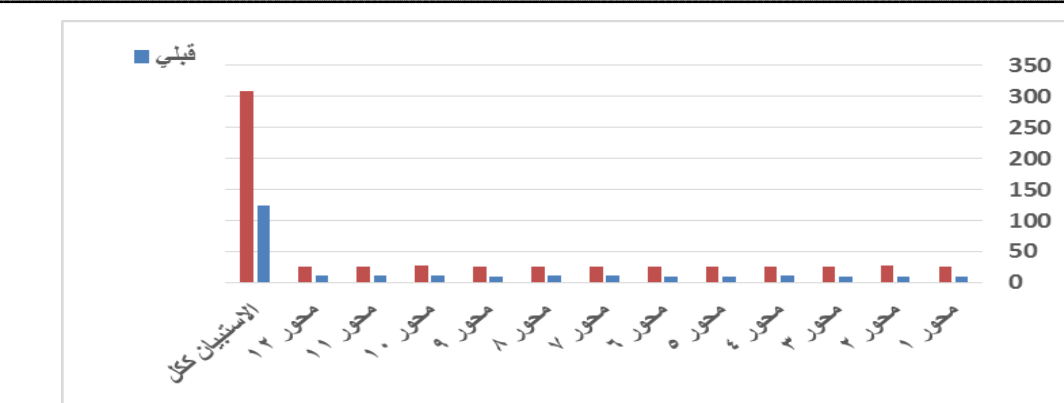

شكل (r) دلالت الفروق بين القياسين القبلي والبعدي يُ الأداء التدريسي للطالبات المعلمات

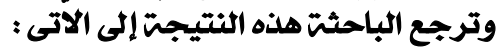

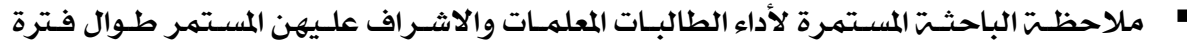

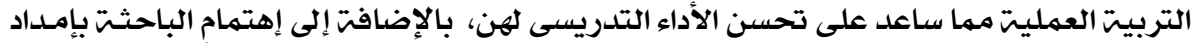

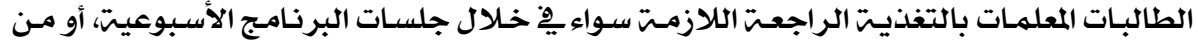

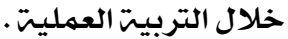

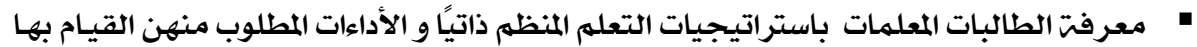

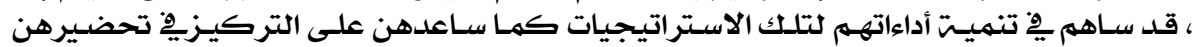

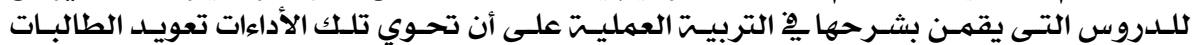

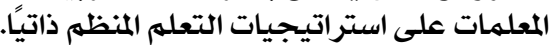

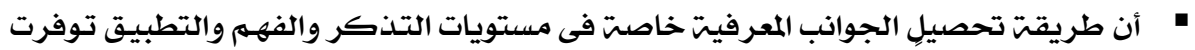

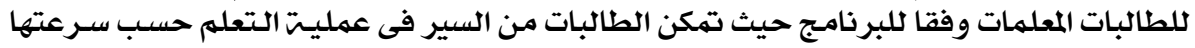
الذاتيت

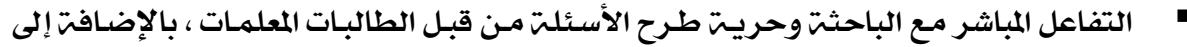

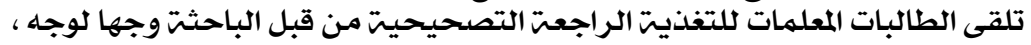

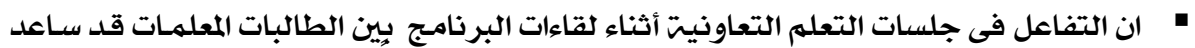

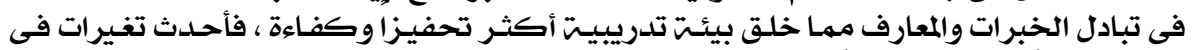

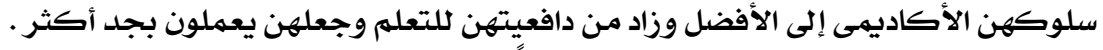

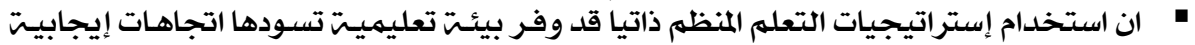

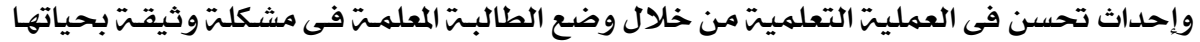

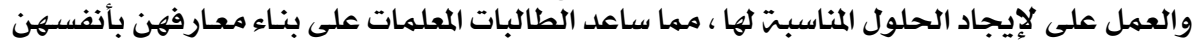

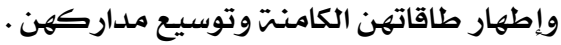

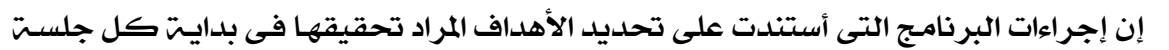

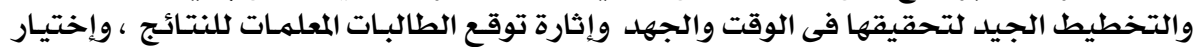

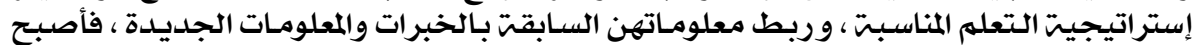

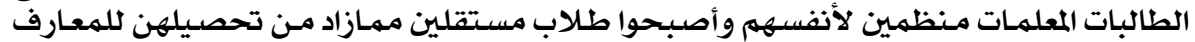

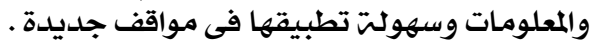

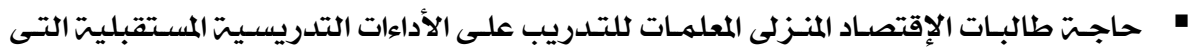

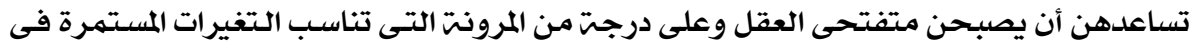

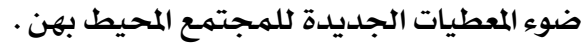




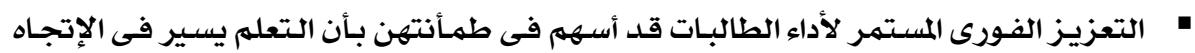

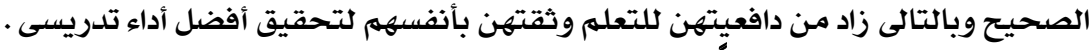

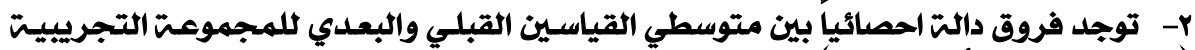

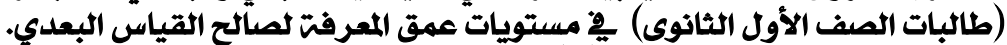

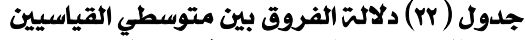

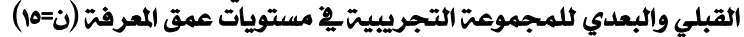

\begin{tabular}{|c|c|c|c|c|c|c|c|}
\hline \multirow{2}{*}{ قاحيمست "ت" } & \multirow{2}{*}{ معلتل } & \multicolumn{2}{|c|}{ بعلي } & \multicolumn{2}{|c|}{ قبلي } & \multirow{2}{*}{ القياس } & \multirow[t]{2}{*}{ المتغير } \\
\hline & & $\varepsilon$ & $p$ & $\varepsilon$ & P & & \\
\hline rr.v. & 794.9 & $1 .\{\mathrm{V}$ & 1E.^. & 1.7. & $1 . \wedge \mathrm{V}$ & درجت & مستوى التتذكر وإعادة \\
\hline $11 .+7$ & ros.o & $1.7 \%$ & $7.7 \mathrm{~V}$ & 1.81 & $1 . \S \mathrm{V}$ & درجت & مستوى تطبيق المفاهيي \\
\hline IE.rA & orr.r & • & V.T. & $1 . £ V$ & 1.r. & درجت & مستوى التفكير \\
\hline 17.rr & OAV.O & .911 & V.rr & $1 . Y \wedge$ & $1 . \cdot V$ & درجت & مستوى التفكير الممتد. \\
\hline$\varepsilon 1 .+Y$ & $00 .$. & Y.\&1 & ra.se & $r . r$ & 0.7 . & درجت & الاختبار ككل \\
\hline
\end{tabular}

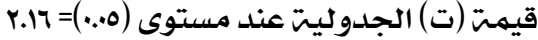

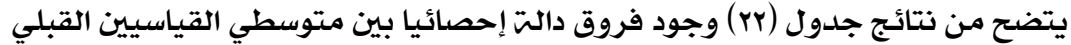

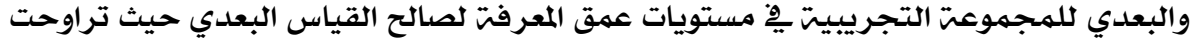

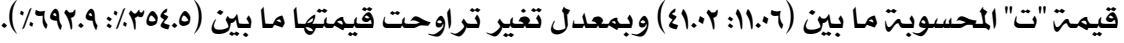

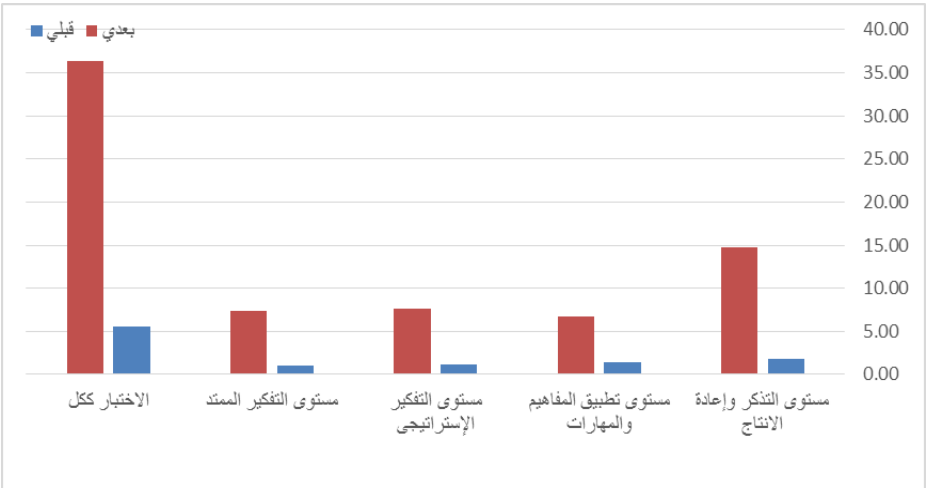

ثكل (ع) الفروق بين متوسطي درجات القبلي والبعدي للمجموعت التجريبيت

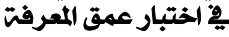

$$
\text { وترجع الباحثت هذه النتيجتَ إلى الآتى : }
$$

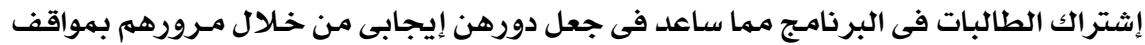

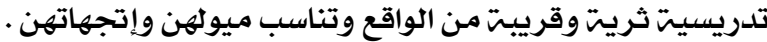

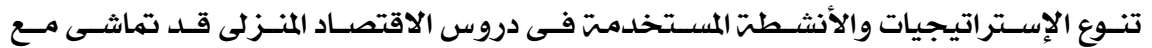

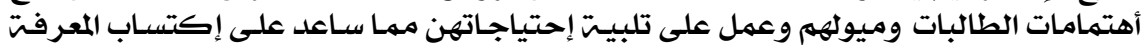

تتظيهم بيئت التعله وإختيار الحلول المناسبت وردئ والتخطيط والتذكر وهذه مهارات تعله ذاتياً.

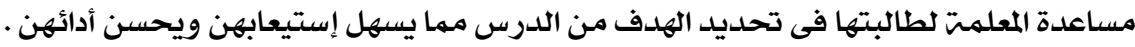

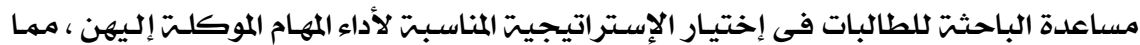

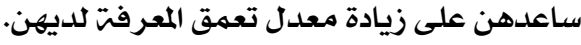




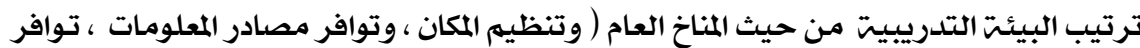

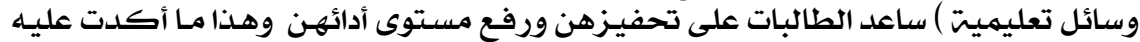

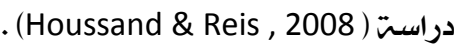

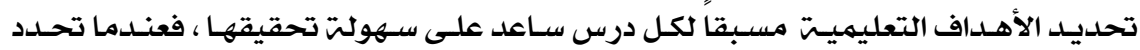

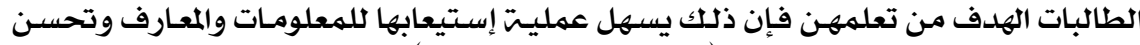

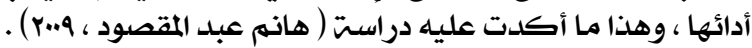

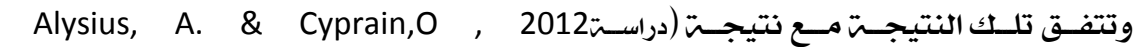

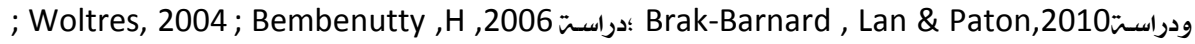

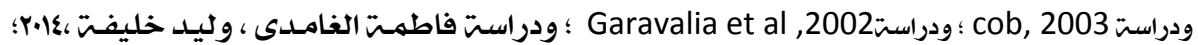

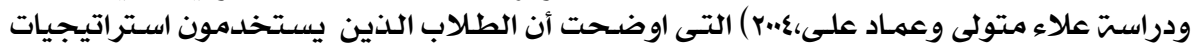

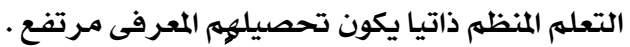

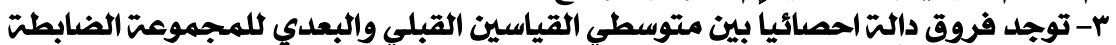

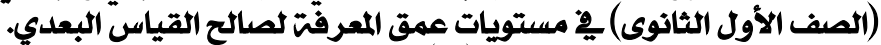

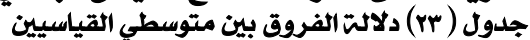

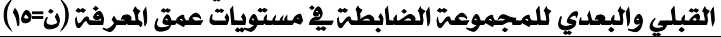

\begin{tabular}{|c|c|c|c|c|c|c|c|}
\hline \multirow{2}{*}{ قاحيمست "ت" } & \multirow{2}{*}{ معدل } & \multicolumn{2}{|c|}{ بعلي } & \multicolumn{2}{|c|}{ قبلي } & \multirow{2}{*}{ وحلدة القياس } & \multirow[t]{2}{*}{ المستويات } \\
\hline & & $\varepsilon$ & $P$ & $\varepsilon$ & P & & \\
\hline IT.YY & $\{0 . . \cdots$ & r.IY & $11 . \mathrm{Vr}$ & 1.7. & r.Ir & درجت & مستوى التتذكر وإعادة \\
\hline V.r. & Y0\%.00 & $1.2 \mathrm{~V}$ & $0 . Y$. & 1.81 & $1 . \S V$ & درجت & مستوى تطبيق الماهاهيم \\
\hline 0.7. & Y^V.O. & $Y . \bullet V$ & $\$ .1 \%$ & I.YA & $1 . \cdot V$ & درجتة & مستوى التفكير \\
\hline 7.29 & rr..." & 1.50 & ६.ร. & 1.20 & r.r. & درجت & مستوى التفكير الممتلد. \\
\hline M.rV & rY乏.క纟 & r.\&Y & YO.\&V & r.Vr & $7 . .+$ & درجت & الاختبار ككل \\
\hline
\end{tabular}

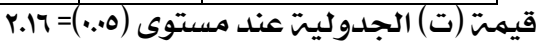

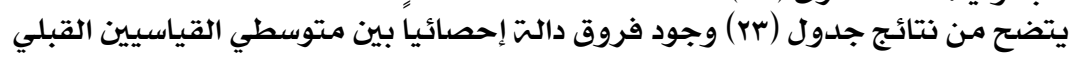

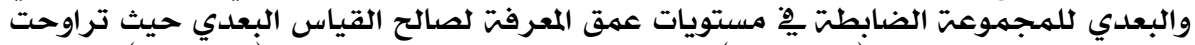

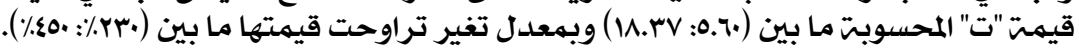

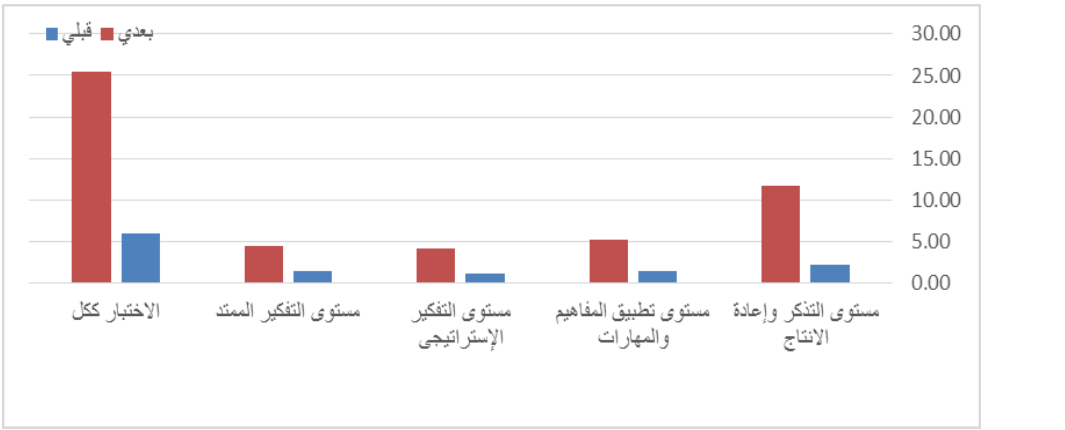

ثكل (ه) الفروق بين متوسطي درجات القبلي والبعدي للمجموعت الضابطت

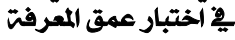




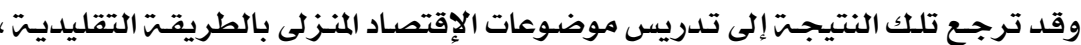

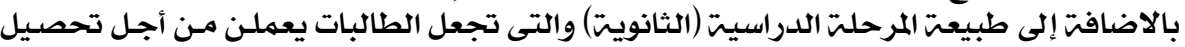

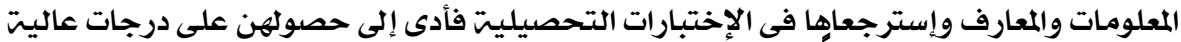

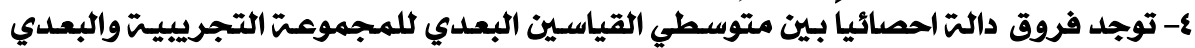

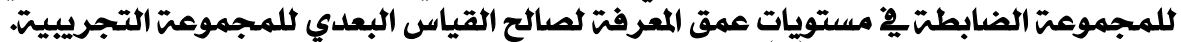

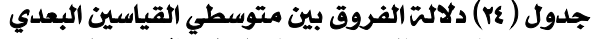

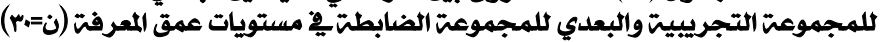

\begin{tabular}{|c|c|c|c|c|c|c|}
\hline \multirow{2}{*}{ قالمحسموبت" } & \multicolumn{2}{|c|}{ بعدي ضابطتة } & \multicolumn{2}{|c|}{ بعلدي تجريبيت } & \multirow{2}{*}{ القياس } & \multirow[t]{2}{*}{ المستويات } \\
\hline & $\varepsilon$ & م & $\varepsilon$ & $p$ & & \\
\hline$\varepsilon . \pi$ & r.IY & $11 . V \Gamma$ & $1.2 \mathrm{~V}$ & $1 \xi . \wedge \cdot$ & درجتة & مستوى التذكر وإعادة الإنتاج. \\
\hline r.01 & $1.2 \mathrm{~V}$ & O.r. & $1.7 \mathrm{r}$ & $7 . \mathrm{TV}$ & درجت & مستوي تطبيق المفاهيم والمهارات. \\
\hline 7. & r..V & \&..1\% & $\cdot \wedge r$ & v.. & درجت & مستوى التفكير الاستراتيجي. \\
\hline 7.11 & $1 . r 0$ & ६.६. & .91 & V.rr & درجت & مستوى التفكير الممتد. \\
\hline $1.1 \%$ & $r . \leqslant Y$ & ro.\&v & $\overline{r . \$ 1}$ & rד.s. & درجت & الاختبار ككل \\
\hline
\end{tabular}

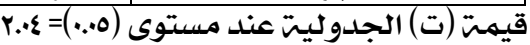

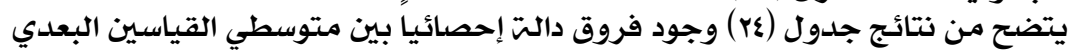

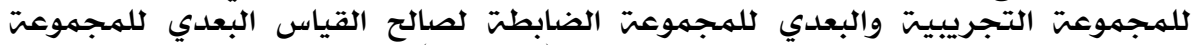

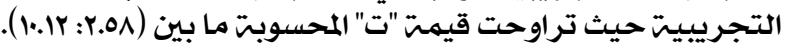

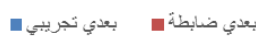

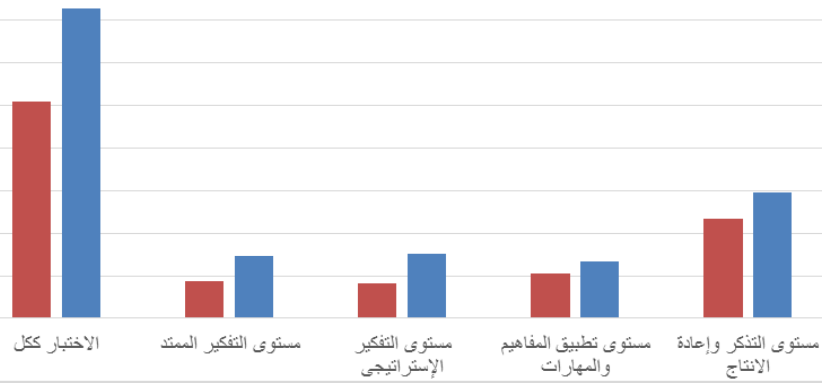

هكل (7) الفروق بين متوسطي درجات البعدي للمجموعت التجريبيت والبعدي للمجمومت الضابطتّيُ اختبار عمق المعرفت

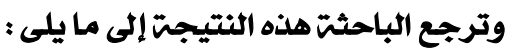

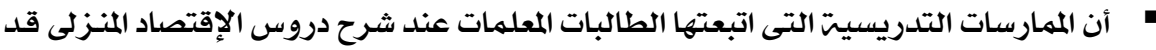

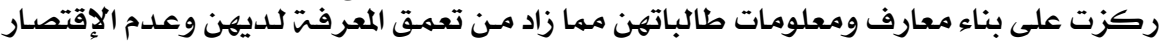

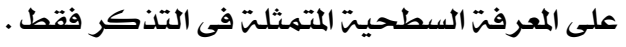

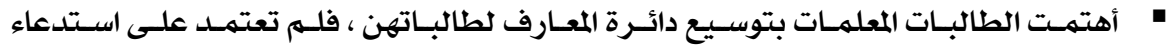

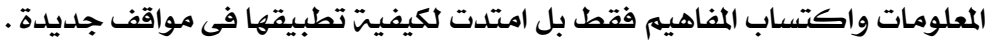

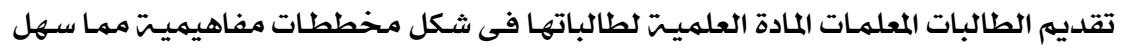

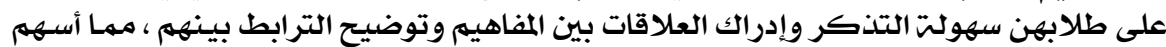

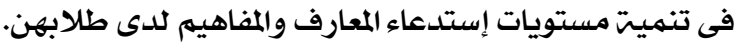

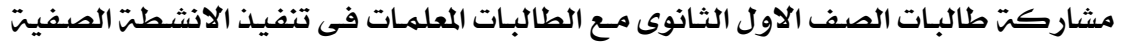

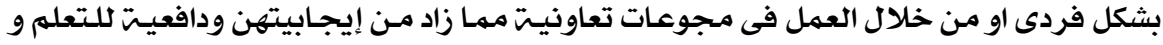

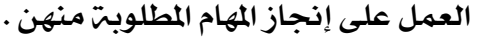

$$
r \cdot \Lambda
$$


مشاركت طالبات الصف الاول الثانوى مـع الطالبات المعلمات على التفكير بشكل إسـتراتيجي

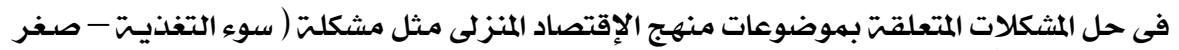

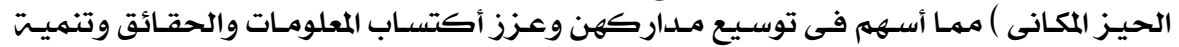

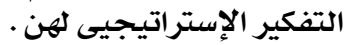

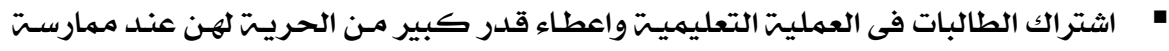

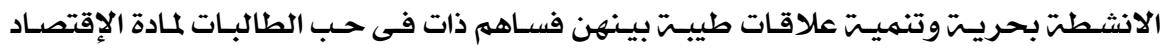

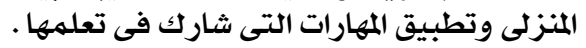

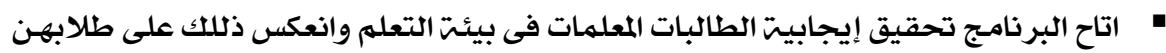

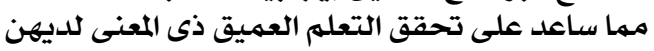

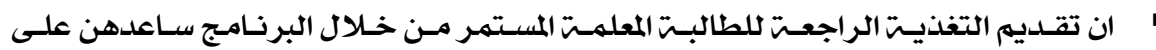

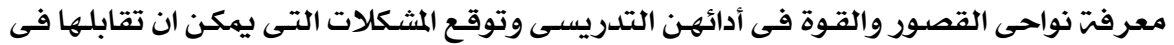

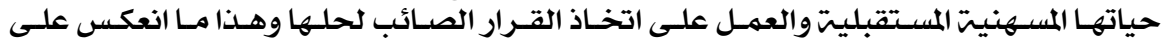

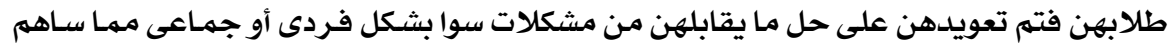

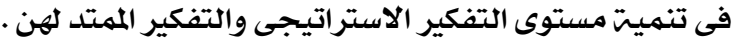

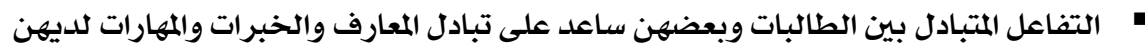

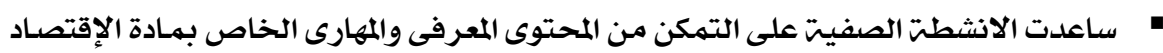

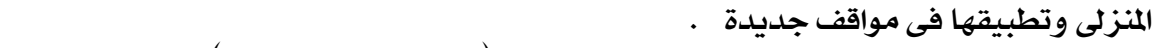

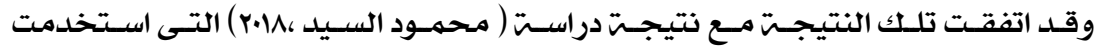

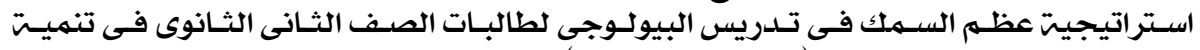

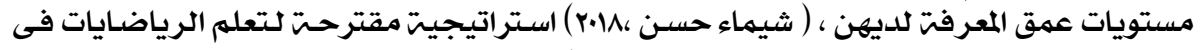

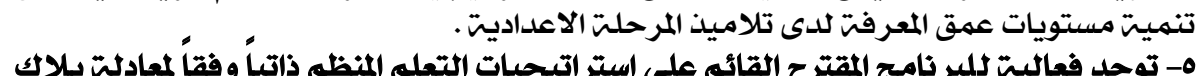

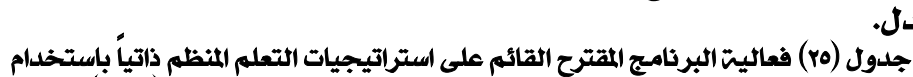
للكسب المعدل.

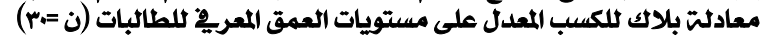

\begin{tabular}{|c|c|c|c|c|c|}
\hline الكسبة & الفعاليتة & القياس البعلدي & القتياسبط القبلي & المستويات & p \\
\hline $10 . \cdot V$ & 1E.Vo & $1 \xi . \wedge \cdot$ & $1 . \wedge \mathrm{V}$ & مستوى التذكر وإعادة الإنتاج. & 1 \\
\hline 7.17 & 7.74 & $7.7 \mathrm{~V}$ & $1 . £ \mathrm{~V}$ & مستوى تطبيق المفاهيم والمهارات. & $r$ \\
\hline V.Vr & V.OV & V.T. & 1.Y. & مستوى التفكير الاستراتيجي. & $r$ \\
\hline V.รT & V.rI & V.rr & $1 .+V$ & مستوى التفكير الممتلد. & $\varepsilon$ \\
\hline$r y .+1$ & M.Yร & ra.s. & 0.7 . & الاختبار ككل & 0 \\
\hline
\end{tabular}

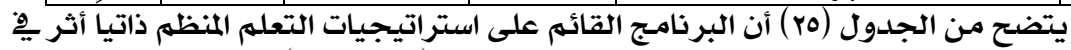

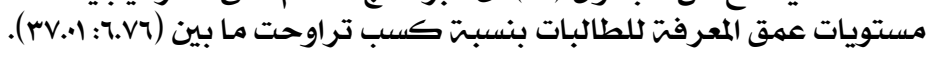

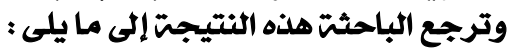

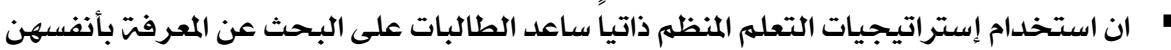

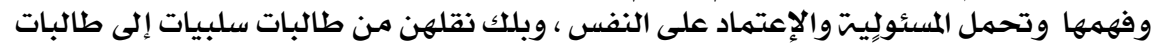

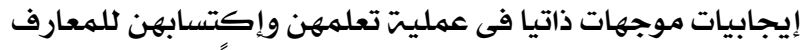

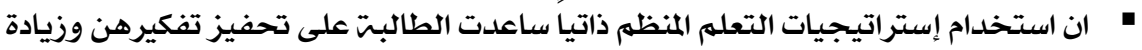

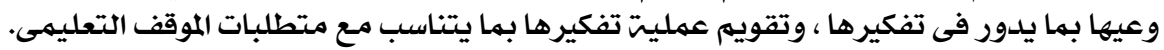




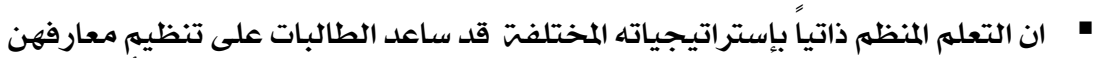

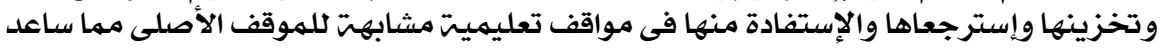

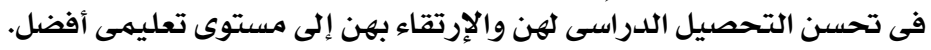

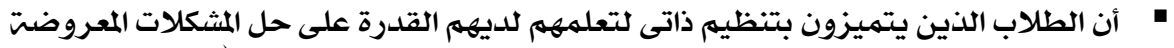

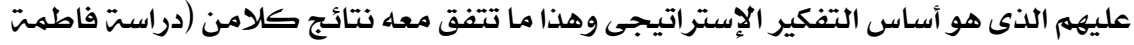

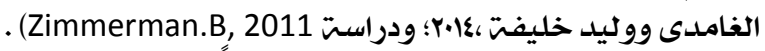

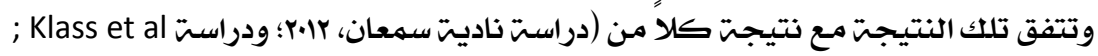

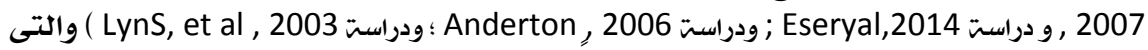

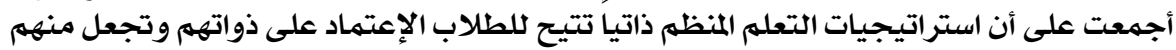

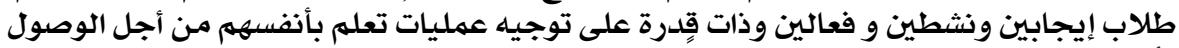

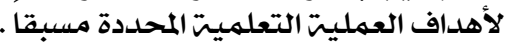

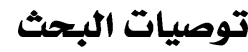

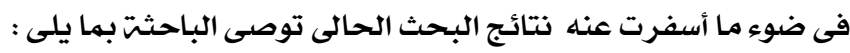

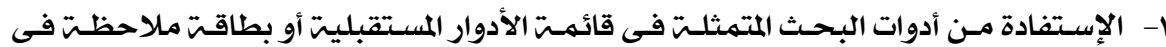

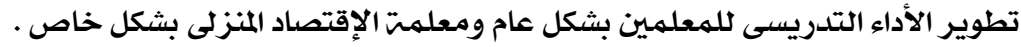

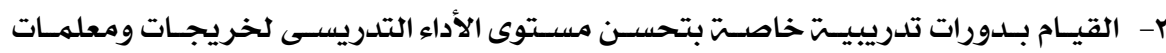

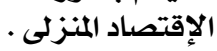

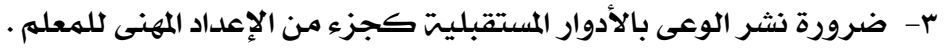

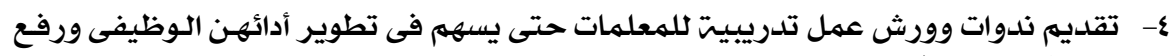
حصيلتهن المعرفيتة.

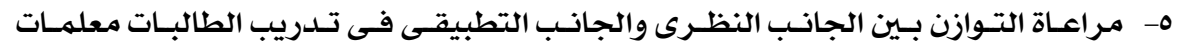

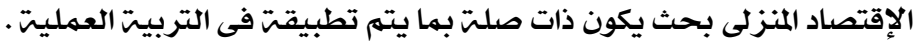

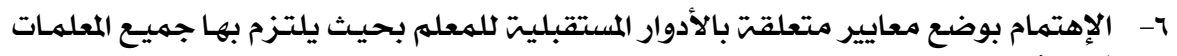
في مختلف المراحل التعليميتة.

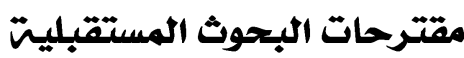

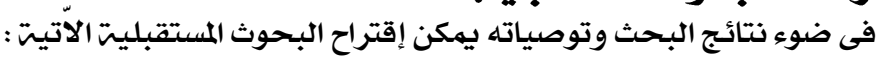

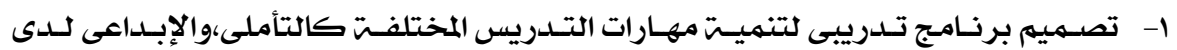

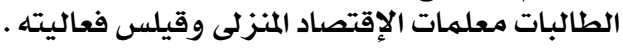

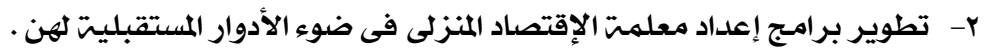

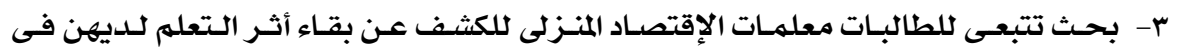
التربيت العمليتة.

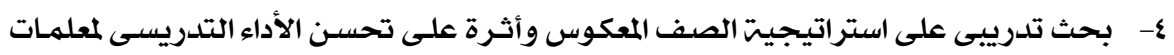

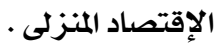

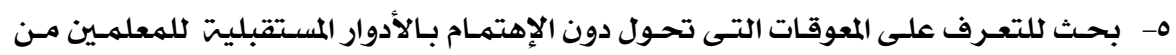
وجهت نظر السادة المختصين. 


\section{المراجع}

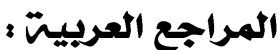

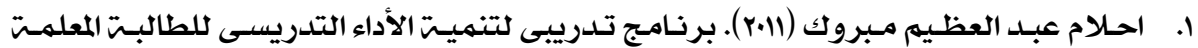

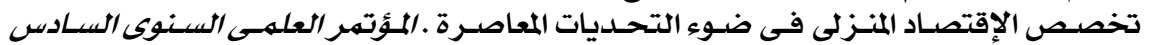

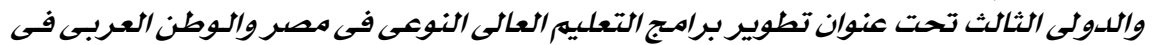

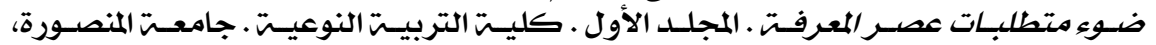
$.1 \% 0-91$

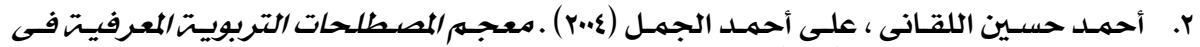

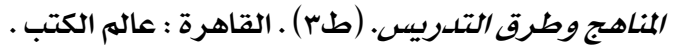

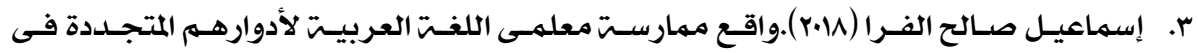

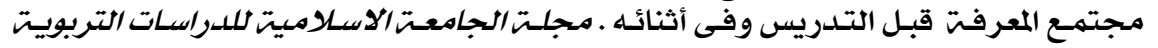

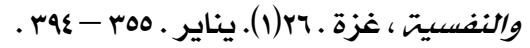

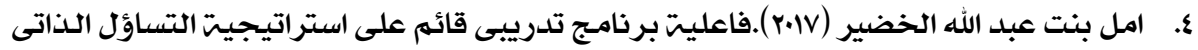

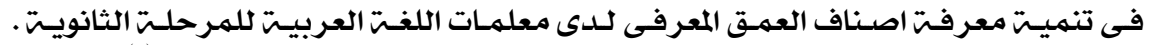

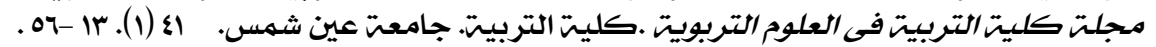

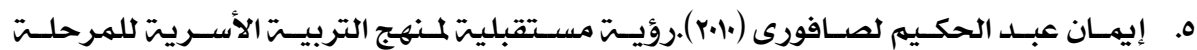

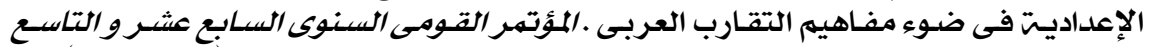

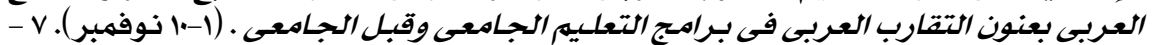

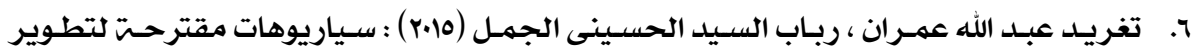

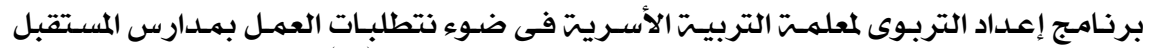

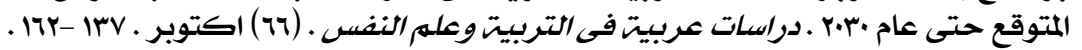

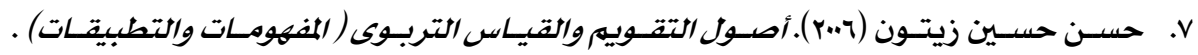
الرياض : الدار الصوتيت للتربيت.

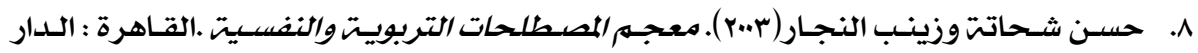
المصريت اللبنانيت.

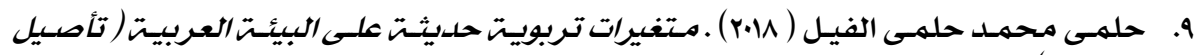
وتوطين) ـ القاهرة : دار الطباعت الحرة .

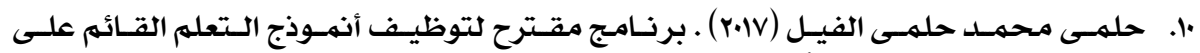

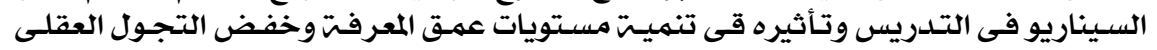

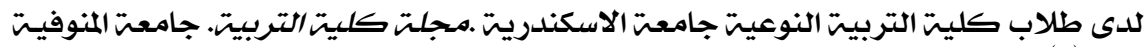

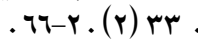

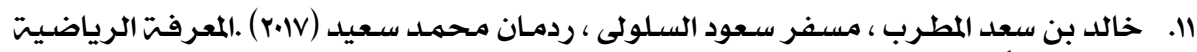

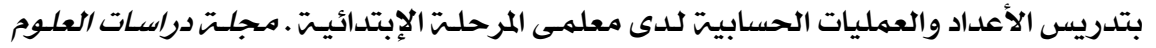

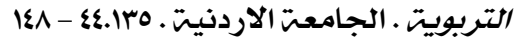




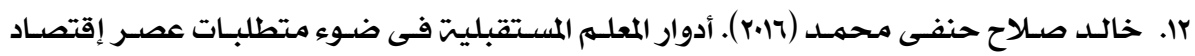

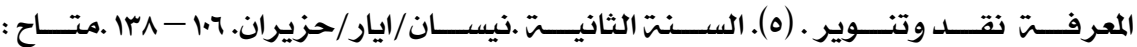
http://tanwair.com/wp-content/uploads/2016/03/105-138.pdf

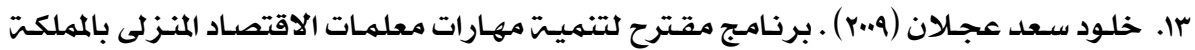

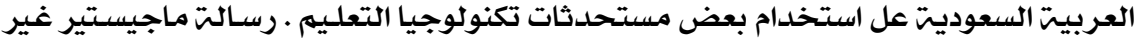

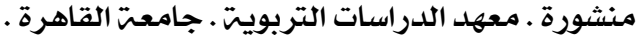

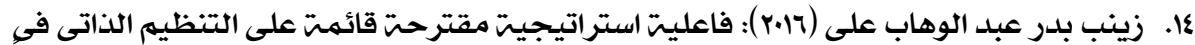

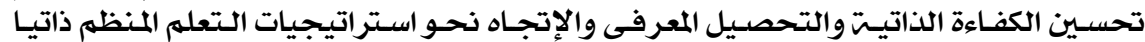

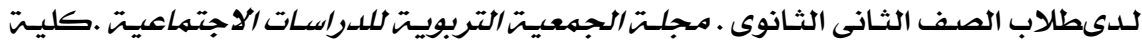

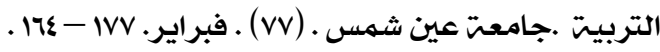

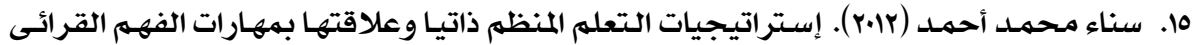

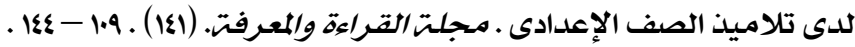

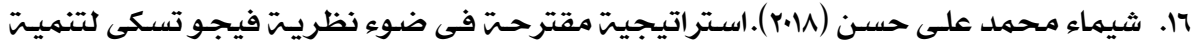

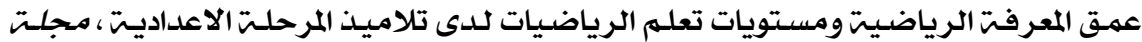

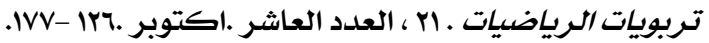

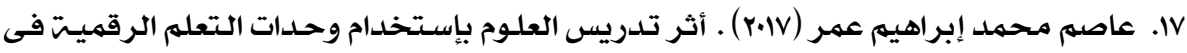

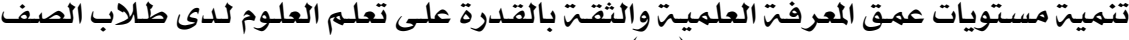

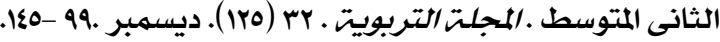

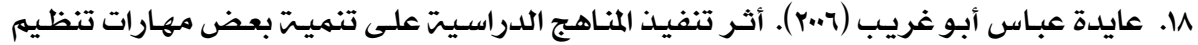

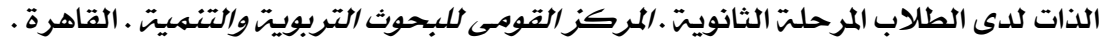

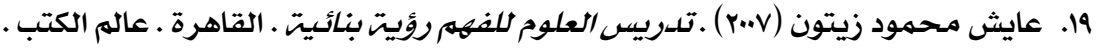

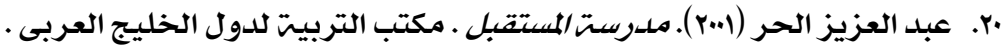

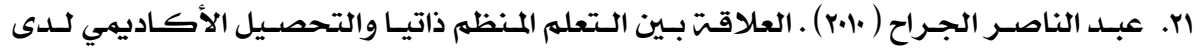

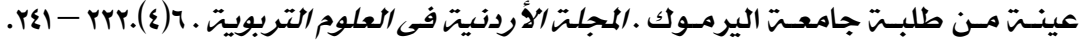

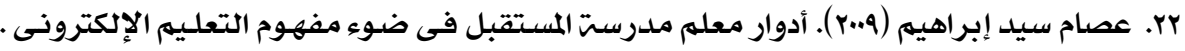

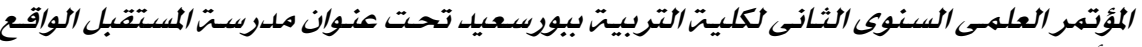

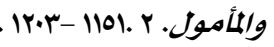

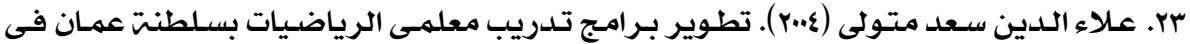

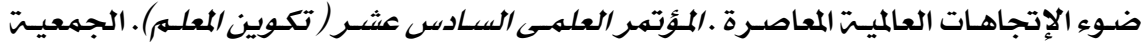

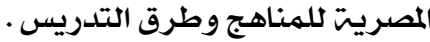

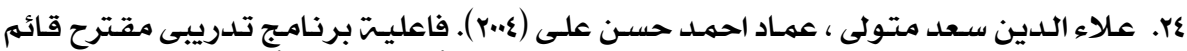

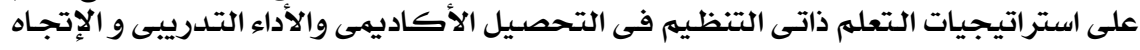

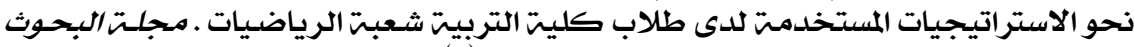

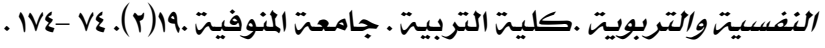

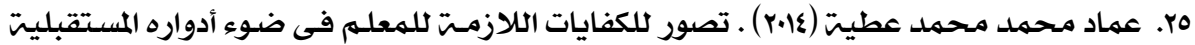

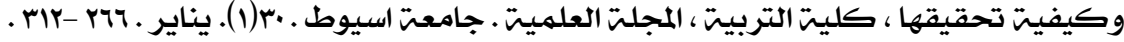




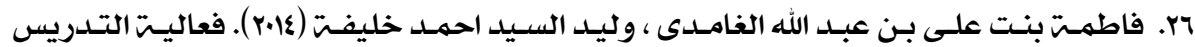

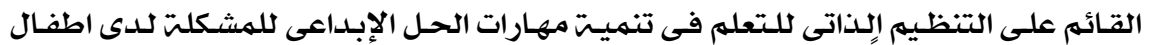

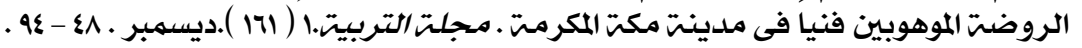

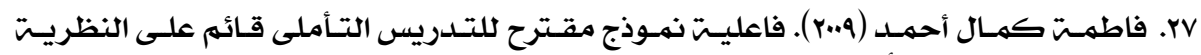

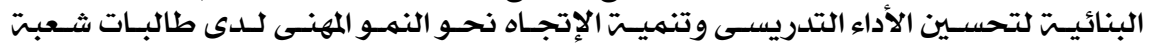

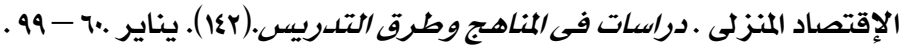

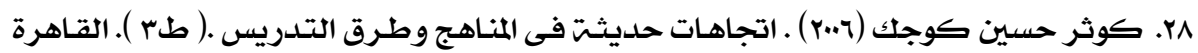

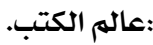

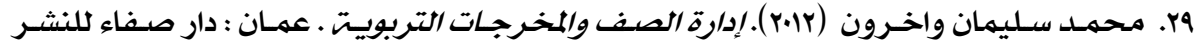

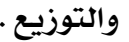

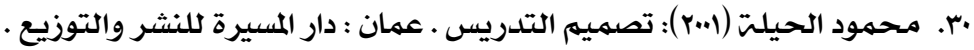

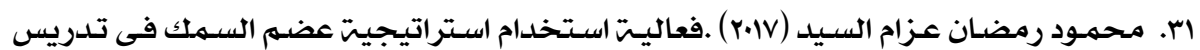

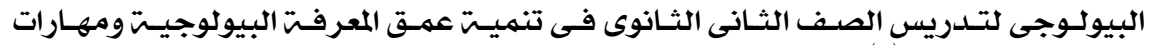

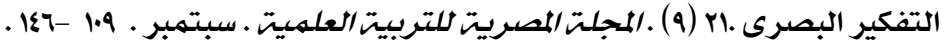

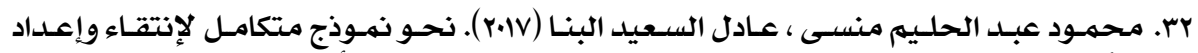

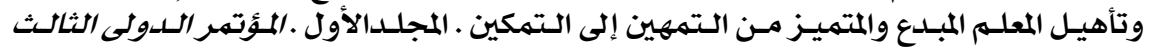

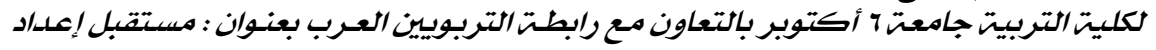

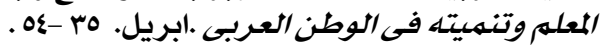

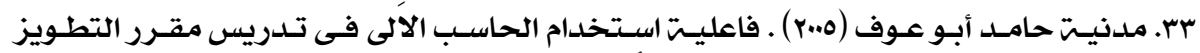

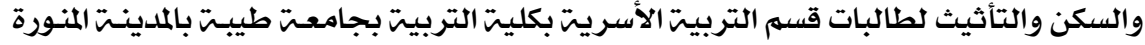

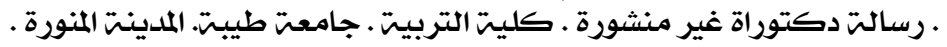

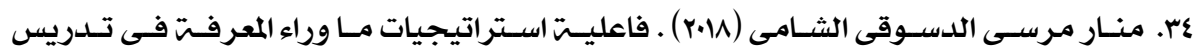

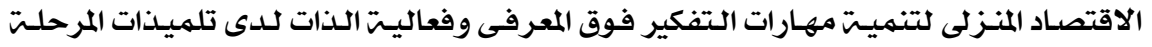

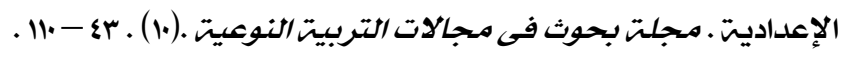

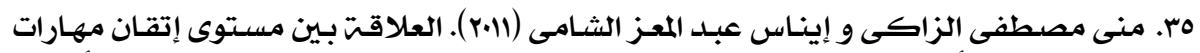

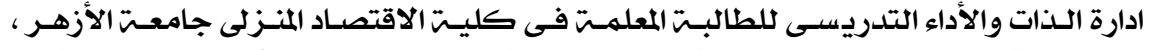

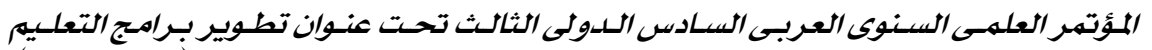

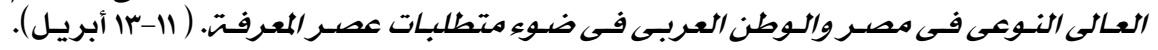

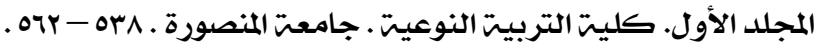

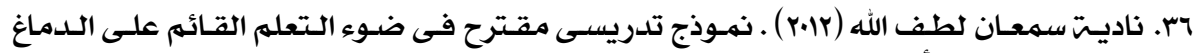

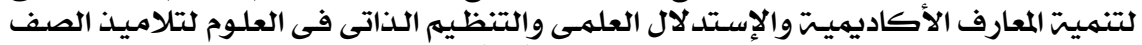

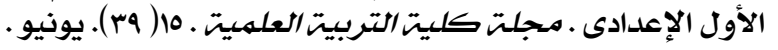

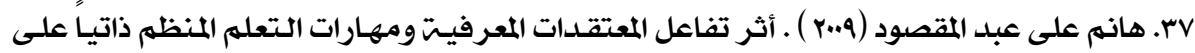

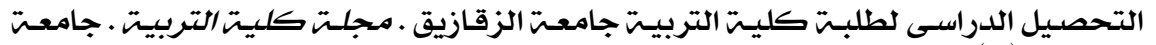

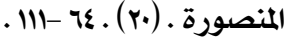

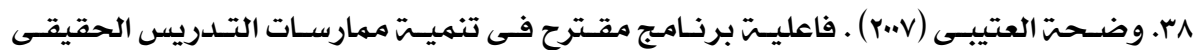

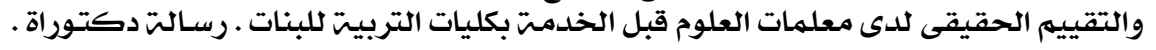
جامعت الاميرة نورة. 


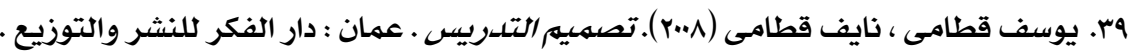

40. Alysius, A. \& Cyprain, O. (2012) . Effects of self-instructional learning strategy on secondary schools students academic achievement in solving mathematical word problem in Nigeria. international multidisciplinary journal .6(4) . 302-323.

41. Anderton ,B (2006). Using the online course to promote self-regulated learning strategy in preserves teachers . Journal of interactive online learning $.5(2) .156-177$.

42. Baer, $E$ (2016) . Leading for Educational Equity in a context of Accountability : Instructional Technology Method and Depth of knowledge. PHD Southern university Edwardsville .

43. Barnard-Brak , L, lan, W\& Paton, $\mathrm{V}(2010)$.profiles in self-regulated learning in the online learning environment . international review of research in open and distance learning .11(1) . 61-80.

44. Bembenutty , H (2006). Self-regulation of learning . Academic exchange Quartrly. 10(4) . 221-248.

45. Bennet, A. and Bennet, D. (2006). Learning as Associative Patterning . 36( 4). 371-376.

Avilable

at https:/www.emeraldinsight.com/doi/pdfplus/10.1108/03055720610716638

46. Bennet, d\& Bennet, A (2008) . THE Depth of Knowledge Surface, Shallow or Deep? . October . Available at : file:///C:/Users/MGM/Downloads/KnoweldgeSurfaceShalloworDeep3.pdf

47. Bremer , Claudia (2010) . Fit For E-Learning ? Training For E-learning Competences . Goeth-University. Frankfurt. Germany.

48. Caires , S, Alemeida, L \& Vieiral ,D (2012). Becoming ateacher : Student Teachers Experiences and Perceptions about teaching Practice . European Journal of teacher education . 35 (2) . 163-178.

49. Chickering, A. W., Dalton, J. C., \& Stamm, L. (2005). Encouraging authenticity \& spirituality in higher education . San Francisco. CA: JosseyBass.

50. Chimento, $P$, Aparecida , $S$ (2013) : Self-Regulation in the Learning Process : Actions through Self-Assessment Activities With Brazilian Students , International Education Students . 6(10) . $47-62$, Available at : http://dx.doi.org/10.5539/ies.v6n10p47. 
51. chung.M..( 2000). The Development of self-Regulated Learning. Asia pacifi Education Review, 1(1). 55-66.

52. Cob, $R$ (20030. the relationship between self-regulated learning behaviors and academic performance in web-based course, unpolished phd, the faculty of Virginia polytechnic institute and state university Virginia .

53. Edwards, C , Carr, S \& Siegel , W (2006). Influences of Experiences and training on effevtive teavhing practices to meet the needs of diverse learners in schools. Education. 126 (3).580-592.

54. Eseryal, $\mathrm{D}(2014)$. An investigation of the interrelationships between motivation engagement and complex problem solving in game-based learning, Journal of educational technology \&socient . 17 (1). $42-53$

55. Garavalia, L. Scheuer, D., \& Carroll, C, (2002). Comparative analysis of firstand Third- Year Pharmacy student is perceptions of student- regulated learning strategies and motivation. American Journal of pharmaceutical Education. (66). 219- 223.

56. Gureasko-Moore,S., DuPaul, G.J., \& White,G.P. (2006) . The effects of selfmanagement in general education classrooms on the organizational skills of adolescents with ADHD. Behavior Modification. 30(2). 159-183.

57. Hartshorne, R, Ferding , R and Dawson, k (2005). Preparing Current and Future Teacher to teach with Technology : An Examination of Schooluniversity Collaboration . Journal of Computing in Teacher Education . 21(3) . 77-85.

58. Holmes , S (2011). Teacher Preparedness for teaching and Assessing Depth of Knowledge. PHD. university of southern Mississippi .

59. Houssand, A. \& Reis, S.M.(2008). Self-regulated learning in reading : Gifted pedagogy and instructional setting . journal of advanced academics . 20 (1) . $108-136$.

60. Judd, J. (2005). The relationship between self-regulatory learning strategies and the academic achievement of high school chemistry students. Unpublished Thesis in the university of Hawaii, educational psychology, 1-57

61. Klassen et al (2007). Academic procrastination of undergraduates: Low selfefficacy to self-regulate predicts higher levels of procrastination , contemporary educational psychology. 33 (4) 
62. Leutwyler, B; Maag Merki, K. (2009). School Effects on Students' SelfRegulated Learning. A multivariate Analysis of the Relationship between Individual Perceptions of School Processes and Cognitive, Metacognitive, and Motivational Dimensions of Self-Regulated Learning. Journal for Educational. 1(1). 197-223.

63. Lynn, S.\& Fuchs, D. \& Owen, R. , Katie , S. (2003) . Enhancing third - grad students mathematical problem solving with self-regulated learning strategy. Journal of Educational Psychology, 95 (13) . 306-315.

64. Marilena,Z, Leana T (2016) .The Relationships between self-regulated Learning Skills, Causal Attributions and Academic-Success to Trainee Teachers Preparing to Gifted Student, Educational Research and Reviews . 11 (13) . 1217-1227. Avilable at : http://www, academicjournals.org/ERR.

65. Matthews, B (2010). Developing Higher Order Thinking Questions Based on Webb's Dok and Fcat content Complexity .(November 22-23). Available at

:https://www.rjuhsd.us/cms/lib05/CA01001478/Centricity/Domain/15/CC SS/Higher\%200rder\%20Thinking\%20Questions\%20preso.pdf

66. Mills, Janis Jewell (2014). Preparing Students With $21^{\text {st }}$ Century Skills : Educator Training and Preparedness into Curriculum , Published PHD , Edgewood College , Ministry of education $21^{\text {st }}$ Century Competencies , Available at : https://eric.ed.gov/?id=ED569754

67. Mills, Janis Jewell(2014): Preparing Students with $21^{\text {st }}$ Century skills: Educator training and preparedness to integrate into Curriculum , published phd, Edgewiid college

68. Nata ,R.(2003) : Progress In Education.New York :Nova Science Publishers ,Inc.

69. Oenardi , L, Harry, S , Kevin ,L , Wade , G (2014) . Self-Regulated Learning Skills and Online Activities between Higher and Lower Performers on a Web-intensive Underrate Engineering Course , Journal of Educators Online , 11 (3) . Available at : http://www.thejeo.com

70. Phillion, J \& Malewski, E \& Sharma, S and Wang, Y (2009). Reimagining the Curriculum: Future Teachers and Study Abroad. The interdisciplinary Journal of Study Abroad, 323-393 . 
71. Pintrich, P. (2000). The Role of goal orientation in self-regulated learning .In M. Boekaerts, P. Pintrich, \&M. Zeidner (Eds). Handbook of SelfRegulation. San Diego: Academic Press.

72. Ranlli ,Jim. (2013) . Designing Online Strategy Instruction for Integrated Vocabulary Depth of Knowledge and Web-Based Dictionary Skills . calico Journal , 30(1) . 16-43.

73. Ruohotie ,P (2002). Motivation and Self-regulation in learning: Theoretical Understanding for Learning in the Virtual University, Finland.37-70.

74. Schreiber, J. B. (2004). A path analytic model of the effect of epistemological beliefs and retrieval tactics on test performance. Paper presented at the American Educational Research Association, San Diego, CA.

75. Schunk, D.H., \& Ertmer, P.A. (2000). Self-regulation and academic learning: Self-efficacy enhancing interventions. In M. Boekaerts. P. Pintrich, \&M. Seidner (Eds.), Self-regulation: Theory research and applications. Orlando, FL: Academic Press. 631-649

76. Smith, S, Witzel , B \& Browenell , M (2001). How can I help Students with Learning Disabilities in Algebra. Journal of intervention in School and climic. 37 (2). 101-104

77. Stevenson, Mary ( 2013) . Understanding Mathematics in depth investigation into the conceptions of secondary mathematics teachers on two subject knowledge enhancement courses, phd . education in mathematics education .Ireland.

78. Thomas, Jonathan (2017) . Noticing and Knowledge : Exploring theoretical Connections between Professional Noticing and Mathematical Knowledge for Teaching, the Mathematics Educator , 26 (6). 3-25.

79. Tinker, Bob (2003). Thinking about Science, the Concord consortium Educational technology LAB . available at: http ://www.concord.org.(Eric).

80. Webb , $N$ (2007) . issues related to Judging the alignment of curriculum standards and Assessments . Applied Measurement in Education . 20 (1) . 725 .

81. Webb , N (2009) . Webb's Depth of Knowledge Guide, , Career and Technical education definitions, available at : file://C:/Users/MGM/Downloads/Webbs DOK Guide.pdf 
82. Wirth J,\& Leutner ,D (2008) . Implications of Theoretical Models for Assessment Methods . Journal of Psychology Learning as a Competence Self-regulated . 216(2).102-110.

83. Wolters, C(2004). Advancing achievement goal theory : Using goal Structures and goal Orientations to predict students motivation . Cognition and achievement. Journal of education psychology . 96 (21) . 236- 250.

84. Zimmerman , BJ (2011). an educator with passion for developing selfregulation of learning through social learning. A Paper Presented during the Annual Meeting of theAmerican Educational Research Association,( April 11).New Orleans. Louisiana 